Pacific Northwest

National Laboratory

Operated by Battelle for the

U.S. Department of Energy

\section{Characterization of 200-UP-1 Aquifer Sediments and Results of Sorption-Desorption Tests Using Spiked Uncontaminated Groundwater}

\author{
V. L. LeGore \\ K. N. Geiszler \\ S. R. Baum \\ M. M. Valenta \\ I. V. Kutnyakov
}

T. S. Vickerman

M. J. Lindberg

November 2005

Prepared for the U.S. Department of Energy under Contract DE-AC05-76RL01830 


\title{
DISCLAIMER
}

This report was prepared as an account of work sponsored by an agency of the United States Government. Neither the United States Government nor any agency thereof, nor Battelle Memorial Institute, nor any of their employees, makes any warranty, express or implied, or assumes any legal liability or responsibility for the accuracy, completeness, or usefulness of any information, apparatus, product, or process disclosed, or represents that its use would not infringe privately owned rights. Reference herein to any specific commercial product, process, or service by trade name, trademark, manufacturer, or otherwise does not necessarily constitute or imply its endorsement, recommendation, or favoring by the United States Government or any agency thereof, or Battelle Memorial Institute. The views and opinions of authors expressed herein do not necessarily state or reflect those of the United States Government or any agency thereof.

\author{
PACIFIC NORTHWEST NATIONAL LABORATORY \\ operated by \\ BATTELLE \\ for the \\ UNITED STATES DEPARTMENT OF ENERGY \\ under Contract DE-AC05-76RL01830
}

Printed in the United States of America
Available to DOE and DOE contractors from the Office of Scientific and Technical Information,
P.O. Box 62, Oak Ridge, TN 37831-0062;
ph: (865) 576-8401
fax: $(865) 576-5728$
email: reports@adonis.osti.gov

\footnotetext{
Available to the public from the National Technical Information Service, U.S. Department of Commerce, 5285 Port Royal Rd., Springfield, VA 22161 ph: (800) 553-6847 fax: $(703) 605-6900$ email: orders@ntis.fedworld.gov online ordering: http://www.ntis.gov/ordering.htm
}

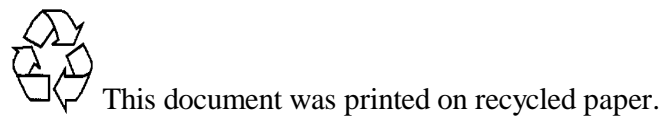




\section{Characterization of 200-UP-1 Aquifer Sediments and Results of Sorption- Desorption Tests Using Spiked Uncontaminated Groundwater}

$\begin{array}{lll}\text { W. Um } & \text { V. L. LeGore } & \text { T. S. Vickerman } \\ \text { R. J. Serne } & \text { K. N. Geiszler } & \text { M. J. Lindberg } \\ \text { B. N. Bjornstad } & \text { S. R. Baum } & \\ \text { H. T. Schaef } & \text { M. M. Valenta } & \\ \text { C. F. Brown } & \text { I. V. Kutnyakov } & \end{array}$

November 2005

Prepared for Fluor Hanford Inc., and the U.S. Department of Energy under Contract DE-AC05-76RL01830

Pacific Northwest National Laboratory

Richland, Washington 99352 


\section{Executive Summary}

Fluor Hanford, Inc. (FHI) and the U.S. Department of Energy (DOE) asked Pacific Northwest National Laboratory (PNNL) to perform sediment characterization on 13 core samples collected in three new groundwater wells in the Hanford Site 200-UP-1 operable unit during 2004. PNNL also conducted Laboratory batch sorption-desorption experiments for key contaminants of concern (COC) such as Tc-99, U (VI), Cr (VI), I-129, Se-79, and Np-237 during FY 2005. The study completed and summarized in this report will help determine the current risk of the groundwater plume and aid in choosing remediation alternatives for the COC in 200-UP-1 subsurface environments should remediation be necessary.

Sediment characterization showed only 4 out of 13 core liner samples were intact, and the others were slough material that dropped to the bottom of the borehole before the split-spoon sampling. The intact samples showed typical Ringold Unit E characteristics such as being dominated by gravel and sand. Moderately reducing conditions are inferred in some core from borehole $\mathrm{C} 4299$. This reducing condition was likely caused by the hard tool process used to drill the wells. One core liner from C4299 (B19140) showed significant presence of ferric iron oxide/clay coatings on the gravel surfaces. The 200-UP-1 sediments do contain some clay minerals that exhibit significant cation exchange capacity and thus should be good adsorbents of cationic contaminants. This is especially true of the Ringold Lower mud sample, B19377, from borehole $\mathrm{C} 4300$. No highly contaminated sediments-including uranium-were found in the cores from the three new boreholes in the 200-UP-1 operable unit. The presence of slough and "flour" caused by hard tooling is a serious challenge to obtaining field-representative sediments for use in geochemical experiments to determine the adsorption-desorption tendencies of redox sensitive elements such as uranium.

The adsorption of COC on intact Ringold Formation sediments and Fe/clay coatings showed that most of the anionic contaminants [Tc(VII), Se(VI), U(VI), Cr(VI), and I(-I)] did not adsorb well compared to cationic $[\mathrm{Np}(\mathrm{V}), \mathrm{Sr}(\mathrm{II})$, and $\mathrm{Cs}(\mathrm{I})]$ radionuclides. The high hydrous iron oxide content in $\mathrm{Fe}$ oxide/clay coatings caused the highest $\mathrm{K}_{\mathrm{d}}$ values for $\mathrm{U}$ and $\mathrm{Np}$, suggesting that these hydrous iron oxides are the key solid adsorbent in the sediments that control the fate of $U$ and $\mathrm{Np}$. Enhanced adsorption behavior for Tc and $\mathrm{Cr}$, and perhaps Se, on the composite B19136 and B19137 sediment was considered an "artifact" caused by the induced reducing conditions from the hard tool drilling.

Additional U(VI) adsorption $\mathrm{K}_{\mathrm{d}}$ studies were performed on Ringold Formation sediments subjected to varying solution geochemical conditions such as varying the dissolved $U$ and total bicarbonate/carbonate concentration in the groundwater to develop a more robust data base of $\mathrm{U}(\mathrm{VI}) \mathrm{K}_{\mathrm{d}} \mathrm{S}$. The $<2 \mathrm{~mm}$ size fraction of three $200-\mathrm{UP}-1$ sediments showed a linear U (VI) adsorption isotherm up to $1 \mathrm{ppm}$ of total $\mathrm{U}$ (VI) concentration in solution. This fact validates the use of a linear adsorption isotherm $\left(\mathrm{K}_{\mathrm{d}}\right)$ to predict $\mathrm{U}(\mathrm{VI})$ adsorption for sediments in the 200-UP-1 groundwater plume. However, this is not the same as stating that the U (VI) $\mathrm{K}_{\mathrm{d}}$ value will be constant if the groundwater chemical composition at 200-UP-1 changes with space or time. 
The additional $\mathrm{U}(\mathrm{VI}) \mathrm{K}_{\mathrm{d}} \mathrm{S}$ obtained from varying carbonate concentrations in solution indicated that $\mathrm{U}(\mathrm{VI})$ adsorption was strongly influenced by the concentration of dissolved carbonate species. U (VI) adsorption decreased with increasing concentrations of carbonate. As carbonate and calcium concentrations in the groundwater reach values that exceed the solubility limit for the mineral calcite, there is a slight increase in $\mathrm{U}(\mathrm{VI}) \mathrm{K}_{\mathrm{d}}$ likely caused by uranium coprecipitation with the fresh calcite precipitate. Thus, uranium sorption-desorption processes at Hanford are quite complicated and highly variable dependent on groundwater composition.

If remediation of the existing groundwater U (VI) plume at 200-UP-1/200-ZP-1 operable units is required and some form of pump and treat is chosen, it is recommended that the aquifer be treated with chemicals to increase $\mathrm{pH}$ and alkalinity and decrease dissolved calcium and magnesium to prevent precipitation of additional calcite. Manipulating the groundwater chemical composition in this fashion would decrease the adsorption affinity of U (VI) to the aquifer sediments. However, if the dissolved calcium and magnesium are not reduced, it is quite possible that increasing the alkalinity and $\mathrm{pH}$ will cause the co-precipitation of $\mathrm{U}(\mathrm{VI})$ with calcite or other alkaline-earth carbonates, thus making it more difficult to remove uranium from the aquifer.

Alternative methods to immobilize the uranium in place, to create fixed (recalcitrant to dissolution) $\mathrm{U}$ (VI) in the sediments, might be more effective than trying to remove the uranium by pump and treat. Unfortunately, no aquifer sediments were obtained during the drilling campaign that contained enough Hanford-generated uranium within them to perform quantitative desorption tests germane to the 200-UP-1 uranium plume remediation issue.

This report provides recommended $\mathrm{K}_{\mathrm{d}}$ values that should be used for risk predictions for the 200-UP-1 groundwater plume traveling through the lithologies within the aquifer present at the 200-UP-1 (and by proxy 200-ZP-1) operable units. The recommended values do not consider the impacts of the temporary generation of reducing conditions caused by hard tool drilling within the coarse Ringold Unit E sediments, which contain appreciable percentages of gravels that release ferrous ions upon being broken up. The recommended $\mathrm{K}_{\mathrm{d}}$ values are chosen to include some conservatism (lower values are emphasized from the available $\mathrm{K}_{\mathrm{d}}$ range) as is standard risk assessment practice.

In general, desorption $\mathrm{K}_{\mathrm{d}}$ values for aged contaminated sediments can be larger than $\mathrm{K}_{\mathrm{d}}$ values determined in the adsorption direction in short-term laboratory experiments. This possibility is most important when predictive modeling is used to estimate release of contaminants back to water during soil flushing and pump-and-treat remediation alternatives. A small amount of desorption hysteresis was observed for uranium in a flow-through column test using uranium-spiked synthetic groundwater followed by flushing with un-spiked synthetic groundwater in the $<2$-mm sized sediment from core liner B19140. To accommodate the potential for desorption hysteresis and other complications, a second suite of uranium desorption $\mathrm{K}_{\mathrm{d}}$ values has been recommended to estimate removal of uranium by pump-and-treat techniques using the natural groundwater as the lixiviant. 


\section{Acknowledgments}

The authors wish to thank Mark Byrnes (Fluor Hanford, Inc.), Mark Freshley, and John Zachara (PNNL) for jointly providing funds to perform this work and for providing technical comments on the draft report. Mark Byrnes and Steve Trent (Fluor Hanford, Inc.) and Chris Cearlock (Washington Closure Group, Hanford) provided additional data and details on the core samples that helped us determine which samples would be best for detailed characterization. Mark Byrnes, Craig Swanson (Fluor Hanford, Inc.), Marcel Bergeron (PNNL) and Al Robinson (consultant) met with the senior authors twice to outline programmatic needs and interests, which helped focus the details on work performed.

The authors thank Bill Deutsch (PNNL) for providing technical comments and Rosalind Schrempf and Susan Tackett (PNNL) for performing the final document editing and facilitating the final word processing. 



\section{Contents}

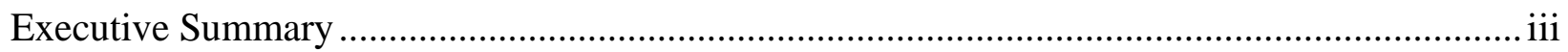

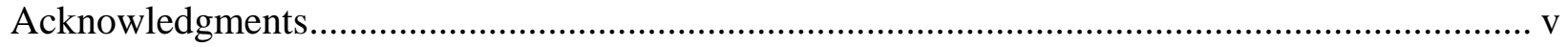

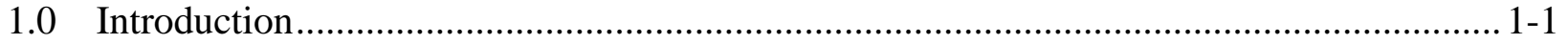

2.0 Scope

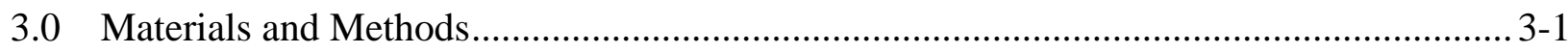

3.1 Task 1 Sediment Characterization ………………................................................ 3-1

3.1.1 Core Sample Opening ……………………......................................... 3-1

3.1.2 Particle Size Distribution ...................................................................... 3-1

3.1.3 Moisture Content ……………........................................................... 3-1

3.1.4 Total/Inorganic Carbon Content ………………...................................... 3-1

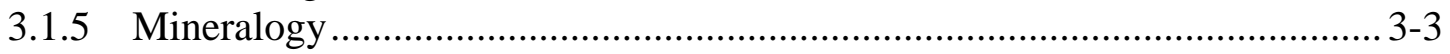

3.1.6 Specific Surface Area ……………………...................................... 3-3

3.1.7 Gamma Energy Analysis ..................................................................... 3-4

3.1.8 Elemental Analysis (ACT Laboratory Analysis) ........................................... 3-4

3.1.9 Labile Uranium Leaching Using Sodium (Bi) Carbonate Solution.................3-4

3.1.10 Iron (Fe) Extractions ........................................................................... 3-5

3.1.11 Cation Exchange Capacity ……………………….............................. 3-5

3.1.12 Solution Analysis ............................................................................. 3-6

3.1.13 1:1 Sediment-to-Water Extract ...................................................................... 3-7

3.2 Task 2 Batch Adsorption Experiments ............................................................. 3-7

3.3 Task 3 Additional $\mathrm{U}(\mathrm{VI}) \mathrm{K}_{\mathrm{d}}$ Measurements ......................................................... 3-9

3.3.1 In-situ U(VI) Desorption $\mathrm{K}_{\mathrm{d}}$ Measurement............................................... 3-9

3.3.2 U(VI) $\mathrm{K}_{\mathrm{d}} \mathrm{S}$ with Varying Background Groundwater Conditions......................3-9

3.3.3 U(VI) Transport in a Flow-through Column ............................................... 3-10

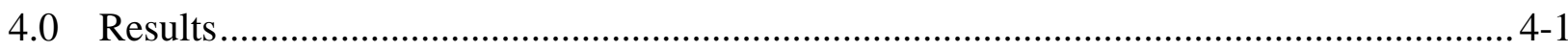

4.1 Task 1 Sediment Characterization ………………............................................ 4-1

4.1.1 Sediment Description.......................................................................... 4-1

4.1.2 Solution Analyses ............................................................................... 4-2

4.1.3 Intact Sediments for Task 2 Adsorption Experiments ................................. 4-19

4.2 Task 2 Batch Adsorption Experiments ................................................................. 4-33

4.2.1 Adsorbents Description............................................................................... 4-33

4.2.2 Characterization of Fe Oxide/Clay Coatings ...............................................4-33

4.2.3 Distribution Coefficient $\left(\mathrm{K}_{\mathrm{d}}\right)$ Measurements .............................................. 4-35 
4.3 Task 3 Results: Additional U(VI) $\mathrm{K}_{\mathrm{d}}$ Measurements ...................................... 4-39

4.3.1 In-situ Desorption U(VI) $\mathrm{K}_{\mathrm{d}}$......................................................... 4-39

4.3.2 U(VI) Adsorption $\mathrm{K}_{\mathrm{d}} \mathrm{S}$ with Varying Dissolved

Uranium Concentrations ..................................................................... 4-40

4.3.3 U(VI) Adsorption $\mathrm{K}_{\mathrm{d}}$ as a Function of Dissolved Total Carbonate ............. 4-40

4.3.4 Column Experiment for U(VI)...................................................... $4-41$

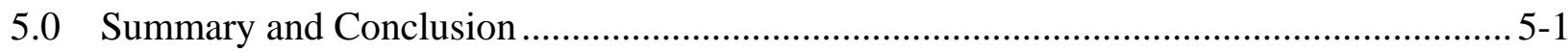

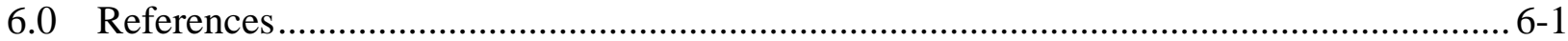

Appendix - Additoinal Data for 200-UP-1 Samples........................................................ A-1 


\section{Figures}

1. Sediment in Core Liner B192K1 from Borehole C4298 …............................................ 4-3

2. Sediment in Core Liner B192K2 from Borehole C4298 ............................................... 4-4

3. Sediment in Core Liner B192K3 from Borehole C4298 ................................................. 4-5

4. Sediment in Core Liner B192K4 from Borehole C4298 ................................................. 4-6

5. Sediment in Core Liner B19136 from Borehole C4299 ….............................................. 4-7

6. Sediment in Core Liner B19137 from Borehole C4299 ................................................. 4-8

7. Sediment in Core Liner B19138 from Borehole C4299 .................................................. 4-9

8. Sediment in Core Liner B19139 from Borehole C4299 ............................................. 4-10

9. Sediment in Core Liner B192140 from Borehole C4299 ............................................. 4-11

10. Sediment in Core Liner B19373 from Borehole C4300 ............................................ 4-12

11. Sediment in Core Liner B19374 from Borehole C4300 .......................................... 4-13

12. Sediment in Core Liner B19375 from Borehole C4300 …............................................ 4-14

13. Sediment in Core Liner B19377 from Borehole C4300 .............................................. 4-15

14. XRD Tracing of B19140 Bulk Sample Collected from Borehole C4299 ...................... 4-25

15. XRD Tracings of Mg+2 Saturated, Glycerol Solvated Clay Fractions ......................... 4-26

16. Labile U(VI) Concentration Leached by Carbonate Extractant ................................. 4-28

17. Calcium Released from Sediments by Carbonate Extractant ....................................... 4-28

18. Measured pHs During Carbonate Leaching .............................................................. 4-29

19. FESEM Images with EDS of Fe Oxide/Clay Coatings Found in B19140 (C4299) ........ 4-34

20. TEM Image and Electron Diffraction Pattern of Fe Oxide/Clay

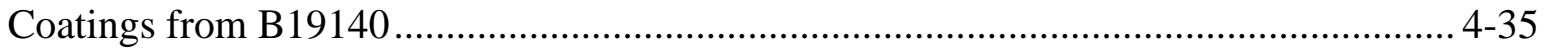

21. U(VI) Adsorption Isotherms for 200-UP-1 Sediments .............................................. 4-41

22. U(VI) Adsorption $\mathrm{K}_{\mathrm{d}} \mathrm{S}$ as a Function of Alkalinity .................................................. 4-42

23. Breakthrough Curve for U(VI) with Measured Data and CXTFIT Model Fits............... 4-44

\section{Tables}

1. Chemical Composition of Simulated Groundwater ................................................. 3-8

2. Description of Core Liners............................................................................ $4-1$

3. Groundwater Samples Obtained During Drilling ............................................. 4-16

4. Pore Water Extracted from Cores and 1:1 Sediment to Water Extracts ........................ 4-17

5. Moisture and Carbon Content of Sediments and pH, Alkalinity, and EC of 1:1 ........... 4-19

6. Description of Intact Samples ......................................................................... 4-20

7. Summary of Particle-Size Distributions for Bulk Samples as Determined by Dry Sieve/Hydrometer Method ........................................................................................ 4-21

8. Major Element Oxides (wt. \%) of Sediment Samples Using Fusion/ICP-MS ................ 4-22

9. Trace Element (mg/kg) of Sediment Samples using Fusion/ICP-MS ........................... 4-22

10. Specific Surface Area of Different Size Fractions from 200-UP-1 Sediments ............... 4-27

11. Cation Exchange Capacity of 200-UP-1 Sediments .................................................. 4-30

12. Results of Fe Extraction of 200-UP-1 Sediments Using Three Different Methods ........ 4-30

13. Extracted Iron, Aluminum, Silicon, and Manganese in 200-UP-1 Sediments ................ 4-32

14. Description of Adsorbents used for Batch $K_{d}$ Measurements in Task 2....................... 4-33

15. Batch Adsorption Distribution Coefficients $\left(\mathrm{K}_{d} \mathrm{~s}\right)$ for COC on 200-UP-1 Samples........ 4-38 
16. In-situ U(VI) Desorption $\mathrm{K}_{\mathrm{d}} \mathrm{S}$.

17. $\mathrm{U}(\mathrm{VI})$ Adsorption $\mathrm{K}_{\mathrm{d}} \mathrm{s}$ as a Function of Alkalinity ...............................................4-43

18. Column Conditions and Transport Parameters ............................................................. 4-43

19. Recommended $\mathrm{K}_{d}$ Values to Use in 200-UP-1 Risk Transport Predictions ...................... 5-4

20. Recommended Desorption $\mathrm{K}_{\mathrm{d}}$ Values for Uranium to Use in Remediation Effectiveness Predictions..... 


\section{Acronyms}

200-UP-1 groundwater operable unit in $200 \mathrm{~W}$

200-ZP-1 groundwater operable unit in $200 \mathrm{~W}$

BET method used to measure specific surface area of porous solids

bgs below ground surface

BTC breakthrough curve

CBD citrate-bicarbonate-ditionite chemical extraction solution used to measure total hydrous iron oxide

CCD charge couple device -- used in SEM/TEM instruments to record data

CEC cation exchange capacity

CERCLA Comprehensive Environmental Response, Compensation, and Liability Act

COC contaminant(s) of concern

DOE U.S. Department of Energy

EC electrical conductivity measure of salt content in fluid

EDS energy dispersive spectrometry -attachment to SEM for determining elemental composition

EPA Environmental Protection Agency

FESEM field emission scanning electron microscopy

FHI Fluor Hanford, Inc.

GEA gamma energy analysis

$\mathrm{HH} \quad$ hydroxylamine hydrochloride chemical extraction solution used to measure amorphous hydrous iron oxide method

HRTEM high resolution transmission electron microscopy

IC Ion Chromatograph—used to measure anions

IC inorganic carbon

ICP-MS inductively coupled plasma mass spectroscopy

ICP-OES inductively coupled plasma optical emission spectroscopy

$\mathrm{JADE}^{\circledR} \quad \mathrm{XRD}$ pattern processing software

$\mathrm{K}_{\mathrm{d}}$

distribution coefficient - a measure of contaminant adsorption-desorption tendencies units $(\mathrm{mL} / \mathrm{g})$

MCL maximum contaminant level

NDIR non-dispersive infrared gas analyzer used to measure total and inorganic carbon

NIST National Institute of Standards and Technology

PNNL Pacific Northwest National Laboratory

SEM scanning electron microscopy

Tamm's a chemical extraction solution and method for measuring amorphous and slightly crystalline hydrous iron oxide contents of sediments

TEM transmission electron microscopy

TOC total organic carbon

UFA unsaturated flow apparatus - used to extract pore fluids out of moist sediments

USGS United States Geological Society

XRD $\quad \mathrm{x}$-ray diffraction -method to determine presence and identity of crystalline minerals in sediments

XRF $\quad \mathrm{X}$-ray fluorescence 


\section{Element and Chemical Nomenclature}

\begin{tabular}{|c|c|}
\hline $\mathrm{Al}$ & aluminum \\
\hline $\mathrm{CaCO}_{3}$ & calcite \\
\hline $\mathrm{CO}_{2}$ & carbon dioxide (gas) \\
\hline $\mathrm{Cr}(\mathrm{VI})$ & $\begin{array}{l}\text { chromium species oxidation state }+6 \\
\left(\text { chromate } \mathrm{CrO}_{4}^{2-} \text { ) }\right.\end{array}$ \\
\hline $\mathrm{Cs}(\mathrm{I})$ & cesium species oxidation state $+1\left(\mathrm{Cs}^{+}\right)$ \\
\hline $\mathrm{Fe}(\mathrm{II})$ & iron species oxidation state $+2\left(\right.$ ferrous ion $\left.\mathrm{Fe}^{+2}\right)$ \\
\hline $\mathrm{Fe}(\mathrm{III})$ & iron species oxidation state $+3\left(\right.$ ferric ion $\left.\mathrm{Fe}^{+3}\right)$ \\
\hline $\mathrm{HCl}$ & hydrochloric acid \\
\hline $\mathrm{Hg}$ & mercury \\
\hline $\mathrm{I}(-\mathrm{I})$ & iodine species oxidation state -1 (iodide $\mathrm{I}^{-}$) \\
\hline $\mathrm{KOH}$ & potassium hydroxide \\
\hline $\mathrm{KNO}_{3}$ & potassium nitrate \\
\hline $\mathrm{Mn}$ & manganese \\
\hline $\mathrm{N}_{2}$ & nitrogen gas \\
\hline $\mathrm{Na}_{2} \mathrm{CO}_{3}$ & sodium carbonate \\
\hline $\mathrm{NaCl}$ & sodium chloride \\
\hline $\mathrm{NaHCO}_{3}$ & sodium bicarbonate \\
\hline $\mathrm{NaOAc}$ & sodium acetate \\
\hline $\mathrm{NaOH}$ & sodium hydroxide \\
\hline $\mathrm{Np}(\mathrm{V})$ & $\begin{array}{l}\text { neptunium species oxidation state }+5 \\
\text { (neptunyl } \mathrm{NpO}_{2}^{+} \text {) }\end{array}$ \\
\hline $\mathrm{Se}(\mathrm{VI})$ & $\begin{array}{l}\text { selenium species oxidation state }+6 \\
\text { (selenate } \mathrm{SeO}_{4}^{2-} \text { ) }\end{array}$ \\
\hline $\mathrm{Si}$ & silicon \\
\hline $\operatorname{Sr}(\mathrm{II})$ & strontium species oxidation state $+2\left(\mathrm{Sr}^{2+}\right)$ \\
\hline Tc(VII) & $\begin{array}{l}\text { technetium species oxidation state }+7 \\
\text { (pertechnetate } \mathrm{TcO}_{4}^{-} \text {) }\end{array}$ \\
\hline $\mathrm{U}(\mathrm{VI})$ & $\begin{array}{l}\text { uranium species oxidation state }+6 \\
\text { (uranyl } \mathrm{UO}_{2}^{2+} \text { ) }\end{array}$ \\
\hline
\end{tabular}




\subsection{Introduction}

Fluor Hanford, Inc. (FHI) drilled several new groundwater wells in the 200-UP-1 operable unit during 2004 to better monitor the uranium (U) and technetium-99 (Tc-99) plumes that have been the focus of past pump-and-treat remediation activities. FHI sent Pacific Northwest National Laboratory (PNNL) 13 cores from three of the new wells, C4298, C4299, and C4300. These cores were 4 inches in diameter by 6 inches in length and were taken from depths near the unconfined aquifer surface (water table) to locations approximately 150 to $180 \mathrm{ft}$ below the water table. Wells C4298 and C4299 are on the periphery of the U plume, and C4300 is near the center of the existing $U$ plume. Preliminary sediment characterization data on adjacent sleeves from some of the cores (supplied by FHI) and groundwater taken from the same depths right after coring, analyzed by PNNL, show that very little U or Tc-99 or any other contaminant are present within samples from boreholes C4298 and C4299 (see further discussion in results of Task 1). Sediments from these two boreholes are good candidates to perform adsorption experiments using groundwater that is spiked with contaminants (see further discussion in results of Task 2). Data for the shallowest groundwater sample from borehole C4300 do show elevated $\mathrm{U}$ and Tc-99, but the sediment cores from C4300 are also not significantly contaminated with $\mathrm{U}$ and Tc (see further discussion in results of Task 1).

Depth discrete groundwater samples were taken during the drilling of these three boreholes, and quick turnaround measurements were made for U and Tc-99 to aid in determining at what depth the well screens should be placed in the aquifer. We subsequently analyzed these groundwater samples for other constituents such as common cations, anions, and selected trace metals.

It was expected that borehole C4300 sediments might contain measurable concentrations of contaminants that could be used to perform desorption experiments on sediments that have been in contact with the contaminated groundwater for many years. The original proposal discussed an activity that would have used the contaminated sediment from borehole C4300 for detailed desorption tests. However, the C4300 sediments were not found to be contaminated with enough $\mathrm{U}$, Tc-99, or any other contaminant of interest to be used in detailed laboratory desorption tests so alternative laboratory adsorption-desorption tests were performed (see Task 3 discussions).

Prior to this work, no 200-UP-1- or 200-ZP-1-site-specific adsorption or desorption data (i.e., $\mathrm{K}_{\mathrm{d}}$ values) were available for the sediments or key contaminants present in the 200-UP-1 and 200-ZP-1 operable unit groundwater plumes. Site-specific sorption data for key contaminants of concern (COC) (Tc-99, U(VI), Cr(VI), I-129, Se-79, and Np-237) were obtained with the uncontaminated sediments from two of the new boreholes (C4298 and C4299). In addition, $\mathrm{K}_{\mathrm{d}} \mathrm{S}$ for Sr-90 and Cs-137 (not generally considered COC in Hanford groundwater) were also obtained on the same sediment samples to allow us to compare the new 200-UP-1 specific data to a much larger $\mathrm{K}_{\mathrm{d}}$ data base for other Hanford sediments, which generally contains numerous data for Sr-90 and Cs-137. That is, from comparison of the commonly available Sr-90 and Cs-137 data sets on past work with the new studies, some inferences can be made on how the 200-UP-1 $\mathrm{K}_{\mathrm{d}}$ values for COC might agree with sediments from other Hanford locations. 
This site-specific sorption data, when complemented by the chemical, geologic, mineralogic, hydrologic, and physical characterization data that are also being collected (see Sampling and Analysis Plan for the 200-UP-1 Groundwater Monitoring Well Network, DOE 2002) can be used to develop a robust, scientifically defensible data base to allow risk predictions to be generated and to aid in future remediation decisions for 200-UP-1 and 200-ZP-1 operable units. 


\subsection{Scope}

The Applied Geology and Geochemistry Group within PNNL proposed three interrelated tasks. The first task was to more completely characterize the selected aquifer sediments from the three new Comprehensive Environmental Response, Compensation, and Liability Act (CERCLA) boreholes (C4298, C4299, and C4300). This effort would aid in the interpretation of data from subsequent tasks and provide information for any mechanistic studies that might be completed by the science and technology scientists lead by Dr. John Zachara, Environmental Molecular Science Laboratory Chief Scientist. The second task was to perform scoping empirical batch sorption tests to provide a 200-UP-1 site-specific $\mathrm{K}_{\mathrm{d}}$ data base for key COC such as Tc-99, U, Cr(VI), I-129, Se-79, and Np-237 to the risk modeling team. The third task was to perform desorption experiments on the sediments from $\mathrm{C} 4300$, provided that they contained adequate concentrations of contamination that has been in contact with contaminated groundwater for the past $\sim 40$ years. To determine whether this third task would be useful and feasible required that the characterization from the first task be completed. Specific details on the three proposed tasks are found in a proposal submitted to FHI in January 2005 (available on request.)

After it was found that the sediments from C4300 were not contaminated with enough U, Tc-99, or any other COC, some additional batch adsorption tests were performed with simulated groundwaters with a wider range of ionic strength, $\mathrm{pH}$, and carbonate and uranium concentrations so that a more robust sorption data base would be available for the key COC, uranium. In addition, a flow-through column experiment was conducted wherein U(VI)-spiked $(\sim 220 \mu \mathrm{g} / \mathrm{L})$ simulated groundwater was flushed through sediment from the C4299 borehole to evaluate U(VI) transport. This experiment better simulates the movement of a uranium plume into previously uncontaminated sediments and allows a second determination of the U(VI) sorption tendencies, which can be compared with the $\mathrm{K}_{\mathrm{d}}$ determined in the laboratory batch experiments. 


\subsection{Materials and Methods}

\subsection{Task 1 Sediment Characterization}

\subsubsection{Core Sample Opening}

A total of 13 split-spoon core samples were opened in the laboratory and characterized for physical and geological properties. Digital photographs were taken of each sample and after removing several small aliquots, the remaining sediment was stored in a refrigerator for future use. Drainable pore water was collected from the wetter cores, filtered using a $0.45-\mu \mathrm{m}$ syringe filter, and sent for solution analyses. Pore water from fine mud samples and cores that were less moist was extracted using an unsaturated flow apparatus (UFA). The UFA-obtained fluids were also filtered (using a $0.45-\mu \mathrm{m}$ filter) and analyzed.

\subsubsection{Particle Size Distribution}

The dry sieving and hydrometer methods were used to determine the particle-size distribution for selected core samples. The method is based on the American Society for Testing and Materials procedure Standard Test Method for Particle-Size Analysis of Soils (ASTM Method D422-63). The silt/clay, sand, and gravel size fractions were separated by sieving. The silt and clay size fractions were further separated using Stokes law settling velocities to determine the weight percentage of each size-fraction. Each clay fraction and the less than $2 \mathrm{~mm}$ (gravel removed) sized separate sample was also characterized for mineralogy using X-ray diffraction (XRD).

\subsubsection{Moisture Content}

The water contents of the sediments were determined gravimetrically according to PNNL procedure PNL-MA-567-DO-1 (PNL 1990) based on the American Society for Testing and Materials procedure Standard Test Method for Laboratory Determination of Water (Moisture) Content of Soil and Rock (ASTM D2216-98). Aliquots of the sediment were put in pre-weighed containers, weighed, and oven-dried at $105^{\circ} \mathrm{C}$ until constant weight was achieved. The gravimetric water content was calculated as percentage change in soil weight before and after oven drying. The dry weights were measured two times with an additional 24 hours of oven drying to ensure a constant weight was obtained.

\subsubsection{Total/Inorganic Carbon Content}

The total carbon concentration in each core sample was measured with a Shimadzu TOC-V CSN instrument with a SSM-5000A Total Organic Carbon Analyzer by combustion at approximately $900^{\circ} \mathrm{C}$ based on ASTM Method Standard Test Methods for Analysis of Metal Bearing Ores and Related Materials by Combustion Infrared Absorption Spectrometry (ASTM E1915-01). Aliquots of sediment were placed into pre-combusted, pre-weighed ceramic combustion sample holders and weighed on a calibrated balance. After the combustion sample holders were placed into the furnace introduction tube, approximately 2 minutes waiting period 
was allowed for the ultra-pure oxygen carrier gas to remove any carbon dioxide introduced to the system from the atmosphere during sample placement. After this sparging process, the sample was moved into the combustion furnace and the combustion was begun. The carrier gas then delivered the sample combustion products to the cell of a non-dispersive infrared (NDIR) gas analyzer, where the carbon dioxide $\left(\mathrm{CO}_{2}\right)$ was detected and measured. The amount of $\mathrm{CO}_{2}$ measured is proportional the total carbon content of the sample. Adequate system performance was confirmed by analyzing known quantities of a calcium carbonate standard.

Sediment/solid samples were analyzed for inorganic carbon (IC) content by placing a sediment aliquot into a ceramic combustion boat. The combustion boat was placed into the IC introduction tube, where it was sparged with ultra-pure oxygen for 2 minutes to remove atmospheric $\mathrm{CO}_{2}$. A small amount (usually $0.6 \mathrm{ml}$ ) of $3 \mathrm{M}$ phosphoric acid was then added to the sample in the combustion boat. The boat was moved into the IC combustion furnace, where it was heated to $200^{\circ} \mathrm{C}$. Samples were completely covered by the acid to allow full reaction to occur. Ultra-pure oxygen swept the resulting $\mathrm{CO}_{2}$ through a dehumidifier and scrubber into the cell of a NDIR gas analyzer, where the carbon dioxide was detected and measured. The amount of $\mathrm{CO}_{2}$ measured is proportional to the inorganic carbon content of the sample.

Organic carbon content was determined by the difference between the inorganic carbon and total carbon concentration.

The carbon content of liquid samples was determined using PNNL Technical Procedure AGG-TOC-001, Operating of Carbon Analyzer (TOC-V + SSM-5000A + ASI (Shimadzu), which is similar to Environmental Protection Agency (EPA) publication SW-846, Test Methods for Evaluating Solid Waste Physical/Chemical Methods: Method 9060 Total Organic Carbon (EPA 2000c).

Liquid samples were analyzed for total carbon by introducing a sample aliquot into a combustion chamber with an oxidation catalyst and heated to $680^{\circ} \mathrm{C}$. The released carbon from the combustion was converted to $\mathrm{CO}_{2}$ that was swept from the combustion chamber by ultra-pure oxygen, dehumidified, and scrubbed to remove halogens. The carrier gas then delivered the sample combustion products to the cell of a NDIR gas analyzer where the carbon dioxide was detected and measured. The NDIR output an analog detection signal that formed a peak; the peak area was measured by the TOC-Control V software. Adequate system performance was confirmed by analyzing for known quantities of a liquid carbon standard.

Liquid samples were analyzed for total organic carbon by first acidifying a sample aliquot (10 to $2000 \mu \mathrm{L}$ ) with $3 \mathrm{M} \mathrm{HCl}$ to a $\mathrm{pH}$ less than 3 . The acid volatilized inorganic carbon to the atmosphere without collection. The residual acidified sample was introduced into a combustion chamber with an oxidation catalyst and heated to $680^{\circ} \mathrm{C}$. The released carbon from the combustion was converted to $\mathrm{CO}_{2}$, which was swept from the combustion chamber by ultra-pure oxygen, dehumidified, and scrubbed to remove halogens. The carrier gas then delivered the sample combustion products to the cell of the NDIR gas analyzer, where the carbon dioxide was detected and measured. The amount of $\mathrm{CO}_{2}$ measured was proportional to the total organic carbon content of the sample. 
Inorganic carbon for a liquid sample is calculated from the difference of the total carbon analysis and the total organic carbon analysis.

\subsubsection{Mineralogy}

The mineralogy of each bulk sediment sample was determined using powder XRD analysis. The bulk sample was prepared by grinding about $2 \mathrm{~g}$ of homogenized sample. For clay-size fraction analysis, approximately $100 \mathrm{~g}$ of sample was mixed with $1.0 \mathrm{~L}$ of $0.001 \mathrm{M}$ sodium hexametaphosphate and shaken well overnight. The sand fraction was separated using wet sieving through a \#230 sieve (0.0625-mm mesh diameter), and the silt fraction was separated from the clay fraction by Stoke's Law settling. Each clay suspension was concentrated to an approximate volume of $30 \mathrm{~mL}$ by adding a few drops of $10 \mathrm{~N} \mathrm{MgCl}_{2}$ to the dispersed slurry. Clay-size mounts were prepared using an aluminum slide method.

All sediment samples were analyzed on a Scintag XRD unit using monochromated $\mathrm{Cu} \mathrm{K} \alpha$ radiation $(\lambda=1.5418 \AA)$. Randomly oriented bulk samples were scanned from $2^{\circ}$ to $65^{\circ} 2 \theta$ with a dwell time of 2 seconds. Scans were collected automatically and processed using commercial software $\left(\mathrm{JADE}^{\circledR}\right.$ XRD pattern processing software). Mineral identification was based on powder diffraction files published by the Joint Committee for Powder Diffraction Standards. Semi-quantitative analysis of minerals in the bulk samples was determined using the whole pattern fitting technique provided by the $\mathrm{JADE}^{\circledR} \mathrm{XRD}$ pattern processing software. The software fits a diffraction model to the analytical data by non-linear least-square optimization in which crystallographic parameters are varied to improve the fit between the sample and theoretical mixed mineral patterns. Success of the refinement process is measured by a ratio of the residual and total errors. The value referred to as "goodness of fit" is expected to be close to one in the case of an ideal refinement.

Scrapings of the iron oxide-rich/clay coatings on sample B19140 were characterized using field emission scanning electron microscopy (FESEM) to visualize the particle morphology, SEM-energy dispersive spectrometry (EDS) to evaluate the chemical composition of small regions of individual particles or several closely packed fine-grained particles, and highresolution transmission electron microscopy (HRTEM) and scanning electron microscopy, which also allowed single-particle electron diffraction patterns to be collected allowing crystallinity to be evaluated. HRTEM analysis was carried out on a JEOL JEM 2010 microscope with a specified point-to-point resolution of $0.194 \mathrm{~nm}$. This microscope is fitted with a $\mathrm{LaB}_{6}$ filament with an operating voltage of $200 \mathrm{kV}$. All images were digitally recorded with a slow scan charge couple device (CCD) camera (image size 1024 x 1024 pixels). Quantification of the spectra was based on theoretical cross section but absorption correction was not considered due to the thinsection nature of specimen.

\subsubsection{Specific Surface Area}

Specific surface area was measured with a Quantachrome autosorb 6-B gas sorption system using the $\mathrm{N}_{2}$-BET method (Brunauer et al. 1938). The samples were outgassed for a minimum of 5 hours at $110^{\circ} \mathrm{C}$ and at $3 \mu \mathrm{m} \mathrm{Hg}$ pressure. Because the instrument glassware has a narrow neck ( 0.9-cm inner diameter), particles larger than $7 \mathrm{~mm}$ were excluded for measuring surface area. 
The specific surface area was measured at liquid nitrogen temperature (approximately $77 \mathrm{~K}$ ) to allow any $\mathrm{N}_{2}$ molecules to adsorb at the solid surface. The BET method is well known and is given by

$$
\frac{P}{V_{a}\left(P_{O}-P\right)}=\frac{1}{V_{m} C}+\frac{C-1}{V_{m} C}\left(\frac{P}{P_{o}}\right)
$$

where $\mathrm{V}_{\mathrm{a}}$ is the quantity of gas adsorbed at pressure, $\mathrm{P}, \mathrm{V}_{\mathrm{m}}$ is the quantity of gas adsorbed to form a complete monolayer, $\mathrm{P}_{\mathrm{o}}$ is the saturation pressure of the gas, and $\mathrm{C}$ is the BET constant. The values of $\mathrm{V}_{\mathrm{m}}$ and $\mathrm{C}$ are determined by a regression line of the adsorption isotherm plotted with $\mathrm{P} / \mathrm{V}_{\mathrm{a}}\left(\mathrm{P}_{\mathrm{o}}-\mathrm{P}\right)$ vs. $\mathrm{P} / \mathrm{P}_{\mathrm{o}}$. The specific surface area of a solid is determined by

$$
\text { Area }=\frac{V_{m}}{22414} a_{m} N_{A} 10^{-20}
$$

where $\mathrm{a}_{\mathrm{m}}$ is the average area occupied by a single adsorbate molecule, and $\mathrm{N}_{\mathrm{A}}$ is Avogadro's number (Gregg and Sing 1982; Webb and Orr 1997).

\subsubsection{Gamma Energy Analysis}

The sediment sample from the shallowest core from C4300 was analyzed using a 60\%efficient intrinsic-germanium gamma detector. The germanium counter was calibrated for distinct geometries using mixed gamma standards traceable to the National Institute of Standards and Technology (NIST). Spectral analysis was conducted using libraries containing most mixedfission products, activation products, and natural-decay products. Control samples were run throughout the analysis to ensure correct operation of the detector. The controls contained isotopes with photo peaks spanning the full detector range and were monitored for peak position, counting rate, and full-width half-maximum. This is based on PNNL procedure RPL-001, Gamma Energy Analysis, Operation, and Instrument Verification using Genie2000 Support Software (PNNL 1997).

\subsubsection{Elemental Analysis (ACT Laboratory Analysis)}

The elemental composition of the bulk sediment samples was determined by a combination of fusion ( $\mathrm{KOH}-\mathrm{KNO}_{3}$ treatments) of the sediment with subsequent analysis of the dissolved material by inductively coupled plasma optical emission spectrometer (ICP-OES) and inductively coupled plasma mass spectrometer (ICP-MS) analyses. This work was conducted at ACT Laboratory (Tucson, Arizona), and the results were compared against known rock and soil standards prepared at the same time.

\subsubsection{Labile Uranium Leaching Using Sodium (Bi) Carbonate Solution}

The concentration of labile (easily removable fraction, such as ion-exchangeable or watersoluble) uranium in the sediment samples from the $<2-\mathrm{mm}$ size fraction of selected borehole sediment samples was measured using a sodium bicarbonate/carbonate mixed solution (1.44 $\times 10^{-2} \mathrm{M}$ in $\mathrm{NaHCO}_{3}$ and $2.8 \times 0^{-3} \mathrm{M}$ in $\mathrm{Na}_{2} \mathrm{CO}_{3}$ ). The reagent $\mathrm{pH}$ was 9.3 , and the 
solid-to-solution ratio of $50 \mathrm{~g} / \mathrm{L}$ was used for uranium leaching. The leached uranium concentration was determined as a function of time ranging from 1 to 30 days. Extract solutions were filtered using $0.45-\mu \mathrm{m}$ syringe filters and analyzed for uranium using ICP-MS. The solid to solution ratio was kept constant at $50 \mathrm{~g} / \mathrm{L}$ by adding fresh reagent to replace the small aliquot $(1 \mathrm{~mL})$ removed at each sampling time. This procedure is described in Kohler et al. (2004).

\subsubsection{Iron (Fe) Extractions}

Three chemical extraction methods were used to assess their effectiveness at targeting amorphous (or active) versus more crystalline (or free) iron-oxide phase (Anderson and Jenne 1970; McAlister and Smith 1999; Loeppert and Inskeep 1996; Dong et al. 2000). All reagent solutions used in the extraction procedures were prepared using reagent-grade chemicals in double de-ionized water. Two solutions, $0.1 \mathrm{M}$ hydroxylamine hydrochloride $(\mathrm{HH})$ in $0.01 \mathrm{M}$ nitric acid or $0.175 \mathrm{M}$ ammonium oxalate with $0.1 \mathrm{M}$ oxalic acid at $\mathrm{pH} 3$ (Tamm's reagent or method), were used to extract only the amorphous iron oxides such as ferrihydrite (Chao and Zhou 1983; Loeppert and Inskeep 1996). The third method was used to extract all crystalline and amorphous iron oxides. This extractant was a mixed solution of $0.3 \mathrm{M}$ sodium citrate, $1.0 \mathrm{M}$ sodium bicarbonate, and between 0.5 and $1 \mathrm{~g}$ of sodium dithionite (CBD) as described in (Loeppert and Inskeep 1996).

In the $\mathrm{HH}$ method, $25 \mathrm{~mL}$ of $0.1 \mathrm{M}$ hydroxylamine hydrochloride in $0.01 \mathrm{M}$ nitric acid was added to 0.5 gram of sample and shaken for 30 minutes. The samples were filtered, and the concentrations of $\mathrm{Fe}, \mathrm{Mn}, \mathrm{Al}$, and $\mathrm{Si}$ were analyzed using ICP-OES. In the Tamm's method, $30 \mathrm{~mL}$ of $0.175 \mathrm{M}$ ammonium oxalate with $0.1 \mathrm{M}$ oxalic acid at $\mathrm{pH} 3$ was added with 0.5 gram of sample in a light-proof container and shaken for exactly 2 hours. The $\mathrm{pH}$ adjustment to $\mathrm{pH} 3$ was completed using hydrochloric acid. The extracted samples were filtered using a $0.45-\mu \mathrm{m}$ syringe filter and analyzed using ICP-OES for concentrations of Fe, $\mathrm{Mn}, \mathrm{Al}$, and $\mathrm{Si}$. In the CBD method, $20 \mathrm{~mL}$ of $0.3 \mathrm{M}$ sodium citrate solution and $2.5 \mathrm{~mL}$ of $1 \mathrm{M}$ sodium bicarbonate solution were added to the sample tube and shaken with 2.5 grams of sediment. The tube was heated in an oven at $75-80^{\circ} \mathrm{C}$ for several minutes with occasional shaking, and the temperature was controlled such that it never exceeded $80^{\circ} \mathrm{C}$. After about 15 minutes, 0.5 gram of sodium dithionite was added and stirred into the solution. The solution was occasionally shaken for 15 minutes, and another 0.5 gram of sodium dithionite was added. The tube was shaken occasionally for an additional 10 minutes. The samples were removed from the oven and cooled to room temperature. The cooled samples were filtered, and the concentration of $\mathrm{Fe}, \mathrm{Mn}, \mathrm{Al}$, and Si were analyzed using ICP-OES. Sediment iron extractions were conducted in triplicate, and final results were reported as an average value of the triplicate measurements with one standard deviation.

\subsubsection{Cation Exchange Capacity}

The cation exchange capacity (CEC) of selected sediment samples was measured by a radiotracer procedure (Routson et al. 1973). Approximately 2 grams of sediment was placed in a Bio-Rad poly-prep chromatography column. The sample was saturated with $0.8 \mathrm{M} \mathrm{NaOAc/}$ $0.2 \mathrm{M} \mathrm{NaCl}$ solution. Next, $50 \mathrm{~mL}$ of a solution with $0.4 \mathrm{M} \mathrm{SrCl}_{2}$ was added to the column and drained. The final few milliliters were collected to determine the final Sr concentration using ICP-OES. After the sediment sample was drained completely, the bottom of the column was 
capped, and $3 \mathrm{~mL}$ of the $0.04 \mathrm{M} \mathrm{SrCl}_{2} /{ }^{85} \mathrm{Sr}$ tracer solution was introduced. The activity of ${ }^{85} \mathrm{Sr}$ was initially determined to be about $10 \mathrm{uCi}$ of ${ }^{85} \mathrm{Sr}$ at $\mathrm{pH} 7$. After allowing 1 hour contact time, the solution was expelled using vacuum filtration. This step was repeated several times. Three 3-mL aliquots of 95\% ethanol were slowly drained through the sediment packed in the column to rinse the spiked ${ }^{85} \mathrm{Sr}$ solution remaining in the pore spaces. Excess ethanol was removed using vacuum filtration. Aliquots of the ${ }^{85} \mathrm{Sr}$-spiked influent and last effluent solution and the rinsed sediment were placed in appropriate geometries and were counted using gamma energy analysis (GEA). The total CEC of each sediment (meq/g) was calculated by dividing the final rinsed spiked sediment from the column (activity per unit weight of soil $(\mathrm{cpm} / \mathrm{g})$ ) by the specific activity of the spiked equilibration solution (cpm/meq).

\subsubsection{Solution Analysis}

\subsubsection{1 pH and Electrical Conductivity}

The $\mathrm{pH}$ of 1:1 sediment: water extracts was measured with a solid-state $\mathrm{pH}$ electrode and an Orion $\mathrm{pH}$ meter calibrated with $\mathrm{pH}$ 4, 7, and 10 buffer solutions. Electrical conductivity (EC) was measured using a Pharmacia Biotech Conductivity Monitor. Approximately 2 to 3 milliliters of filtered sample was measured in the conductivity meter and compared to potassium chloride standards with a range of 0.001 to $1.0 \mathrm{M}$.

\subsubsection{Alkalinity}

Alkalinity was measured using a standard titration with acid method. The alkalinity procedure is equivalent to the U.S. Geological survey method in the National Field Manual for the Collection of Water-Quality Data (USGS 2004).

\subsubsection{Cations and Trace Metals}

The concentrations of major cations in the groundwaters, pore waters, 1:1 water extracts, and chemical extracts were measured with a Perkin Elmer Optima 3300 DV ICP-OES using highpurity calibration standards according to EPA Method 6010B (EPA 2000a). A Thermo elemental PQ2 ICP-MS was used to analyze trace metal concentrations including concentrations of Tc-99 and U-238 in the groundwaters, pore waters, and adsorption test effluents. The analytical procedure is equivalent to EPA Method 6020 (EPA 2000b).

\subsubsection{Anions}

The anion concentrations in the groundwaters, pore waters and 1:1 water extracts were determined using a Dionex DX600 Ion Chromatograph. Carbonate, chloride, fluoride, nitrate, phosphate, and sulfate were separated using a Dionex AS17 column with a gradient elution of 1 to $35 \mathrm{mM} \mathrm{NaOH}$. This methodology is based on EPA Method 300.0A (EPA 1984) with the exception of using the gradient elution of sodium hydroxide. 


\subsubsection{Ferrous/Ferric Iron Concentration}

The concentrations of $\mathrm{Fe}(\mathrm{II})$ and $\mathrm{Fe}(\mathrm{III})$ in the groundwaters and sediment pore waters were determined using the Ferrozine colorimetric method (Gibbs 1976). The samples were filtered and acidified with hydrochloric acid $(0.02 \mathrm{~mL}$ of $6 \mathrm{M} \mathrm{HCl}$ per 2.5 - $\mathrm{mL}$ sample). The absorbance of Fe(II) standards and samples was measured using a portable UV-Visible spectrophotometer at $562 \mathrm{~nm}$. The concentration of Fe(II) was determined based on the previously developed standard curve using known ferrous iron standards. Total iron concentration was measured using ICP-OES, and the concentration of $\mathrm{Fe}(\mathrm{III})$ was calculated as the difference between $\mathrm{Fe}$ (II) and total Fe concentrations.

\subsubsection{1:1 Sediment-to-Water Extract}

Water-soluble inorganic elements were extracted from the sediments and analyzed to characterize the amount of water-soluble ions. The water-extractable constituents were obtained from the samples using a 1:1 sediment-to-deionized water extract method. The weight of deionized water needed was calculated based on the weight of the field-moist samples and their previously determined moisture contents. The appropriate amount of deionized water was added to screw-cap jars containing the field-moist sediments. The jars were sealed and briefly shaken by hand, then placed on a slowly moving shaker for 1 hour. The samples were allowed to settle overnight until the supernatant liquid was fairly clear. The supernatant was carefully decanted and separated into unfiltered aliquots for electrical conductivity and $\mathrm{pH}$ measurements. The filtered aliquots, after passing through $0.45-\mu \mathrm{m}$ filters, were used for analyses of cations, anions, and alkalinity.

\subsection{Task 2 Batch Adsorption Experiments}

Selected sediments from the 13 200-UP-1 cores were used in batch adsorption tests as is, or after removal of the gravel fraction, or after combining several of the cores to form composites. A description and listing of the final sediment samples used in these adsorption tests is shown in Section 4.0, Table 14. Batch adsorption experiments were conducted in either individual 50 or $15-\mathrm{mL}$ polypropylene centrifuge tubes with a solid concentration of $333 \mathrm{~g} / \mathrm{L}$ (1:3 solid-tosolution ratio) to study COC (Tc-99, U(VI), $\mathrm{Cr}(\mathrm{VI}), \mathrm{I}-129, \mathrm{Se}-79$, and $\mathrm{Np}-237)$ and $\mathrm{Sr}-85$ and Cs-137 adsorption. Noticeable Fe oxide coatings were found in the C4299 (B19140) sample, and some of the ferric iron/clay coating on the gravel surfaces was removed using spatulas. The Fe oxide/clay coatings were also used as an additional adsorbent to investigate the effects of $\mathrm{Fe}$ oxide/clay coatings on the adsorption behavior of COC. Because of the limited amount of available Fe oxide/clay coatings, a solid-to-solution ratio of $10 \mathrm{~g} / \mathrm{L}$ was used for this sample. The adsorbent (sediment samples) was pre-equilibrated with several batches of a synthetic groundwater, which has a similar chemical composition to 200-UP-1 groundwaters, to remove any easily dissolvable salt and isolate the adsorption reaction from other possible reactions such as precipitation and/or co-precipitation.

The chemical composition of simulated groundwater is given in Table 1. The simulated groundwater was a mixture of two actual uncontaminated groundwaters from the Hanford 
Table 1. Chemical Composition of Simulated Groundwater

\begin{tabular}{||c|c|c||}
\hline Constituents & Concentration (mg/L) & Concentration (meq/L) \\
\hline $\mathrm{Na}^{+}$ & 39.1 & 1.7 \\
$\mathrm{~K}^{+}$ & 9.91 & 0.25 \\
$\mathrm{Ca}^{2+}$ & 40.6 & 2.03 \\
$\mathrm{Mg}^{2+}$ & 18.1 & 1.49 \\
$\mathrm{Sr}^{2+}$ & 0.19 & 0 \\
$\mathrm{Si}^{4+}$ & 20.7 & 2.94 \\
$\mathrm{HCO}^{-}$ & 171 & 2.8 \\
$\mathrm{Cl}^{-}$ & 15.4 & 0.43 \\
$\mathrm{SO}_{4}{ }^{2-}$ & 118 & 2.46 \\
$\mathrm{NO}_{3}{ }^{-}$ & 0.78 & 0.01 \\
$\mathrm{~F}^{3-}$ & 0.55 & 0.03 \\
$\mathrm{PO}_{4}{ }^{3-}$ & 0.4 & 0.01 \\
\hline $\mathrm{Constituent}$ & Concentration $(\mu \mathrm{g} / \mathrm{L})$ & \\
$\mathrm{Al}$ & $<50$ & \\
$\mathrm{~B}$ & 114 & \\
$\mathrm{Cu}$ & 178 & \\
$\mathrm{Fe}$ & 38 & \\
$\mathrm{Mn}$ & $<12.5$ & \\
$\mathrm{Zn}$ & 189 & \\
$\mathrm{U}$ & 3.17 & \\
$\mathrm{Cs}$ & 0.05 & 5.47 \\
$\mathrm{I}$ & 14.4 & \\
\hline Total Cations & \multicolumn{2}{|}{} \\
Total Anions & 7.6 & \\
$\mathrm{pH}$ (measured) & 8.61 & \\
Ionic strength (mM) & \multicolumn{2}{|}{} \\
\hline \hline
\end{tabular}

Site and tap water to create a chemical composition similar to 200-UP-1 groundwater near the middle of the existing $\mathrm{U}$ plume. The pre-equilibration was accomplished by adding synthetic groundwater to the adsorbents, shaking the suspensions overnight, centrifuging, removing the supernatant, and measuring the $\mathrm{pH}$. This procedure was repeated two or three times until the measured $\mathrm{pH}$ was not significantly different than the starting value. The pre-equilibrated adsorbents were dried at room temperature in the centrifuge tubes.

Each tube containing adsorbents was weighed, and the previously measured weight of each tube prior to filling was subtracted to determine the final weight of the adsorbent in each tube.

The COC-spiked groundwater was added to the sediments, and the containers were placed on a slow-moving platform shaker for 7 days. Contact times of 7 days was assumed adequate to reach steady-state conditions during the COC adsorption experiments on 200-UP-1 sediments based on other previous U(VI) adsorption experiments (Kaplan et al. 1996; Davis et al. 2004). One "gravel-only" sample from C4299 (B19140) was also continuously reacted with the spiked groundwater up to 1 month after collecting the 7-day sample. Blank containers containing no 
sediment were also prepared in an identical manner to determine whether there was any container adsorption of COC. After 7 days of contact, the suspensions were centrifuged to separate solution from solids. The supernatants were sampled and passed through $0.45-\mu \mathrm{m}$ filters.

A 2-mL aliquot was collected and analyzed for concentration of COC using ICP-MS, and another filtered aliquot was counted on an intrinsic Ge gamma detector to quantify Sr-85 and Cs-137. Distribution coefficient, $\mathrm{K}_{\mathrm{d}}(\mathrm{mL} / \mathrm{g})$ was calculated using the following equation,

$$
K_{d}=\frac{\left(A_{\text {spike }} \times V_{\text {initial }}\right)-\left(A_{\text {final }} \times V_{\text {initial }}\right)}{A_{\text {final }} \times M_{\text {sediment }}}
$$

where $A_{\text {spike }}$ is the initial concentration of each COC in the spiked solution, $V_{\text {initial }}(\mathrm{mL})$ is the volume of solution, $\mathrm{A}_{\text {final }}$ is the concentration of each $\mathrm{COC}$ in the solution after equilibrium, and $\mathrm{M}_{\text {sediment }}(\mathrm{g})$ is the sediment mass.

\subsection{Task 3 Additional U(VI) $\mathbf{K}_{\mathbf{d}}$ Measurements}

\subsubsection{In-situ U(VI) Desorption $K_{d}$ Measurement}

In-situ desorption $\mathrm{K}_{\mathrm{d}}$ f for $\mathrm{U}(\mathrm{VI})$ in the <2-mm size fraction of three 200-UP-1 sediments (mixture B19136 and B19137; B19377 and B19140) was calculated by taking the ratio of U(VI) concentration present in the pore water, which was removed when the cores were opened (data shown in Table 4 in parentheses), to the labile U(VI) concentration leached out of the sediments using the carbonate-bicarbonate extractant described in Section 3.1.9. Based on work performed by Kohler et al. (2004), labile U(VI) is assumed to refer to the adsorbed U(VI) fraction that can be easily leached out of sediments using the described (bi) carbonate extractant. The labile uranium fraction differs from the total uranium in the sediment, which also includes tightly bound uranium that is part of the crystal structure of minerals. The labile uranium fraction also generally differs from the deionized water fraction (obtained by the method described in Section 3.1.13 and results shown in Table 4), which does not efficiently extract all the uranium that is adsorbed, especially uranium adsorbed to hydrous iron oxides. Pore waters from the sediments were extracted from most of the sediments using an unsaturated flow apparatus (UFA). A few of the sediments were wet enough that pore water readily drained out on its own. The labile U(VI) was removed from an aliquot of the sediments with the (bi) carbonate extractant and includes adsorbed and pore water uranium. After subtracting the pore water uranium from the extracted uranium, the in-situ $\mathrm{K}_{\mathrm{d}}$ can be calculated by the ratio of adsorbed uranium concentration to pore water uranium concentration.

\subsubsection{U(VI) $\mathrm{K}_{\mathrm{d}} \mathrm{S}$ with Varying Background Groundwater Conditions}

Because uranium adsorption reactions are very sensitive to the groundwater geochemical conditions (e.g., $\mathrm{pH}$, ionic strength, total concentration of uranium and other competing chemical constituents), $\mathrm{U}(\mathrm{VI}) \mathrm{K}_{\mathrm{d}} \mathrm{s}$ for the <2-mm size fraction of three 200-UP-1 sediments (mixture B19136 and B19137; B19377 and B19140) were measured for varying U(VI) total solution

concentrations or carbonate concentrations. Because the $\mathrm{U}-\mathrm{K}_{\mathrm{d}}$ on the gravel-only adsorbent was 
negligible, three sediments without gravel-size particles ( $<2-\mathrm{mm}$ size fraction) were used as adsorbents. The solid-to-solution ratio $(300 \mathrm{~g} / \mathrm{L})$ for these tests was similar to the ratio used for the Task 2 batch adsorption tests. The total uranium (VI) solution concentration was varied from $5 \times 10^{-8} \mathrm{M}(12.0 \mu \mathrm{g} / \mathrm{L})$ to $5 \times 10^{-6} \mathrm{M}(1190 \mu \mathrm{g} / \mathrm{L})$ within the simulated 200-UP-1 groundwater solution shown in Table 1 . In another suite of adsorption tests, alkalinity was adjusted by adding various amounts of sodium bicarbonate to the artificial groundwater with a fixed $U$ concentration $\left(10^{-6} \mathrm{M}\right)$. Initial alkalinities $\left(\mathrm{mg} / \mathrm{L}\right.$ as $\left.\mathrm{CaCO}_{3}\right)$ for each of the simulated groundwater solutions were measured using titration and showed a range of $24-205 \mathrm{mg} / \mathrm{L}$ with $\mathrm{pH}$ of $7.9 \pm 0.3$. Batch adsorption experiments and $\mathrm{K}_{\mathrm{d}}$ calculations followed the same methods and equation shown in Section 3.2, described above.

\subsubsection{U(VI) Transport in a Flow-through Column}

A flow-through column experiment was performed to evaluate uranium transport behavior and investigate uranium adsorption/desorption on 200-UP-1 sediment. A glass chromatographic column (length $11.1 \mathrm{~cm}$ and diameter $2.7 \mathrm{~cm}$, Fisher Scientific, New Jersey) was used, and each end of the packed sediment within the column was covered by a small piece of Spectra/Mesh ${ }^{\circledR}$ to prevent the loss of particles during the flow-through experiment. The column was packed with B19140 sediment (<2-mm fraction) and saturated with the simulated 200-UP-1 groundwater solution (see Table 1). Constant flow rate $(3.61 \mathrm{~mL} / \mathrm{hr}$ ) was maintained with a syringe pump, and upward flow was used to minimize channeling in the column. After obtaining a steady flow rate through the column, a bromide $(\mathrm{Br})$-spiked simulated groundwater solution was used as a non-reactive tracer to determine the hydrodynamic dispersion coefficient. After obtaining the Br- breakthrough, the input solution was switched to a U(VI)-spiked groundwater solution, which contained 10-6 M ( 221 $\mu \mathrm{g} / \mathrm{L}) \mathrm{U}(\mathrm{VI})$. The uranium-spiked groundwater was injected for about 24 pore volumes $(604 \mathrm{~mL})$, and then un-spiked groundwater was used to flush out adsorbed uranium (i.e., desorb the uranium). To evaluate whether the adsorption-desorption process was at equilibrium, flow was stopped for 66 hours during the middle of the flushing stage. The relative $\mathrm{U}(\mathrm{VI})$ concentration $\left(\mathrm{C} / \mathrm{C}_{\mathrm{o}}\right)$ was measured as a function of pore volume, and the final U(VI) breakthrough curve (BTC) was fit using the CXTFIT code (Parker and Van Genuchten 1984) using the measured Br hydrodynamic dispersion coefficient (also determined with CXTFIT) and the previously determined U(VI) $\mathrm{K}_{\mathrm{d}}$ values from the batch tests (see Section 3.2) for initial estimates of the $K_{d}$. The $U K_{d}$ was varied by trial and error until the best fit to the BTC was obtained. 


\subsection{Results}

\subsection{Task 1 Sediment Characterization}

\subsubsection{Sediment Description}

The core liners were opened in the laboratory and described by the PNNL geologist as they were being sub-sampled for the various characterization parameters. Table 2 lists descriptions of the locations where the samples originated and the lithologies they represent.

Table 2. Description of Core Liners

\begin{tabular}{|c|c|c|c|c|c|c|}
\hline Borehole & HEIS \# & Liner \# & Depth Interval & Formation & Intact Core? & $\begin{array}{c}\text { Sed Wet } \\
\text { Wt (g) }\end{array}$ \\
\hline \multicolumn{7}{|c|}{ C4298 Well "R"(699-30-66) depth to water table $=254.45 \mathrm{ft}$ bgs } \\
\hline $\mathrm{C} 4298$ & B192K1 & 1 & $279-279.5$ & Ringold Unit E & No - slough & 2013.30 \\
\hline C4298 & B192K2 & 1 & 314-314.5 & Ringold Unit E & No - slough & 1544.35 \\
\hline C4298 & B192K3 & 1 & $347-347.5$ & Ringold Unit E & No - slough & 1646.60 \\
\hline $\mathrm{C} 4298$ & B192K4 & 1 & $386.5-387$ & Ringold Unit E & No - slough & 1329.21 \\
\hline \multicolumn{7}{|c|}{ C4299 Well "P" (699-36-70B) depth to water table = $264.84 \mathrm{ft}$ bgs } \\
\hline C4299 & $B 19136$ & 1 & 271.5-272 & Ringold Unit E & Yes & 2032.09 \\
\hline C4299 & B19137 & 2 & 308.5-309 & Ringold Unit $E$ & Yes & 2024.12 \\
\hline C4299 & B19138 & 1 & $344-344.5$ & Ringold Unit E & No - slough & 1777.87 \\
\hline C4299 & B19139 & 2 & $373.5-374$ & Ringold Unit E & No - slough & 1683.90 \\
\hline C4299 & $B 19140$ & 1 & 419-419.5 & Ringold Unit $E$ & Yes & 1674.00 \\
\hline \multicolumn{7}{|c|}{ C4300 Well "K" (299-W19-48) depth to water table = $258.20 \mathrm{ft}$ bgs } \\
\hline $\mathrm{C} 4300$ & B19373 & 1 & 289-289.5 & Ringold Unit E & No - slough & 1532.17 \\
\hline $\mathrm{C} 4300$ & B19374 & 1 & $341-341.5$ & Ringold Unit E & No - slough & 1322.90 \\
\hline $\mathrm{C} 4300$ & B19375 & 1 & $406-406.5$ & Ringold Unit E & No - slough & 1688.87 \\
\hline C4300 & B19377 & 2 & 427.5-428 & Ringold Lower Mud & Yes & 1263.07 \\
\hline Liner \# = s & spoon san & & & & & slough \\
\hline
\end{tabular}

The materials in the cores sent to PNNL were dominated by slough from the coarse-grained Ringold Unit E strata. Only 4 of the 13 liners represented intact sediment while the rest were disturbed slough that fell to the bottom of the borehole just prior to split-spoon sampling.

Figure 1 through Figure 13 are photographs of the samples taken when the core liners were opened in the laboratory. Liner B19138 contained some aluminum foil embedded in the sample along with slough (see Figure 7). Past experience working with split-spoon samples from the vadose zone, resulted in much higher success at obtaining relatively undisturbed sediments, especially in the deeper two liners of a four-liner sampling where the split-spoon is pushed out in 
front of the casing. Understandably, obtaining intact sediments of coarse, rather unconsolidated materials that are below the water table is more difficult. It appears that the boreholes in 200-UP-1 are prone to sediment "cave in" below the water table prior to split-spoon sampling. All but one of the cores sent to PNNL are from the Ringold Unit E that contains predominately a mixture of pebbles and sand with some larger cobbles. One of the good cores (not slough), B19140, contains an abundance of pebbles and cobbles that are coated with ferric iron oxide-rich materials as evidenced by the orange-red coloration (see Figure 9). Ferric oxides are known to be excellent adsorbents for cationic (metal-like) species. The deepest sample from borehole C4300 (see Figure 13) was obtained from the Ringold lower mud unit, which is predominately fine-grained mud (silt and clay).

\subsubsection{Solution Analyses}

The preliminary groundwater data for the samples received were also used to choose the sediment samples that would be characterized in more detail and then used to determine a chemical composition for the water used in the batch adsorption tests. The description of the groundwater samples obtained and concentrations of key contaminants are shown in Table 3. Groundwater data in Table 3 showed, as expected, that boreholes C4298 and C4299 did not intercept the high-concentration portion of the existing groundwater plume that contains elevated concentrations of Tc-99 and U. The water sample from borehole C4298 at $240 \mathrm{ft}$ bgs must represent perched water or the depth is incorrectly marked because this sample is from above the water table after well completion. The shallowest groundwater sample sent to the laboratory from C4300 does show elevated concentrations of Tc-99 and dissolved U. Note that the water sample came from $290 \mathrm{ft}$ bgs, which is $32 \mathrm{ft}$ below the groundwater surface. This depth is likely deeper than the depths sampled by most of the existing monitoring wells used to delineate the groundwater plume. The contamination plumes at Hanford in general have been assumed to be near the surface of the aquifer such that contamination often exists in a thin layer at the water table, especially if the well is near the location where the contamination penetrates the vadose zone-water table interface. However, at 200-UP-1 the source of the U and Tc-99 contamination that formed the groundwater plume is a few thousand meters distant from $\mathrm{C} 4300$ so that the exact vertical distribution of these contaminants in the aquifer is not known. Thus, the water at borehole $\mathrm{C} 4300$ that is right at the top of the water table might contain higher concentrations of Tc-99 and U than the samples sent to the laboratory, which were collected at various depths deeper within the aquifer. This is consistent with the shallowest groundwater sample collected at C4299 (270 ft bgs) showing the highest concentration of Tc-99 and U compared to other samples. The groundwater sample from C4299 at $270 \mathrm{ft}$ bgs is only $\sim 5 \mathrm{ft}$ below the top of the water table. At borehole C4298, the Tc-99 concentrations were too low to quantify accurately, and the $\mathrm{U}$ concentrations are not elevated above background values so no contamination plume is identifiable as a function of groundwater depth. The natural $U$ concentration versus depth in groundwater at borehole C4298 appears to increase with depth. 


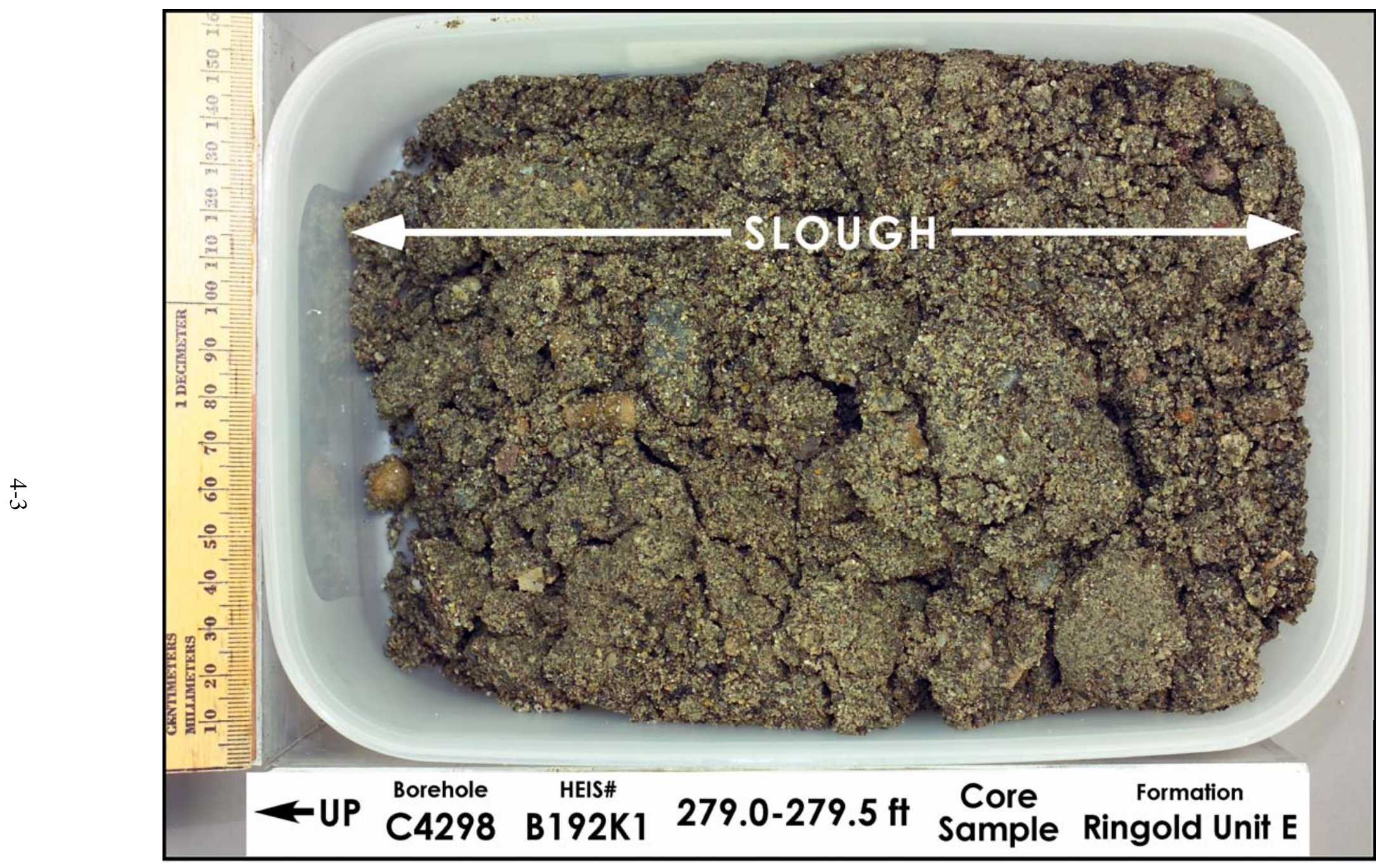

Figure 1. Sediment in Core Liner B192K1 from Borehole C4298 


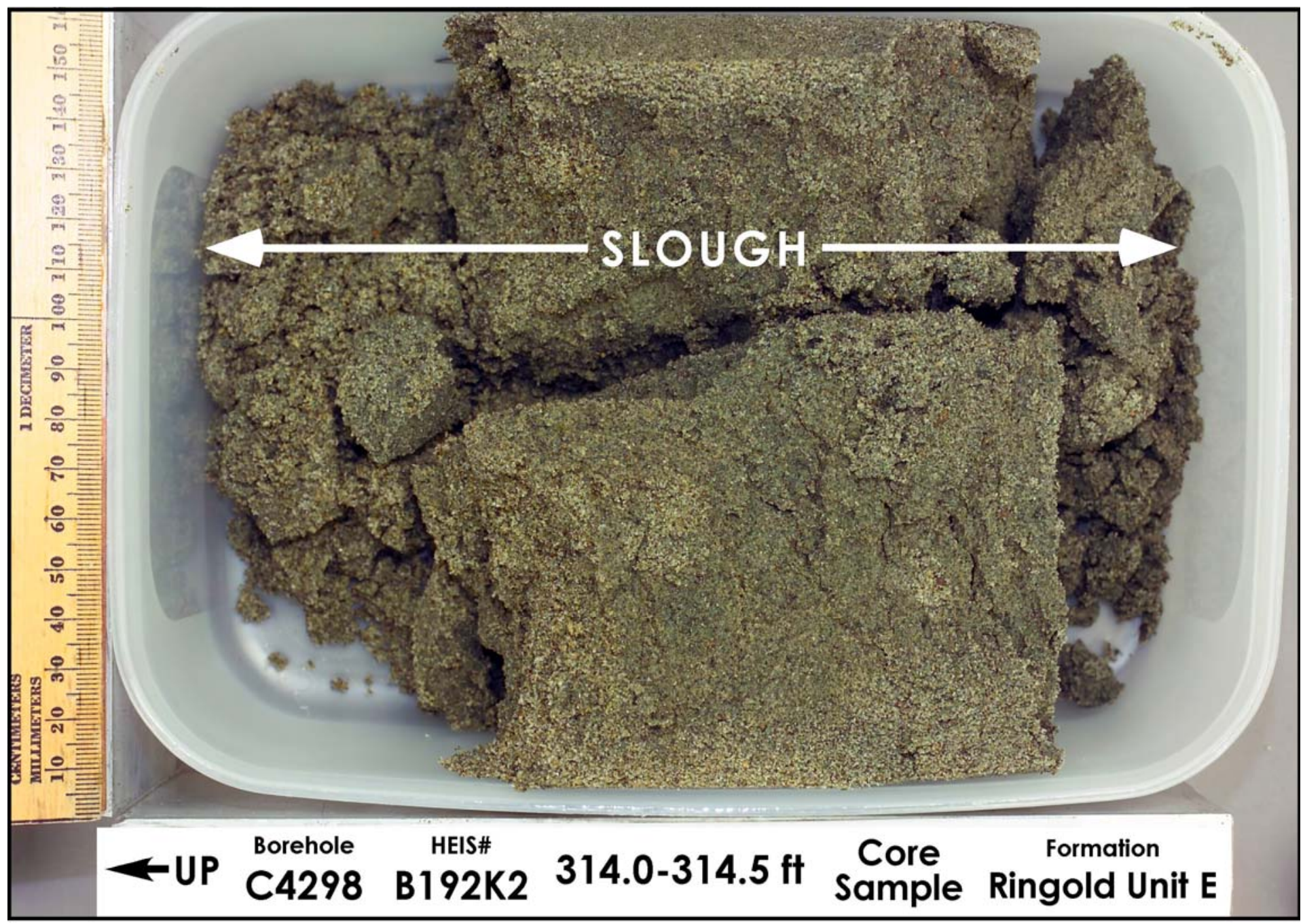

Figure 2. Sediment in Core Liner B192K2 from Borehole C4298 


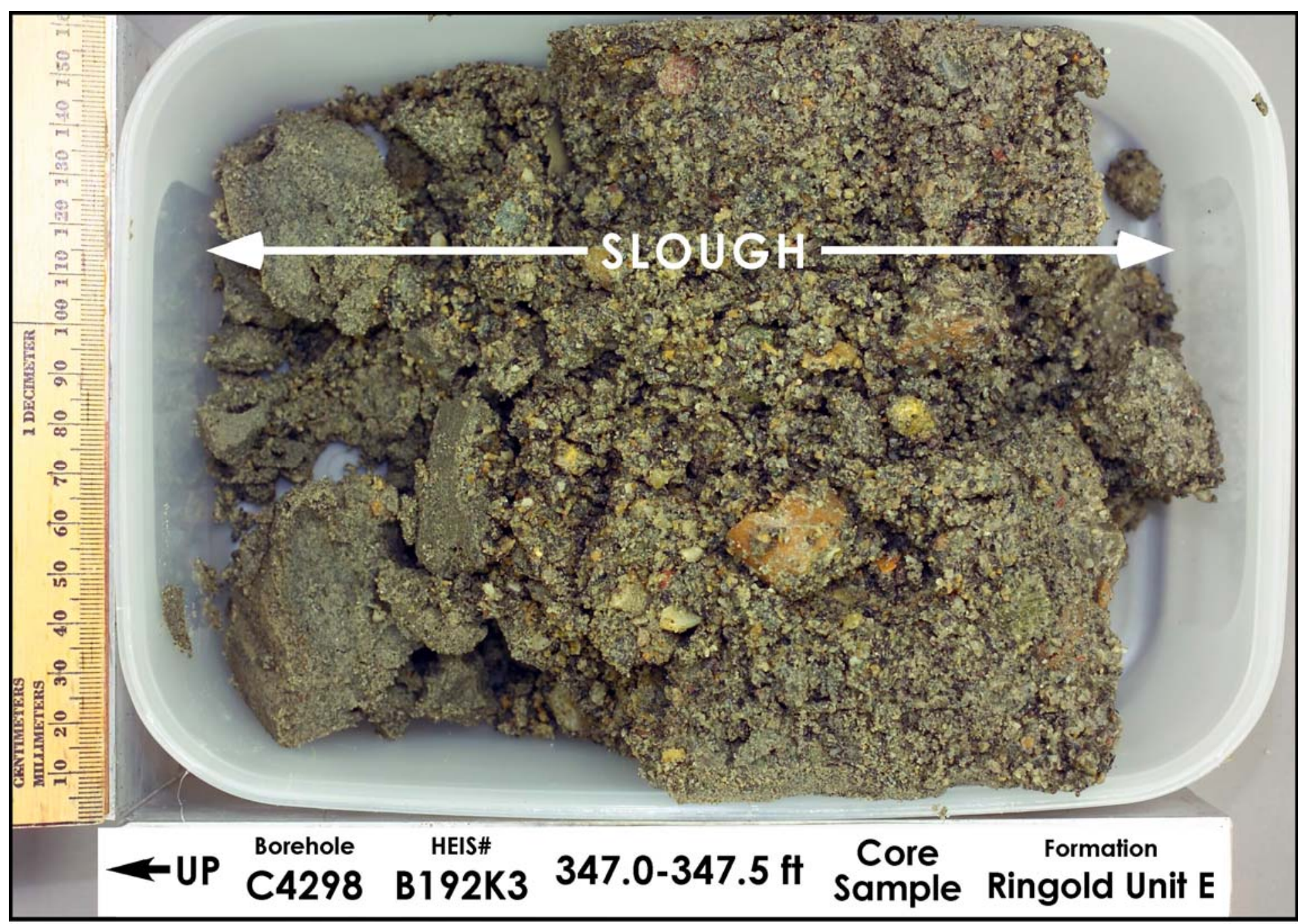

Figure 3. Sediment in Core Liner B192K3 from Borehole C4298 


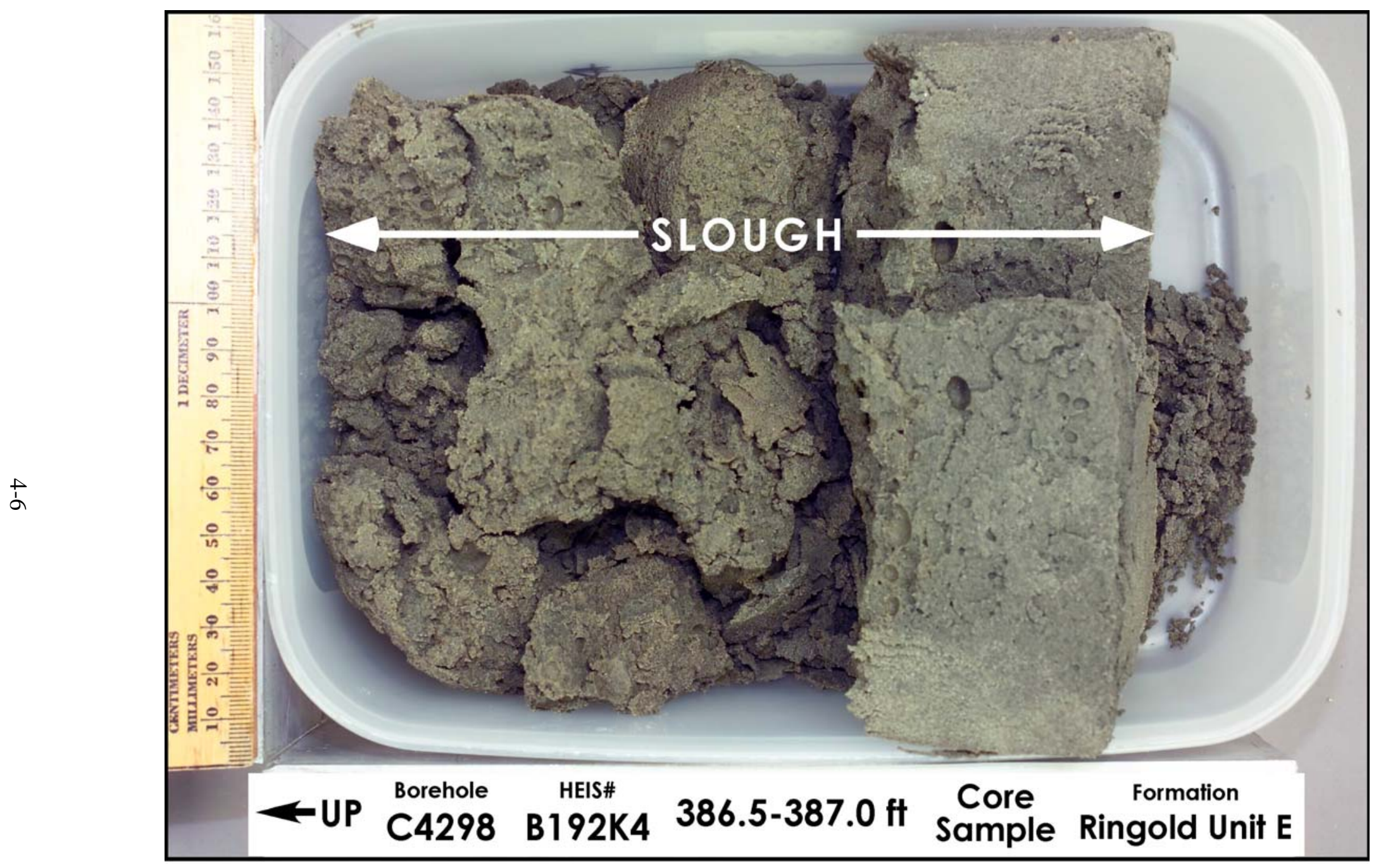

Figure 4. Sediment in Core Liner B192K4 from Borehole C4298 


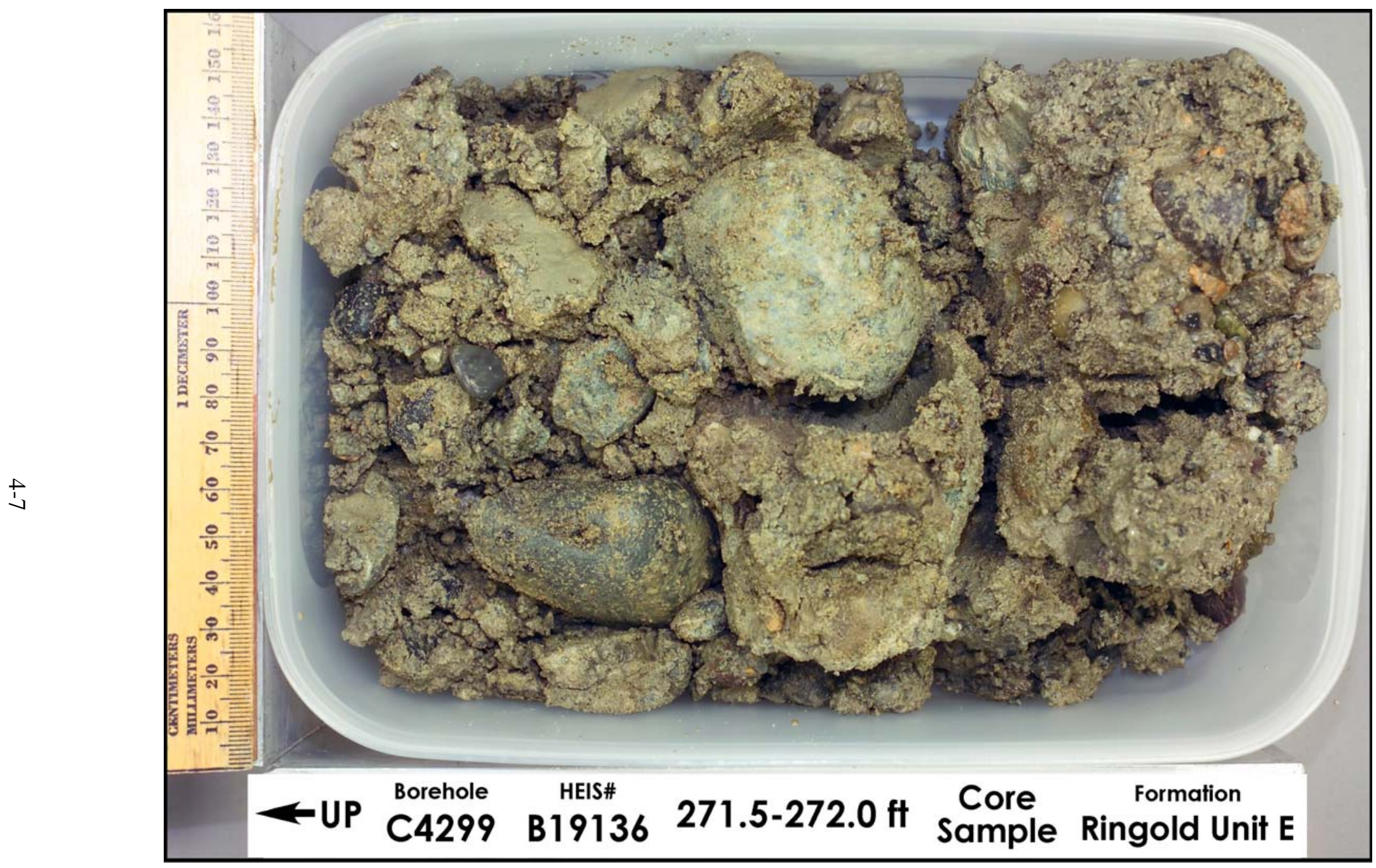

Figure 5. Sediment in Core Liner B19136 from Borehole C4299 


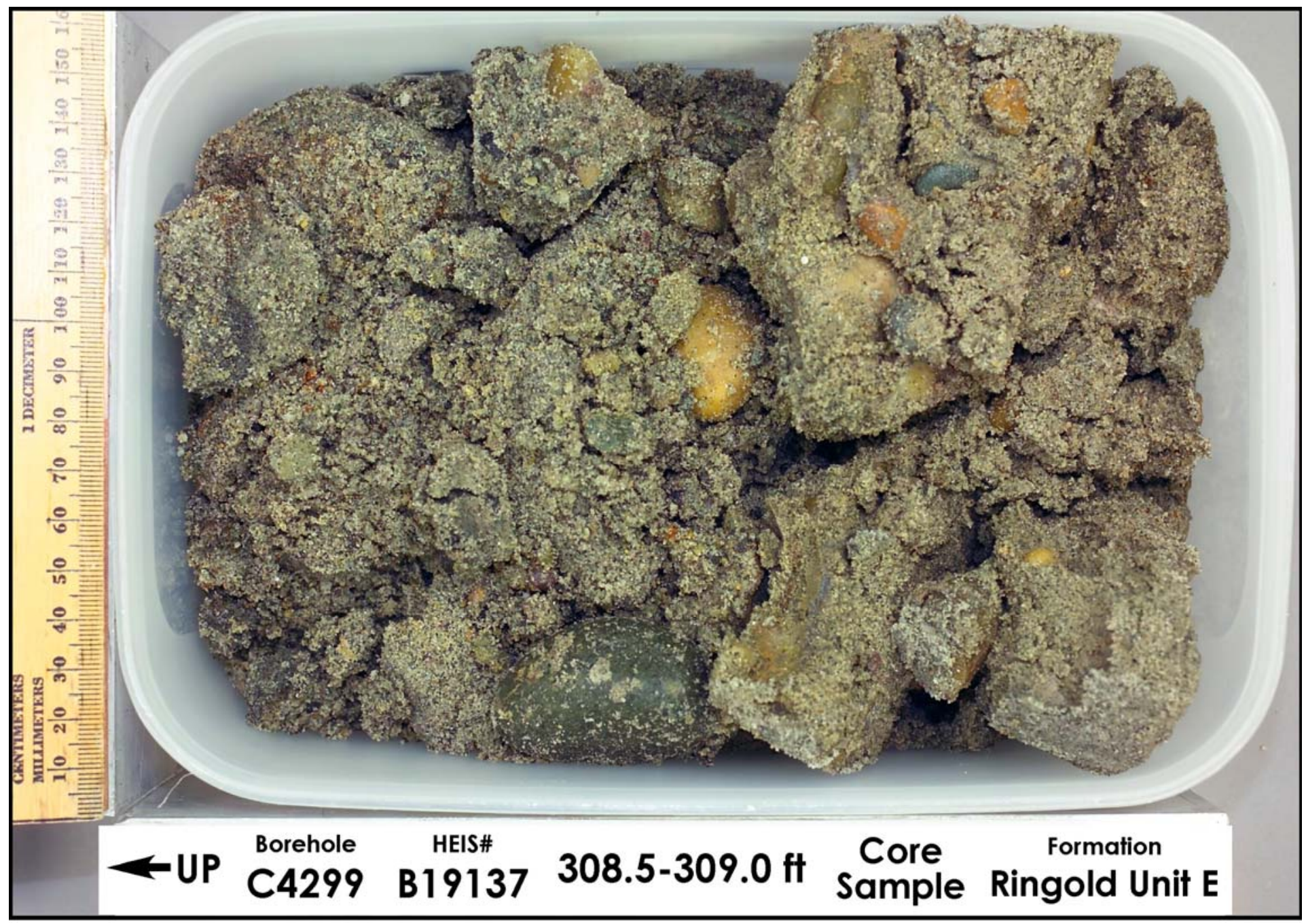

Figure 6. Sediment in Core Liner B19137 from Borehole C4299 


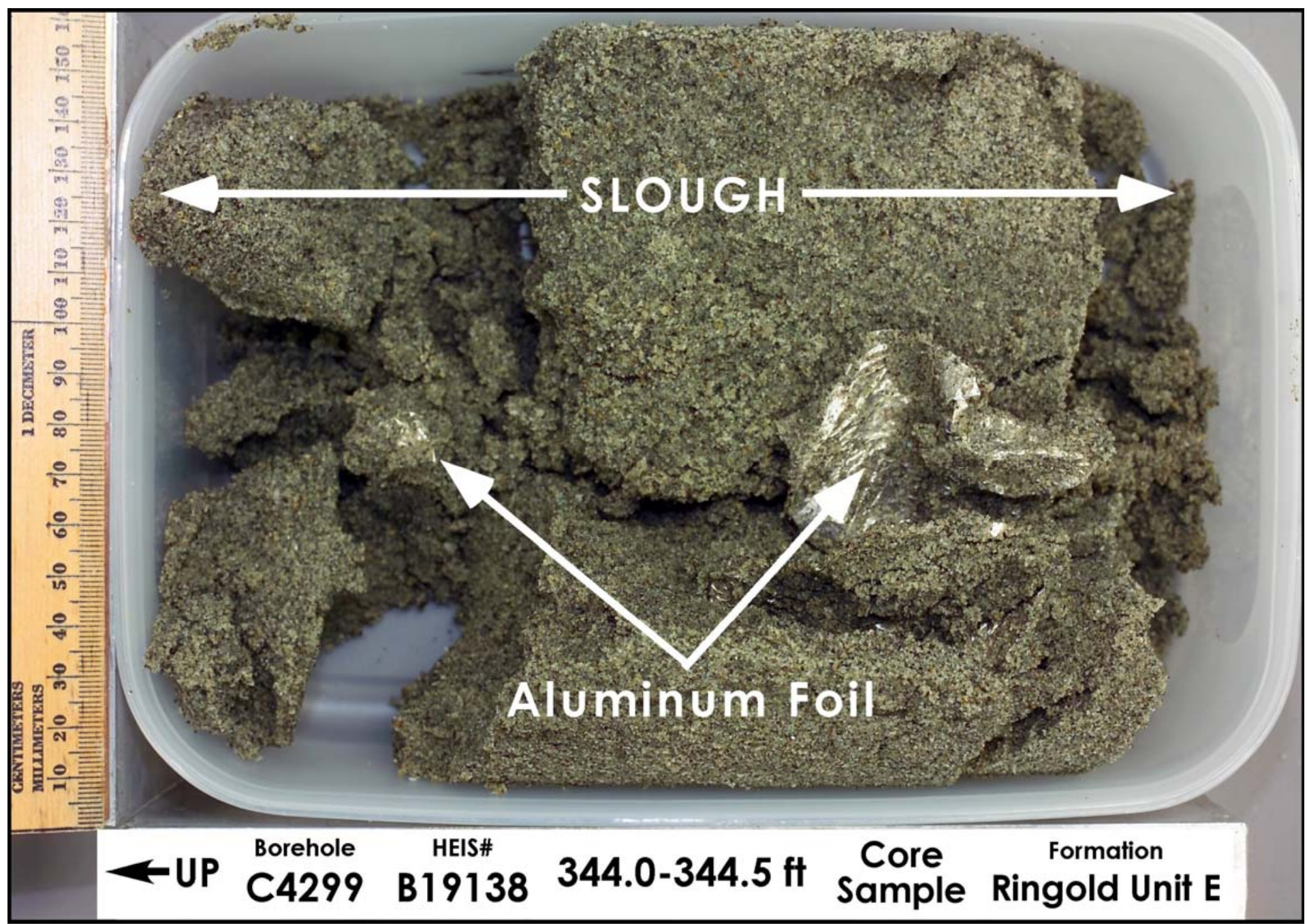

Figure 7. Sediment in Core Liner B19138 from Borehole C4299 


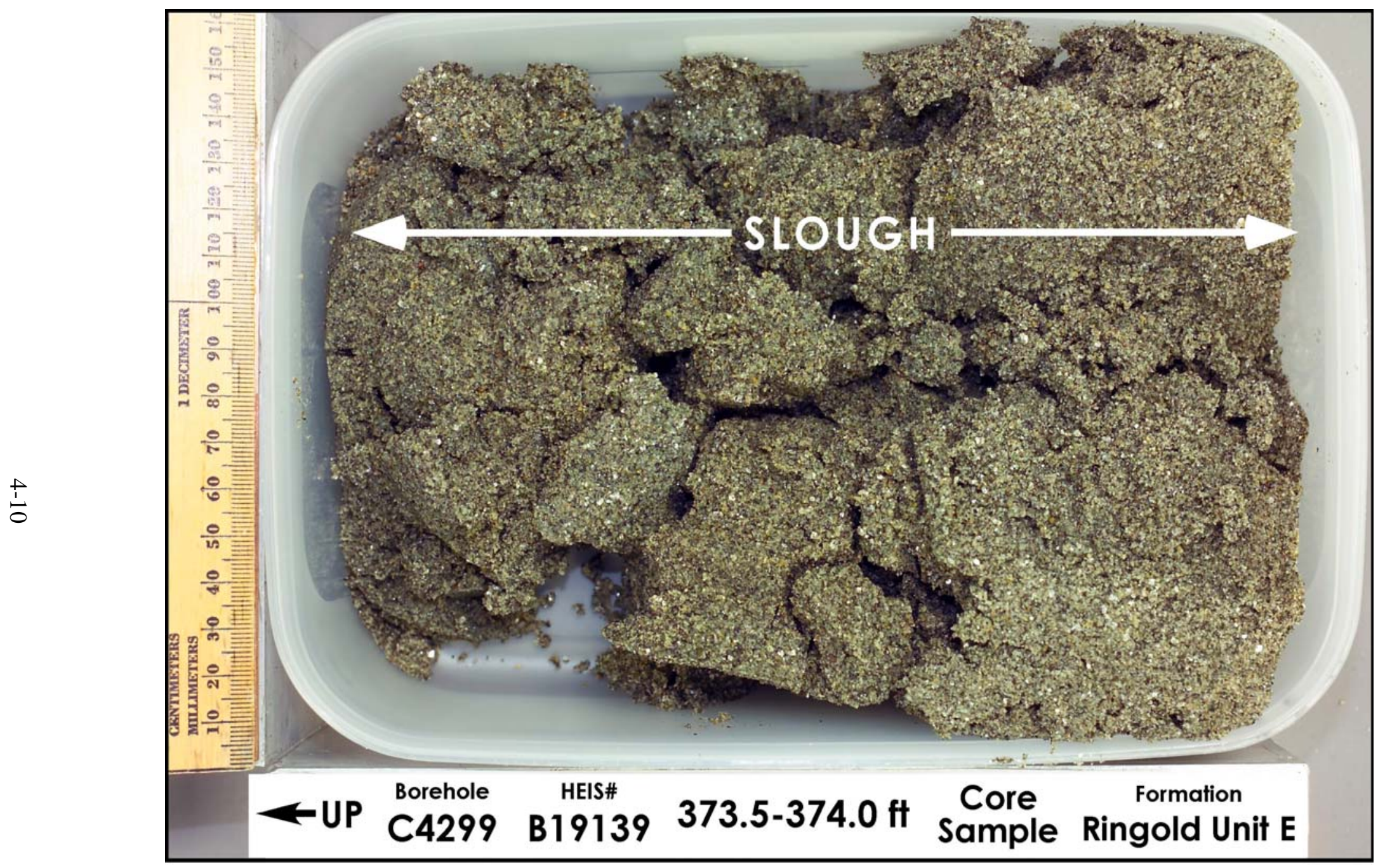

Figure 8. Sediment in Core Liner B19139 from Borehole C4299 


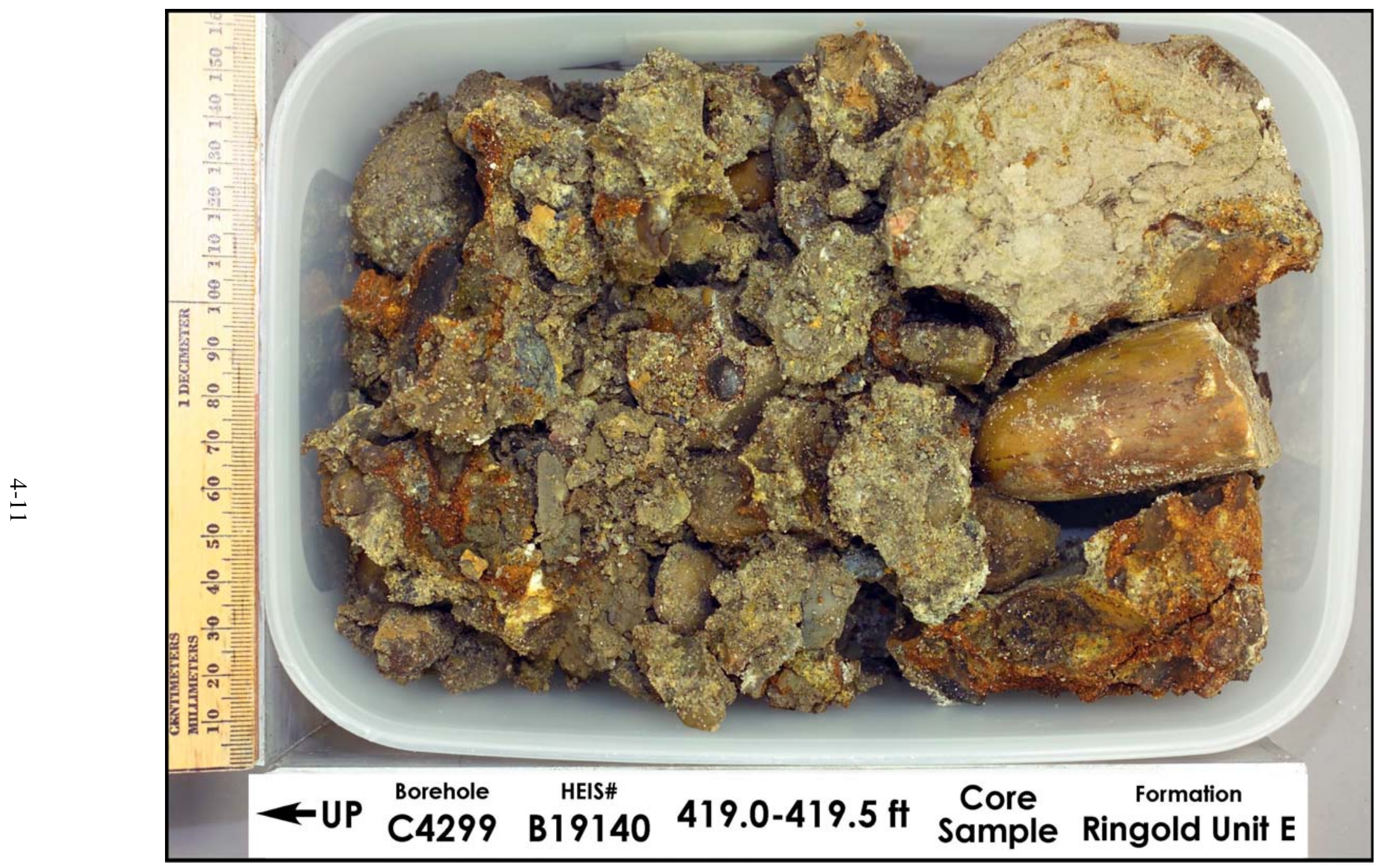

Figure 9. Sediment in Core Liner B192140 from Borehole C4299 


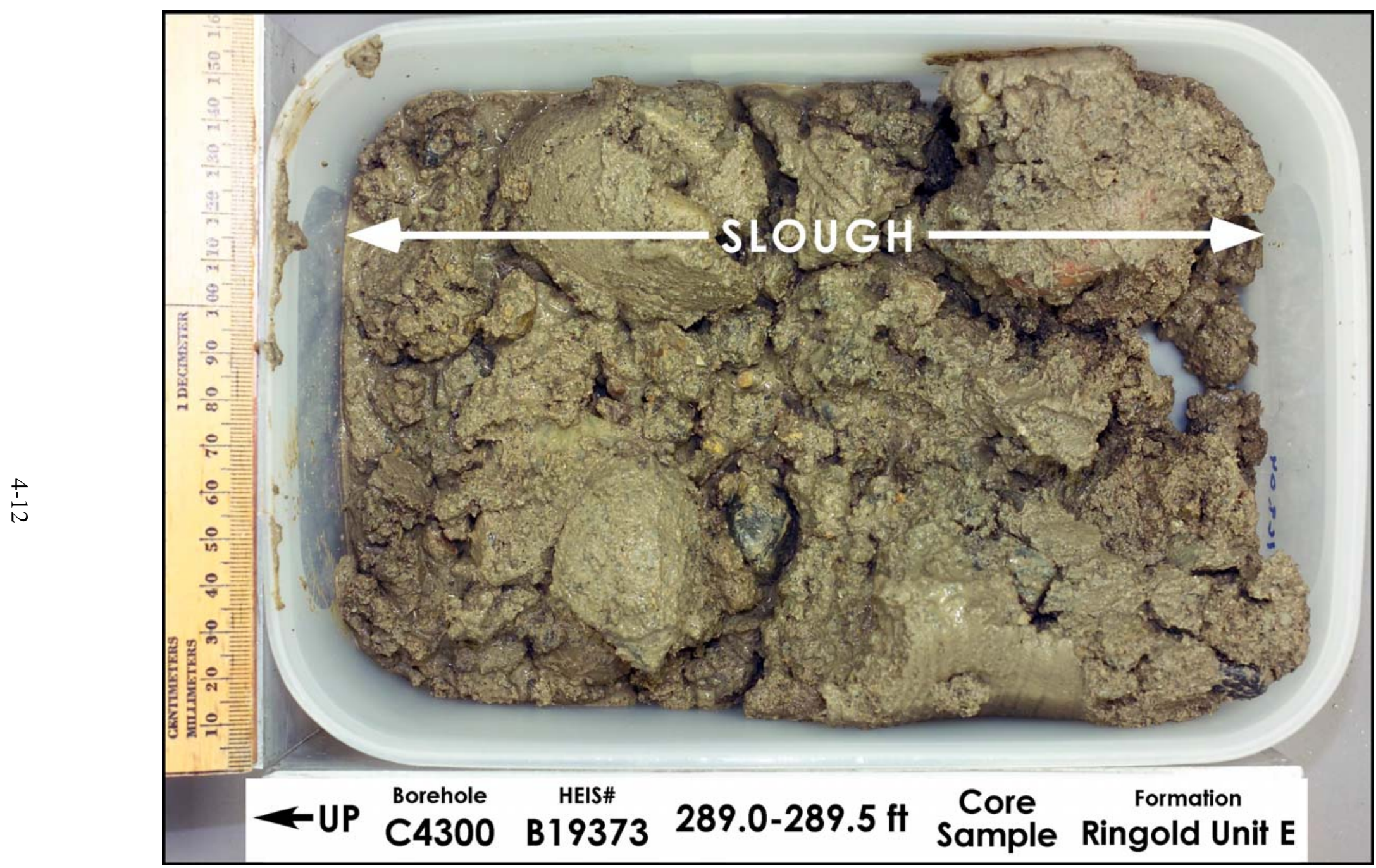

Figure 10. Sediment in Core Liner B19373 from Borehole C4300 


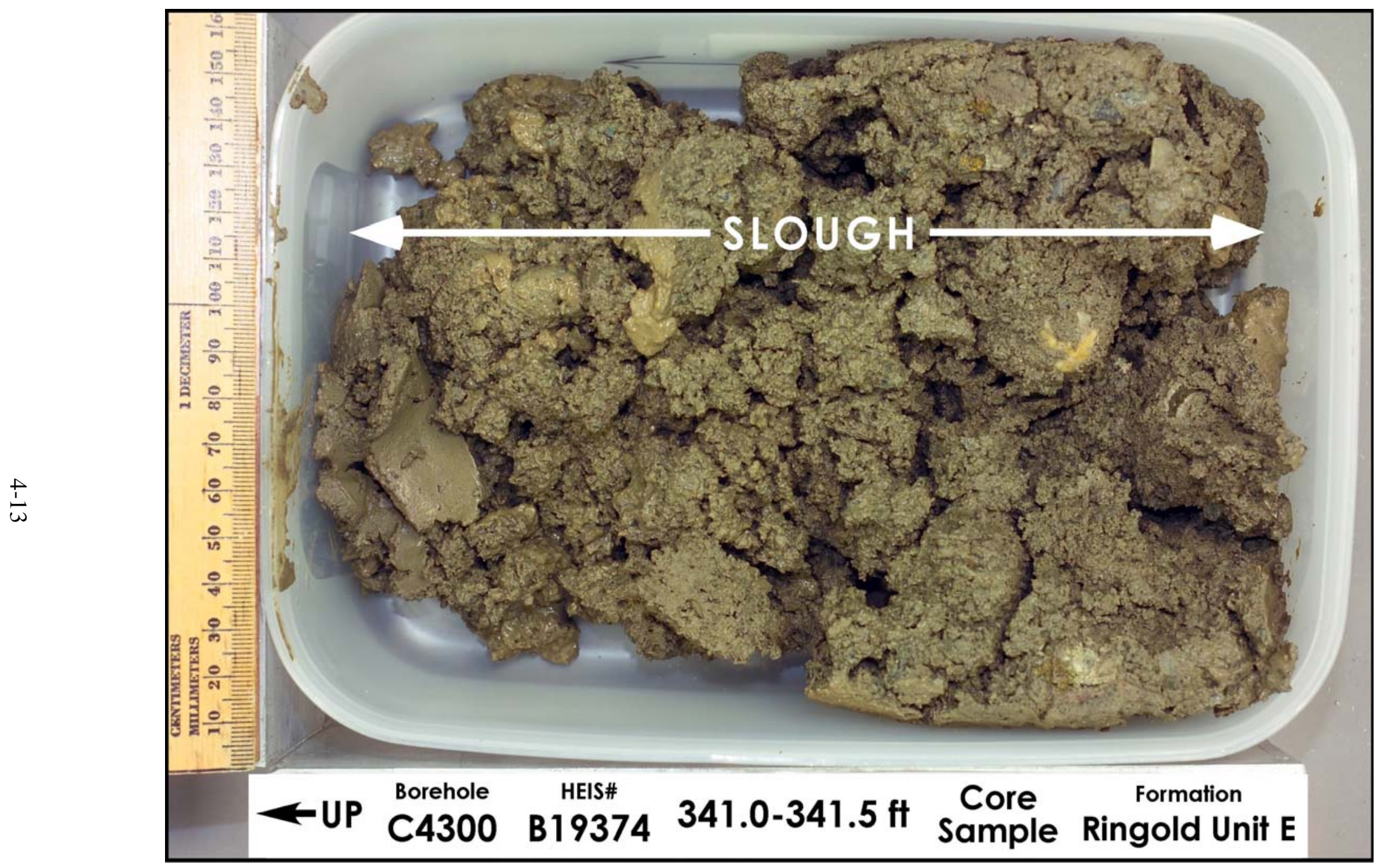

Figure 11. Sediment in Core Liner B19374 from Borehole C4300 


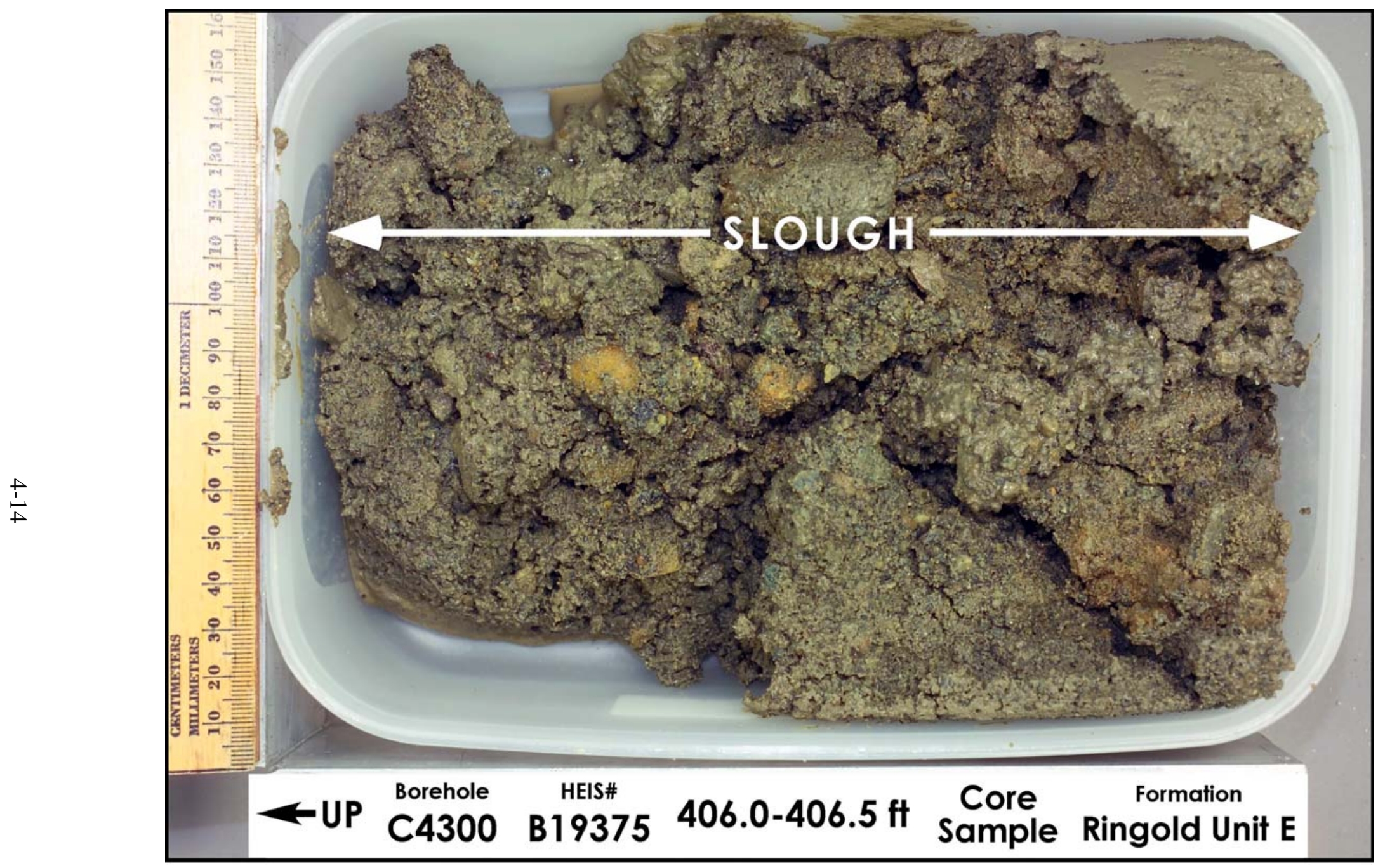

Figure 12. Sediment in Core Liner B19375 from Borehole C4300 


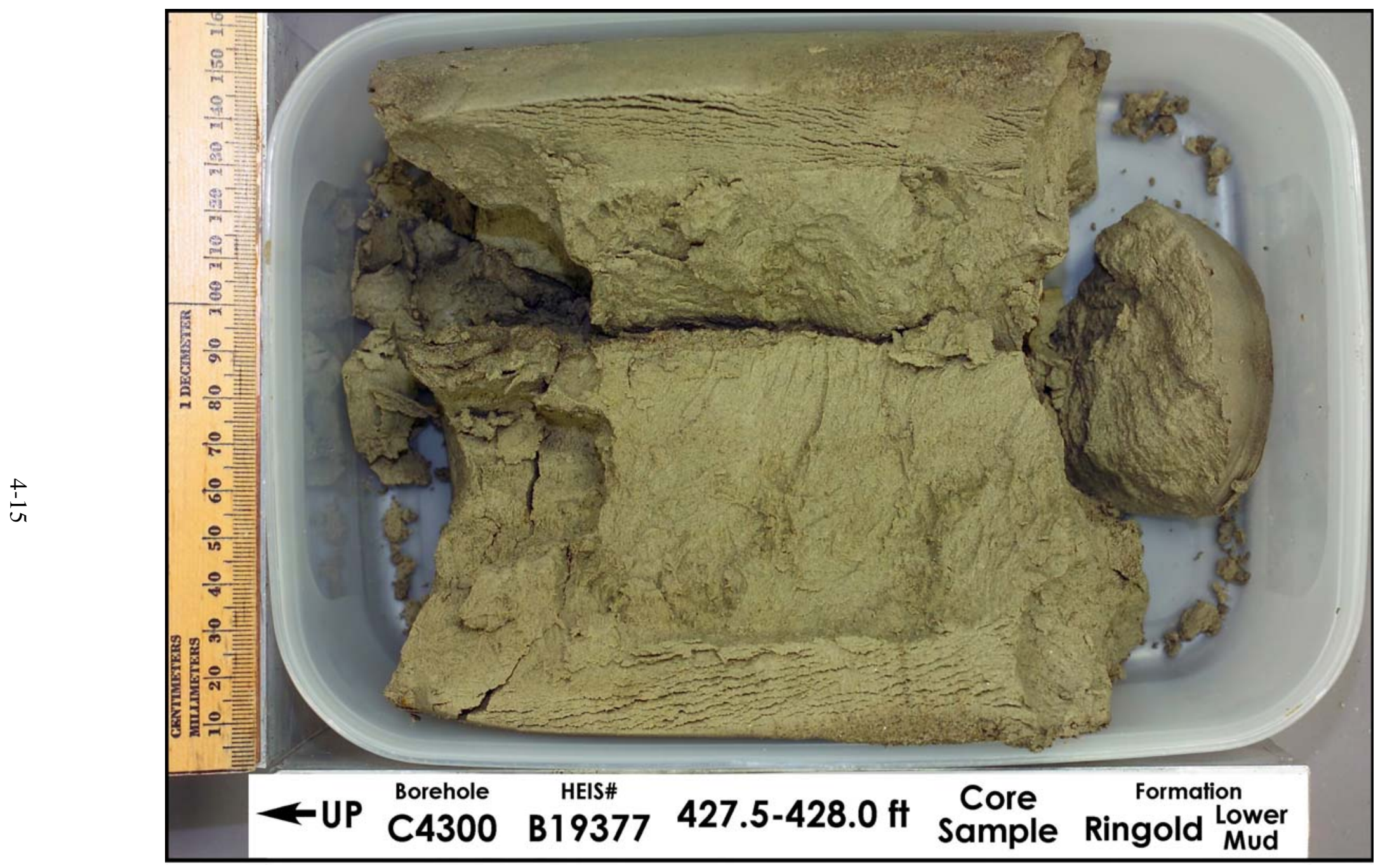

Figure 13. Sediment in Core Liner B19377 from Borehole C4300 
Table 3. Groundwater Samples Obtained During Drilling

\begin{tabular}{|c|c|c|c|c|c|c|c|c|}
\hline WATER & & & & Тс 99 & Тс 99 & U 238 & Total & $\begin{array}{l}\text { Colorimetric } \\
\text { (Ferrozine) }\end{array}$ \\
\hline \multicolumn{4}{|c|}{$\begin{array}{c}\text { C4298 Well "R" (699-30-66) wt @ } 254.45 \text { ft } \\
\text { bgs }\end{array}$} & $\mu \mathrm{g} / \mathrm{L}$ & $\mathrm{pCi} / \mathrm{L}$ & $\mu \mathrm{g} / \mathrm{L}$ & $\mathrm{Fe}(\mathrm{ICP})$ & $\mathrm{Fe}^{2+}$ \\
\hline Sample ID & Well & Depth $(\mathrm{ft})$ & Acidified & & & & $\mu \mathrm{g} / \mathrm{L}$ & $\mu \mathrm{g} / \mathrm{L}$ \\
\hline B19J00 & C4298 & 240 & No & $(0.001)$ & (11.5) & 0.194 & $\mathrm{NA}^{(1)}$ & 0.0 \\
\hline B19J01 & C4298 & 275 & Yes & $<0.002$ & $<34$. & 0.663 & 84 & 0.0 \\
\hline B19J02(F) & C4298 & 345 & Yes & $<0.015$ & $<255$. & 1.02 & $(4)^{(2)}$ & 0.0 \\
\hline B19J03(F) & C4298 & 390 & Yes & $(0.001)$ & $(21.3)$ & 1.14 & (3) & 0.0 \\
\hline \multicolumn{9}{|c|}{ C4299 Well "P" (699-36-70B) wt @ 264.84 ft } \\
\hline B19J05 & C4299 & 270 & Yes & 0.009 & 153 & 1.13 & 6,680 & 219 \\
\hline B19J06 & C4299 & 305 & No & $<0.003$ & $<51$. & 0.204 & (1) & 0.0 \\
\hline B19J07 & C4299 & 340 & No & $(0.001)$ & (8.9) & 0.159 & $(1)$ & 0.0 \\
\hline B19J08 & C4299 & 375 & Yes & $(0.002)$ & $(32.1)$ & 0.794 & 363 & 105 \\
\hline B19J09 & C4299 & 420 & Yes & $<0.010$ & $<170$. & 0.065 & 31 & 82.3 \\
\hline \multicolumn{9}{|c|}{$\begin{array}{c}\text { C4300 Well "K" (299-W19-48) wt @ } 258.20 \\
\text { ft bgs }\end{array}$} \\
\hline B19J10 & $\mathrm{C} 4300$ & 290 & Yes & 0.089 & 1520 & 144 & 32 & 0.0 \\
\hline B19J11 & $\mathrm{C} 4300$ & 300 & Yes & 0.009 & 149 & 1.14 & (3) & 0.0 \\
\hline B19J12 & $\mathrm{C} 4300$ & 402 & Yes & 0.002 & 37.2 & 0.876 & (4) & 0.0 \\
\hline B19J14 & $\mathrm{C} 4300$ & 435 & Yes & 0.002 & 37.0 & 0.885 & (3) & 0.0 \\
\hline \multicolumn{9}{|c|}{$\begin{array}{l}\text { (1) NA = not analyzed } \\
\text { (2) ( ) = measurement is qualitative; below instrument quantitation limit } \\
\text { wt } @=\text { water table contacted at } X \text { depth below ground surface }\end{array}$} \\
\hline
\end{tabular}

Some of the groundwater samples sent to the laboratory from borehole C4299 show measurable concentrations of dissolved total iron and dissolved ferrous iron, which generally indicate reducing conditions that likely are transient and an artifact of the drilling. In contrast, the deepest sediment sample from borehole C4299 (B19140) contains the orange-stained ferric oxide coatings, which indicates oxidizing conditions. How the groundwater and sediment samples from this same depth suggest differing redox conditions-groundwater suggests reducing and sediments suggest oxidizing conditions-is puzzling. One explanation is that during hard tool cable drilling, pebbles and cobbles were crushed/disaggregated exposing fresh ferrous-bearing mineral surfaces to dissolution. It is also possible that zero-valent iron particles could have broken off the metal cable tools and were introduced into the sediments, temporarily reducing the surrounding water. Such observations have been made at other wells drilled on the Hanford Site many times in the past (Bjornstad et al. 1994). Measurable ferrous iron was found in the pore water extracted from the sediment core liners using a filter (for those with drainable liquid) or using the UFA for core liners that did not have drainable liquid. As shown in Table 4, 
the highest ferrous iron concentration $(594 \mu \mathrm{g} / \mathrm{L})$ was found in the $309-\mathrm{ft}$ bgs pore water from C4299, which is greater than the value found in the groundwater sample at $270 \mathrm{ft}$ bgs $(219 \mu \mathrm{g} / \mathrm{L})$. Different redox conditions at different depths in the same wells, especially for C4298 and C4299, suggest the possibility of newly exposed particles containing ferrous ions.

Table 4. Pore Water Extracted from Cores and 1:1 Sediment to Water Extracts

\begin{tabular}{|c|c|c|c|c|c|c|}
\hline $\begin{array}{c}\text { Soil Sample } \\
\text { ID }\end{array}$ & Well & Depth (ft) & $\begin{array}{c}\text { Method } \\
\text { Used to } \\
\text { Get } \\
\text { Water } \\
\end{array}$ & $\begin{array}{c}\mathrm{Fe}(\mathrm{II}) \\
(\mu \mathrm{g} / \mathrm{L}) \\
\text { (Ferrozine) }\end{array}$ & Tc $99(\mu \mathrm{g} / \mathrm{L})$ & U $238(\mu \mathrm{g} / \mathrm{L})$ \\
\hline B192K1 & $\mathrm{C} 4298$ & $279.0-289.5$ & Filter & 0.0 & $0.021(0.008)$ & $0.464(0.068)$ \\
\hline $\mathrm{B} 192 \mathrm{~K} 2$ & $\mathrm{C} 4298$ & $314.0-314.5$ & UFA & 19.2 & $0.006(0.004)$ & $0.964(6.900)$ \\
\hline $\mathrm{B} 192 \mathrm{~K} 3$ & C4298 & $347.0-347.5$ & Filter & 0.0 & $0.010(0.250)$ & $0.375(0.244)$ \\
\hline B192K4 & $\mathrm{C} 4298$ & $386.5-387.0$ & UFA & 100.0 & $0.004(0.004)$ & $1.450(2.280)$ \\
\hline B19136 & C4299 & $271.5-272.0$ & UFA & 19.2 & $0.017(0.007)$ & $2.218(0.973)$ \\
\hline B19137 & C4299 & $308.5-309.0$ & UFA & 593.9 & $0.026(0.016)$ & $1.682(2.230)$ \\
\hline B19138 & C4299 & $344.0-344.5$ & Filter & 0.0 & $0.013(0.009)$ & $0.453(0.148)$ \\
\hline B19139 & C4299 & $373.5-374.0$ & UFA & 0.0 & $0.012(0.009)$ & $0.431(5.260)$ \\
\hline B19140 & C4299 & $419.0-419.5$ & UFA & 0.0 & $0.016(0.250)$ & $0.211(0.052)$ \\
\hline B19373 & $\mathrm{C} 4300$ & $289.0-289.5$ & Filter & 0.0 & $0.016(0.014)$ & $6.750(18.50)$ \\
\hline B19374 & $\mathrm{C} 4300$ & $341.0-341.5$ & Filter & 0.0 & $0.007(0.009)$ & $1.660(0.927)$ \\
\hline B19375 & $\mathrm{C} 4300$ & $406.0-406.5$ & Filter & 0.0 & $0.023(0.001)$ & $1.343(0.525)$ \\
\hline B19377 & $\mathrm{C} 4300$ & $427.5-428.0$ & UFA & 0.0 & $0.009(0.001)$ & $0.314(1.310)$ \\
\hline \multicolumn{7}{|c|}{$\begin{array}{l}\mathrm{Fe}(\mathrm{II}) \text { concentration was measured in the extracted pore water. Tc- } 99 \text { and } \mathrm{U} \text { concentrations analyzed using } 1: 1 \text { water } \\
\text { extract sample with dilution correction to represent calculated pore water values are shown in italics. Concentrations of } \\
\text { Tc- } 99 \text { and U in the actual pore water obtained by draining excess fluid from sleeve or ultracentrifuge are shown in } \\
\text { parentheses. Blue highlighted pairs do not agree as well as most of the others; however, we have no certain explanation } \\
\text { other than the possibility of highly non-equilibrium conditions in the sediment of the two separate aliquots used for } \\
\text { these measurements. Values in red represent elevated above-background U. }\end{array}$} \\
\hline
\end{tabular}

Pore water extracted from the $\mathrm{C} 4299$ sediment collected at a similar depth ( $270 \mathrm{ft}$ bgs) to the groundwater sample (see Table 3 ) having the highest concentration of Tc-99 (153 pCi/L or $0.009 \mu \mathrm{g} / \mathrm{L})$ and $U(1.1 \mu \mathrm{g} / \mathrm{L}$; see Table 3$)$ showed a larger $U$ concentration $(18.5 \mu \mathrm{g} / \mathrm{L})$, but the pore water Tc-99 concentration was negligible. The lower Tc-99 concentration in the pore water from the core than that found in the groundwater sample can be explained by the transient reducing conditions in the core liner that likely formed during drilling and split-spoon sampling. The analysis of the 1:1 water extract solution showed that the Tc-99 concentration was also negligible in the sediment from this core liner, again suggesting transient reducing conditions, which precipitate reduced Tc-99, were present in the core liners. The highest pore water U concentration for borehole C4299 was found at the same depth that showed the highest U concentration plume in the groundwater sample. The extracted pore water showed higher concentrations of $\mathrm{U}$. However, because this core liner was considered to be slough, we cannot ascertain that higher $U$ concentration within the pores is truly related to the native sediment from 
the 270-ft depth where the groundwater was obtained. The slough might have fallen into the open borehole from a shallower depth for which we have no groundwater data.

Table 5 shows the gravimetric moisture contents and carbon contents for core sediments, and $\mathrm{pH}, \mathrm{EC}$, and alkalinity for 1:1 water extracts or the pore water (data in parentheses). The Ringold Lower Mud unit (B19377) showed the highest moisture content, and it was attributed to the fine-grained nature of this sample. Because the samples were collected from the saturated zone below the water table, the measured moisture contents were higher than the range for Hanford vadose zone sediments. However, most all of the measured moisture contents for the saturated 200-UP-1 sediments are lower than values one would calculate for saturated sediments from below the water table. The measured values certainly must be indicative of water loss (drainage) out of the split-spoon sampler as the sampling device is raised to the ground surface. Recall that the split-spoon sampler has only a metal core catcher (fingers) to retain the sampled material within the liners. Drainable fluids can partially escape during the journey back up the casing to ground surface.

All the total carbon, inorganic, and organic carbon content values were small. One sample (B19137) showed $0.22 \%$ inorganic carbon, which is $1.83 \%$ of equivalent calcium carbonate. It is likely that any calcite originally in these relatively old Ringold Unit sediments at their time of emplacement has been dissolved over the millennia by percolating groundwater if the groundwater was unsaturated with respect to carbonate-bearing minerals. However, today the 200-UP-1 groundwater within the Ringold Formation, based on geochemical modeling, is close to equilibrium with calcite and dolomite. Thus, either carbonates were removed in the past or the Ringold sediments may have been low in calcium carbonate content at the time of deposition. Shallower in the vadose zone, one generally finds at least a few tenths of percent to a few percent inorganic carbon, especially in the younger Hanford formation sediments. In the 200 West Area, below the Hanford formation and above the Ringold Formation exists a thin layer of sediments highly enriched in calcium carbonate, commonly called caliche, that was formed by repetitive wetting and evaporation cycles prior to the catastrophic glacial flood events that deposited the Hanford formation sediments on top of the Ringold sediments. 
Table 5. Moisture and Carbon Content of Sediments and pH, Alkalinity, and EC of 1:1 Water Extracts

\begin{tabular}{|c|c|c|c|c|c|c|c|}
\hline $\begin{array}{c}\text { Sediment } \\
\text { Sample ID }\end{array}$ & Well & $\begin{array}{c}\text { Moisture } \\
\text { Content (\%) }\end{array}$ & $\begin{array}{c}\text { Total } \\
\text { Carbon } \\
(\%) \\
\end{array}$ & $\begin{array}{c}\text { Inorganic } \\
\text { Carbon } \\
(\%) \\
\end{array}$ & $\begin{array}{c}\text { Alkalinity } \\
\text { (mg/L) }\end{array}$ & pH & $\begin{array}{c}\mathrm{EC} \\
(\mathrm{mS} / \mathrm{cm})\end{array}$ \\
\hline B192K1 & C4298 & 9.74 & 0.03 & 0.00 & $\begin{array}{c}445.5 \\
(127.4)\end{array}$ & $\begin{array}{c}7.64 \\
(7.69)\end{array}$ & $\begin{array}{c}0.867 \\
(0.255)\end{array}$ \\
\hline B192K2 & C4298 & 17.7 & 0.05 & 0.00 & $\begin{array}{l}261.3 \\
(90.0)\end{array}$ & $\begin{array}{c}7.47 \\
(7.39)\end{array}$ & $\begin{array}{c}0.578 \\
(0.215)\end{array}$ \\
\hline $\mathrm{B} 192 \mathrm{~K} 3$ & $\mathrm{C} 4298$ & 9.64 & 0.02 & 0.00 & $\begin{array}{l}404.3 \\
(86.4) \\
\end{array}$ & $\begin{array}{r}7.17 \\
(7.56) \\
\end{array}$ & $\begin{array}{c}0.771 \\
(0.184) \\
\end{array}$ \\
\hline B192K4 & C4298 & 25.4 & 0.02 & 0.00 & $\begin{array}{l}215.9 \\
(90.0)\end{array}$ & $\begin{array}{c}7.60 \\
(7.52)\end{array}$ & $\begin{array}{c}0.534 \\
(0.229)\end{array}$ \\
\hline B19136 & C4299 & 5.88 & 0.03 & 0.00 & $\begin{array}{c}743.4 \\
(108.3) \\
\end{array}$ & $\begin{array}{c}7.59 \\
(7.81) \\
\end{array}$ & $\begin{array}{c}1.812 \\
(0.318) \\
\end{array}$ \\
\hline B19137 & C4299 & 11.7 & 0.24 & 0.22 & $\begin{array}{l}577.9 \\
(60.0) \\
\end{array}$ & $\begin{array}{c}7.58 \\
(7.45) \\
\end{array}$ & $\begin{array}{c}0.961 \\
(0.214) \\
\end{array}$ \\
\hline B19138 & C4299 & 23.6 & 0.02 & 0.00 & $\begin{array}{c}201.4 \\
(112.7) \\
\end{array}$ & $\begin{array}{c}7.57 \\
(7.54) \\
\end{array}$ & $\begin{array}{c}0.453 \\
(0.268) \\
\end{array}$ \\
\hline B19139 & C4299 & 26.0 & 0.02 & 0.00 & $\begin{array}{l}180.1 \\
(91.5) \\
\end{array}$ & $\begin{array}{c}7.61 \\
(7.42) \\
\end{array}$ & $\begin{array}{c}0.443 \\
(0.222) \\
\end{array}$ \\
\hline B19140 & C4299 & 18.4 & 0.04 & 0.00 & $\begin{array}{l}170.2 \\
(\mathrm{ND})\end{array}$ & $\begin{array}{l}7.48 \\
\text { (ND) }\end{array}$ & $\begin{array}{l}0.573 \\
(\mathrm{ND})\end{array}$ \\
\hline B19373 & $\mathrm{C} 4300$ & 18.5 & 0.02 & 0.00 & $\begin{array}{c}253.2 \\
(130.3) \\
\end{array}$ & $\begin{array}{c}7.63 \\
(7.62) \\
\end{array}$ & $\begin{array}{c}0.686 \\
(0.391) \\
\end{array}$ \\
\hline B19374 & $\mathrm{C} 4300$ & 15.1 & 0.03 & 0.00 & $\begin{array}{l}286.6 \\
(96.6)\end{array}$ & $\begin{array}{c}7.20 \\
(7.65)\end{array}$ & $\begin{array}{c}0.777 \\
(0.264)\end{array}$ \\
\hline B19375 & $\mathrm{C} 4300$ & 13.4 & 0.06 & 0.01 & $378.9(125.6)$ & $\begin{array}{c}7.44 \\
(7.50) \\
\end{array}$ & $\begin{array}{c}0.840 \\
(0.297) \\
\end{array}$ \\
\hline B19377 & $\mathrm{C} 4300$ & 32.5 & 0.02 & 0.00 & $\begin{array}{l}178.7 \\
(99.6) \\
\end{array}$ & $\begin{array}{c}7.59 \\
(7.67)\end{array}$ & $\begin{array}{c}0.400 \\
(0.237)\end{array}$ \\
\hline
\end{tabular}

The 1:1 water extract $\mathrm{pH}$, alkalinity, and $\mathrm{EC}$ values are in general similar to groundwater values and other water extracts of uncontaminated vadose sediments from the Hanford Site. Other analytical results of cations and anions for groundwater, 1:1 water extracts, and pore water are shown in the Appendix.

\subsubsection{Intact Sediments for Task 2 Adsorption Experiments}

Based on the data shown in Tables 1 through 5, a sub-set of the sediments that were not slough was used for more detailed characterization and batch adsorption studies. One sample, B192K1, was used for more detailed characterization even though it was slough. The following sediment samples were created from material present in the liners. The samples created for further testing are listed and described in Table 6. 
Table 6. Description of Intact Samples

\begin{tabular}{||c|c|c|l||}
\hline $\begin{array}{c}\text { Sediment Sample } \\
\text { ID }\end{array}$ & Well & \multicolumn{1}{|c||}{ Formation } & \multicolumn{1}{c||}{ Sample Description } \\
\hline B192K1 & C4298 & Ringold Unit E & Bulk sample including gravel \\
\hline $\begin{array}{c}\text { B19136 and } \\
\text { B19137 }\end{array}$ & C4299 & Ringold Unit E & Mixture of these two liners including gravel \\
\hline $\begin{array}{c}\text { B19136 and } \\
\text { B19137 }\end{array}$ & $\mathrm{C} 4299$ & Ringold Unit E & Mixture of two samples without gravel \\
\hline B19140 & C4299 & Ringold Unit E & Bulk sample including gravel \\
\hline B19140 & C4299 & Ringold Unit E & Bulk sample without gravel \\
\hline B19377 & C4300 & Ringold Lower Mud & $\begin{array}{l}\text { Bulk sample. Because of mud formation there was } \\
\text { no gravel in this liner. }\end{array}$ \\
\hline
\end{tabular}

\subsubsection{Particle Size Distribution}

Particle size distributions of the selected sediment samples described in Table 6 are presented in Table 7. Most of the samples are gravel and sand dominated sediments except B19377 (Ringold Lower Mud) collected from C4300 borehole. Because of the fine-grained nature of mud, silt was the dominant particle size in the B19377 sample. The other samples are typical gravel- and sand-dominated Ringold Unit $\mathrm{E}$ formation, consistent with other geologic characterizations previously published (see Bjornstad 1984, 1990; Bjornstad et al. 2001, 2002; Brown 1959; Connelly et al. 1992; Delaney et al.1991; Fecht and Weekes 1996; Last 1994; Lindsey 1995, 1996; Lindsey et al. 1992a, 1992b, 1994; Myers and Price 1979; Reidel et al. 1992; Slate 2000; Tallman et al. 1979, 1981; Williams et al. 2002; and Wood et al. 2001).

\subsubsection{Chemical Composition (Total Oxide Content)}

The elemental composition of the intact sediments was determined by fusion and ICP analysis, and the results are shown in Table 8 and Table 9. The elemental composition was converted to percentage oxide forms. The iron present in the sediments was assumed to be all ferric oxide, although some reduced ferrous iron oxide may also be present. The bulk chemical composition showed that silica and alumina were the most dominant oxides. Minor amounts of iron oxide were also found. The highest iron oxides were present in sample B19140 (C4299), consistent with previous noticeable iron oxides seen when this liner was opened (Figure 9). 
Table 7. Summary of Particle-Size Distributions for Bulk Samples as Determined by Dry Sieve/Hydrometer Method

\begin{tabular}{||c|c|c|c|c||}
\hline Sediment Sample ID & Gravel (\%) & Sand (\%) & Silt (\%) & Clay (\%) \\
\hline B192K1 with gravel & 25.9 & 68.5 & 4.90 & 0.60 \\
\hline $\begin{array}{c}\text { B19136 and B19137 } \\
\text { with gravel }\end{array}$ & 42.0 & 52.2 & 4.34 & 1.46 \\
\hline B19140 with gravel & 55.0 & 26.7 & 13.2 & 5.10 \\
\hline B19377 with gravel & 0.0 & 20.8 & 69.3 & 9.83 \\
\hline
\end{tabular}

Although high Tc-99 and U concentrations were found in groundwater sample B19J10 associated with borehole C4300, compared to other groundwater samples (see Table 3), no significant $\mathrm{U}$ contamination was found in the core samples as measured by bulk chemical analysis. The highest U contamination $(2.96 \mathrm{mg} / \mathrm{kg}$ ) was found in sample B19377 (C4300), but this concentration is not statistically larger than the range of natural Hanford sediment background values (DOE 1992). In addition, GEA of B19377 (C4300) showed no elevated U concentration based on counting daughter products $\mathrm{Pb}-214$ and $\mathrm{Bi}-214$, which yielded values equivalent to a parent $U$ concentration of $1.5 \mathrm{mg} / \mathrm{kg}$. Further, this value, $2.96 \mathrm{mg} / \mathrm{kg}$, is not high enough for conducting desorption experiments as proposed in Task 3.

\subsubsection{Mineralogy}

Sediment samples collected from the three 200-UP-1 boreholes were characterized by XRD. XRD patterns representing the bulk, sand-, silt- and clay-sized fractions of each sample were prepared as previously described. Samples collected from borehole C4299 at depths of 271.5-272.0 ft bgs and 308.5 to $309.5 \mathrm{ft}$ bgs were combined and treated as one sample.

The XRD results taken from the bulk samples indicated each interval was mineralogically similar. A typical example of an XRD tracing of the bulk sample collected in borehole C4299 (419.0-419.5 ft bgs) is provided in Figure 14 along with the mineral powder diffraction files (PDFTM) for comparison. The sample was dominated by quartz and feldspar, with minor amounts of hornblende and clays (smectite, chlorite, and mica). The feldspar was a combination of several different plagioclase and potassium feldspars; therefore, an exact match was not possible. Subtle differences were observed in the bulk patterns with the broad clay reflection at $5.9^{\circ} 2 \theta$, which is a combination of smectite and chlorite clays. 
Table 8. Major Element Oxides (wt. \%) of Sediment Samples Using Fusion/ICP-MS

\begin{tabular}{|c|c|c|c|c|c|c|c|c|c|c|c|c|}
\hline Element: & $\mathrm{SiO}_{2}$ & $\mathrm{Al}_{2} \mathrm{O}_{3}$ & $\mathrm{Fe}_{2} \mathrm{O}_{3(\mathrm{~T})}$ & $\mathrm{MnO}$ & $\mathrm{MgO}$ & $\mathrm{CaO}$ & $\mathrm{Na}_{2} \mathrm{O}$ & $\mathrm{K}_{2} \mathrm{O}$ & $\mathrm{TiO}_{2}$ & $\mathrm{P}_{2} \mathrm{O}_{5}$ & LOI & Total \\
\hline B192K1 Bulk & 68.2 & 12.33 & 5.43 & 0.104 & 2.54 & 4.72 & 3.17 & 1.46 & 0.726 & 0.13 & 1.12 & 99.94 \\
\hline B19136 and B19137 Bulk with gravel & 77.36 & 9.72 & 4.26 & 0.086 & 0.89 & 1.87 & 2.07 & 1.76 & 0.471 & 0.08 & 1.17 & 99.73 \\
\hline B19136 and B19137 w/out Gravel $(<2 \mathrm{~mm})$ & 75.64 & 10.67 & 3.37 & 0.069 & 1 & 2.35 & 2.86 & 1.69 & 0.413 & 0.1 & 1.35 & 99.52 \\
\hline B19140 Bulk with gravel & 64.47 & 12.54 & 7.93 & 0.131 & 1.73 & 2.51 & 2.13 & 1.5 & 0.775 & 0.1 & 5.56 & 99.37 \\
\hline B19140 Bulk w/out gravel $(<2 \mathrm{~mm})$ & 66.67 & 11.54 & 6.66 & 0.12 & 1.23 & 1.79 & 1.96 & 1.87 & 0.673 & 0.1 & 7.28 & 99.9 \\
\hline B19373 Bulk & 71.69 & 10.48 & 5.19 & 0.075 & 1.23 & 3.31 & 2.34 & 1.29 & 0.969 & 0.31 & 2.85 & 99.73 \\
\hline B19377 Bulk & 68.15 & 12.89 & 4.12 & 0.037 & 1.95 & 1.09 & 1.42 & 2.61 & 0.62 & 0.12 & 6.55 & 99.56 \\
\hline
\end{tabular}

LOI= loss on ignition

Table 9. Trace Element (mg/kg) of Sediment Samples using Fusion/ICP-MS

\begin{tabular}{|c|c|c|c|c|c|c|c|}
\hline Elements & $\begin{array}{c}\text { B192K1 } \\
\text { Bulk }\end{array}$ & $\begin{array}{c}\text { B19136 and B19137 } \\
\text { with gravel }\end{array}$ & $\begin{array}{c}\text { B19136 and B19137 } \\
\text { without gravel }\end{array}$ & $\begin{array}{c}\text { B19140 Bulk } \\
\text { with gravel }\end{array}$ & $\begin{array}{c}\text { B19140 Bulk } \\
\text { without gravel }\end{array}$ & $\begin{array}{c}\text { B19373 } \\
\text { Bulk }\end{array}$ & $\begin{array}{c}\text { B19377 } \\
\text { Bulk }\end{array}$ \\
\hline $\mathrm{Sc}$ & 15 & 8 & 7 & 13 & 11 & 14 & 10 \\
\hline $\mathrm{Be}$ & 1 & 2 & 2 & 2 & 2 & 1 & 2 \\
\hline $\mathrm{V}$ & 133 & 56 & 57 & 116 & 97 & 123 & 82 \\
\hline $\mathrm{Cr}$ & $\mathbf{6 0}$ & $\mathbf{5 0}$ & $\mathbf{3 0}$ & $\mathbf{6 0}$ & $\mathbf{7 0}$ & $\mathbf{5 0}$ & $\mathbf{5 0}$ \\
\hline $\mathrm{Co}$ & 10 & 6 & 5 & 11 & 14 & 10 & 9 \\
\hline $\mathrm{Ni}$ & 30 & 30 & $<20$ & 40 & 40 & 30 & 30 \\
\hline $\mathrm{Cu}$ & 30 & 20 & 10 & 20 & 20 & 20 & 20 \\
\hline $\mathrm{Zn}$ & 40 & $<30$ & $<30$ & 60 & 60 & 40 & 60 \\
\hline $\mathrm{Ga}$ & 13 & 11 & 11 & 15 & 16 & 13 & 17 \\
\hline $\mathrm{Ge}$ & 1.3 & 1.4 & 1.1 & 1.2 & 1.3 & 1.1 & 1.4 \\
\hline $\mathrm{As}$ & $<5$ & $<5$ & $<5$ & 8 & 9 & $<5$ & $<5$ \\
\hline
\end{tabular}


Table 9. (contd)

\begin{tabular}{|c|c|c|c|c|c|c|c|}
\hline Elements & $\begin{array}{l}\text { B192K1 } \\
\text { Bulk }\end{array}$ & $\begin{array}{c}\text { B19136 and B19137 } \\
\text { with gravel }\end{array}$ & $\begin{array}{c}\text { B19136 and B19137 } \\
\text { without gravel }\end{array}$ & $\begin{array}{c}\text { B19140 Bulk } \\
\text { with gravel }\end{array}$ & $\begin{array}{l}\text { B19140 Bulk } \\
\text { without gravel }\end{array}$ & $\begin{array}{c}\text { B19373 } \\
\text { Bulk }\end{array}$ & $\begin{array}{c}\text { B19377 } \\
\text { Bulk }\end{array}$ \\
\hline $\mathrm{Rb}$ & 39 & 54 & 49 & 59 & 71 & 32 & 95 \\
\hline Sr & 380 & 286 & 359 & 292 & 256 & 317 & 184 \\
\hline $\mathrm{Y}$ & 19.5 & 21.5 & 18.3 & 24.3 & 26.7 & 24.5 & 29.3 \\
\hline $\mathrm{Zr}$ & 124 & 176 & 165 & 157 & 171 & 128 & 289 \\
\hline $\mathrm{Nb}$ & 7 & 12.9 & 10.5 & 9.8 & 11.6 & 7.7 & 17.3 \\
\hline Mo & $<2$ & $<2$ & $<2$ & $<2$ & $<2$ & $<2$ & $<2$ \\
\hline $\mathrm{Ag}$ & 1.5 & 1 & 1 & 0.7 & 0.8 & 0.7 & 1 \\
\hline In & 0.1 & 0.1 & 0.1 & 0.1 & 0.1 & 0.1 & 0.1 \\
\hline $\mathrm{Sn}$ & 1 & 1 & $<1$ & 1 & 2 & 1 & 2 \\
\hline $\mathrm{Sb}$ & 0.7 & 0.4 & 0.3 & 0.4 & 0.6 & 0.4 & 0.5 \\
\hline Cs & 1 & 1.4 & 1.2 & 3.5 & 3.7 & 0.9 & 4.5 \\
\hline $\mathrm{Ba}$ & 642 & 609 & 650 & 638 & 684 & 543 & 621 \\
\hline $\mathrm{La}$ & 16.2 & 28.3 & 21.9 & 20.8 & 26.4 & 21.1 & 44.8 \\
\hline $\mathrm{Ce}$ & 32.8 & 55.8 & 43.8 & 44.5 & 67.4 & 40.5 & 90.7 \\
\hline $\mathrm{Pr}$ & 3.89 & 6.04 & 4.85 & 5.19 & 6.55 & 4.85 & 10.2 \\
\hline $\mathrm{Nd}$ & 14.9 & 21 & 17.4 & 19.3 & 24 & 18.7 & 36.7 \\
\hline $\mathrm{Sm}$ & 3.18 & 3.66 & 3.16 & 3.96 & 4.76 & 3.88 & 6.95 \\
\hline $\mathrm{Eu}$ & 0.932 & 0.883 & 0.813 & 1.05 & 1.08 & 1.16 & 1.44 \\
\hline $\mathrm{Gd}$ & 3.43 & 3.61 & 3.16 & 4.17 & 4.79 & 4.1 & 6.56 \\
\hline $\mathrm{Tb}$ & 0.57 & 0.58 & 0.5 & 0.7 & 0.78 & 0.68 & 0.95 \\
\hline Dy & 3.23 & 3.36 & 2.84 & 4.06 & 4.34 & 3.86 & 5.14 \\
\hline Ho & 0.65 & 0.7 & 0.59 & 0.85 & 0.87 & 0.78 & 0.98 \\
\hline $\mathrm{Er}$ & 2.04 & 2.27 & 1.85 & 2.66 & 2.82 & 2.4 & 2.97 \\
\hline $\mathrm{Tm}$ & 0.308 & 0.356 & 0.283 & 0.411 & 0.42 & 0.356 & 0.443 \\
\hline $\mathrm{Yb}$ & 1.96 & 2.3 & 1.79 & 2.65 & 2.64 & 2.23 & 2.73 \\
\hline $\mathrm{Lu}$ & 0.282 & 0.336 & 0.269 & 0.392 & 0.38 & 0.32 & 0.398 \\
\hline Hf & 3.2 & 4.5 & 4.4 & 3.9 & 4.6 & 3.3 & 7.6 \\
\hline $\mathrm{Ta}$ & 0.52 & 1.09 & 0.8 & 0.71 & 0.85 & 0.53 & 1.29 \\
\hline $\mathrm{W}$ & 0.6 & 1.3 & 0.8 & 1 & 1 & 0.5 & 3.8 \\
\hline
\end{tabular}


Table 9. (contd)

\begin{tabular}{|c|c|c|c|c|c|c|c|}
\hline Elements & $\begin{array}{c}\text { B192K1 } \\
\text { Bulk }\end{array}$ & $\begin{array}{c}\text { B19136 and B19137 } \\
\text { with gravel }\end{array}$ & $\begin{array}{c}\text { B19136 and B19137 } \\
\text { without gravel }\end{array}$ & $\begin{array}{c}\text { B19140 Bulk } \\
\text { with gravel }\end{array}$ & $\begin{array}{c}\text { B19140 Bulk } \\
\text { without gravel }\end{array}$ & $\begin{array}{l}\text { B19373 } \\
\text { Bulk }\end{array}$ & $\begin{array}{c}\text { B19377 } \\
\text { Bulk }\end{array}$ \\
\hline $\mathrm{Tl}$ & 0.23 & 0.27 & 0.25 & 0.39 & 0.55 & 0.18 & 0.57 \\
\hline $\mathrm{Pb}$ & 7 & 11 & 8 & 11 & 16 & 9 & 18 \\
\hline $\mathrm{Bi}$ & 0.2 & 0.2 & 0.2 & 0.3 & 0.4 & 0.2 & 0.7 \\
\hline Th & 4.38 & 8.02 & 7.28 & 6.34 & 8.14 & 4.71 & 13.7 \\
\hline $\mathbf{U}$ & 1.07 & 1.64 & 1.5 & 1.87 & 1.93 & 1.47 & 2.96 \\
\hline
\end{tabular}

The bold type indicates COC. 
Examination of the silt- and sand-sized fractions from each interval indicated a dominance of quartz and feldspar along with lesser amounts of hornblende (Figure 15). As expected, the clay minerals smectite and chlorite were also noticeably reduced or absent in the sand fraction. Micas were present in the sand fraction as biotite and muscovite flakes. In the silt fraction, one noticeable difference was observed with the mixed sample C4299 (B19136 and B19137). The clay mineral reflections in this mixed sample at lower angles $\left(<10^{\circ} 2 \theta\right)$ were significantly more intense, indicating the sample had higher clay mineral content in the silt fraction compared to the silt fractions of the other samples.

Characterization of the clay fraction of each sample was initiated after the samples were saturated with $\mathrm{Mg}^{2+}$, preferentially oriented on an aluminum slide, and solvated with glycerol. With the exception of intensity differences, the clay mineral assemblages from each borehole were the same. Normally air-dried and $\mathrm{Mg}^{2+}$-saturated smectites produce a basal (001) reflection at $5.88^{\circ} 2 \theta$; however, in this case the treatment with glycerol expanded the smectite structure to $\sim 18^{\circ} 2 \theta$. This treatment was used to verify the absence of vermiculite, which maintains a basal (001) reflection at $6.09^{\circ} 2 \theta$. Also unaffected by the glycerol treatment are illite and chlorite.

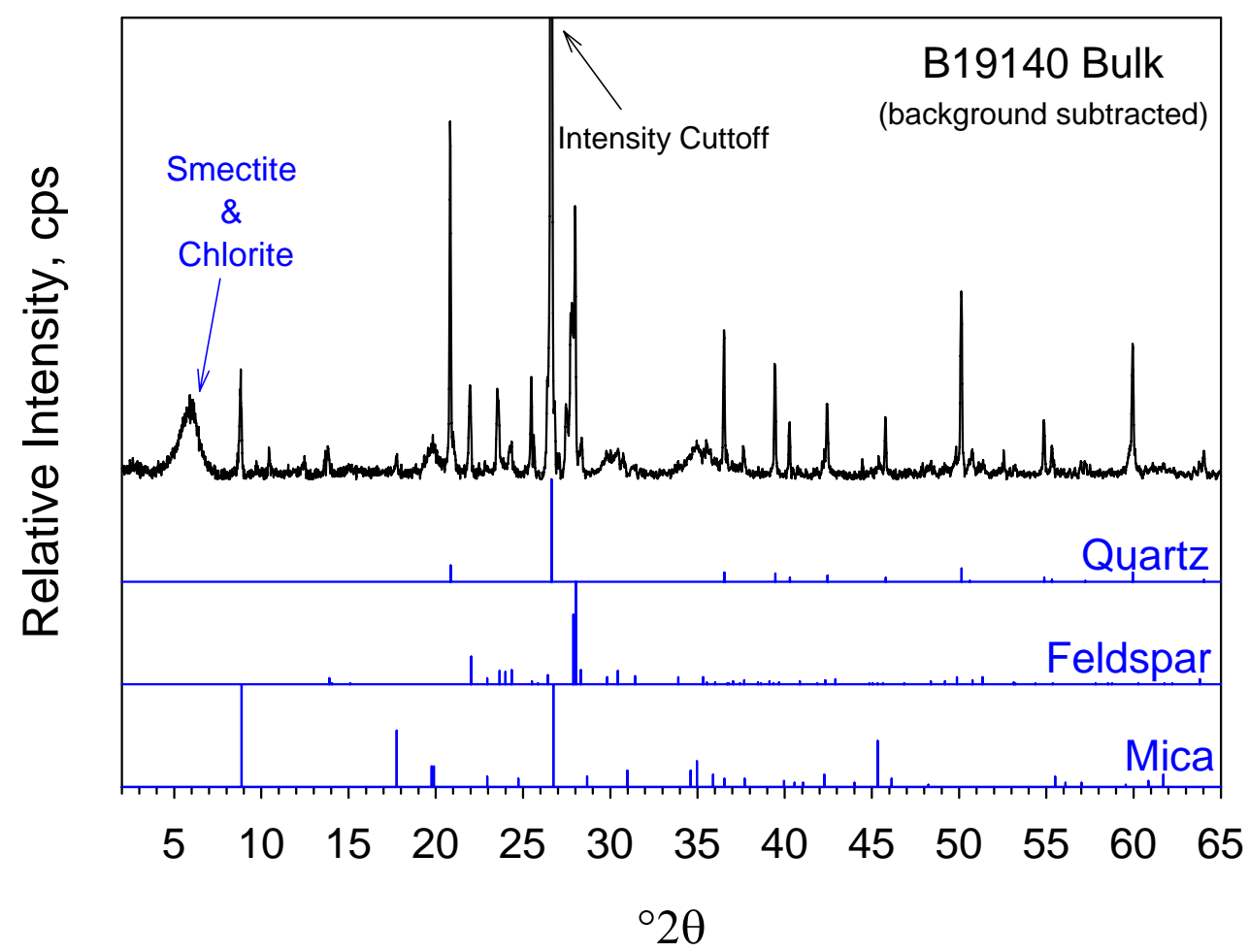

Figure 14. XRD Tracing of B19140 Bulk Sample Collected from Borehole C4299 


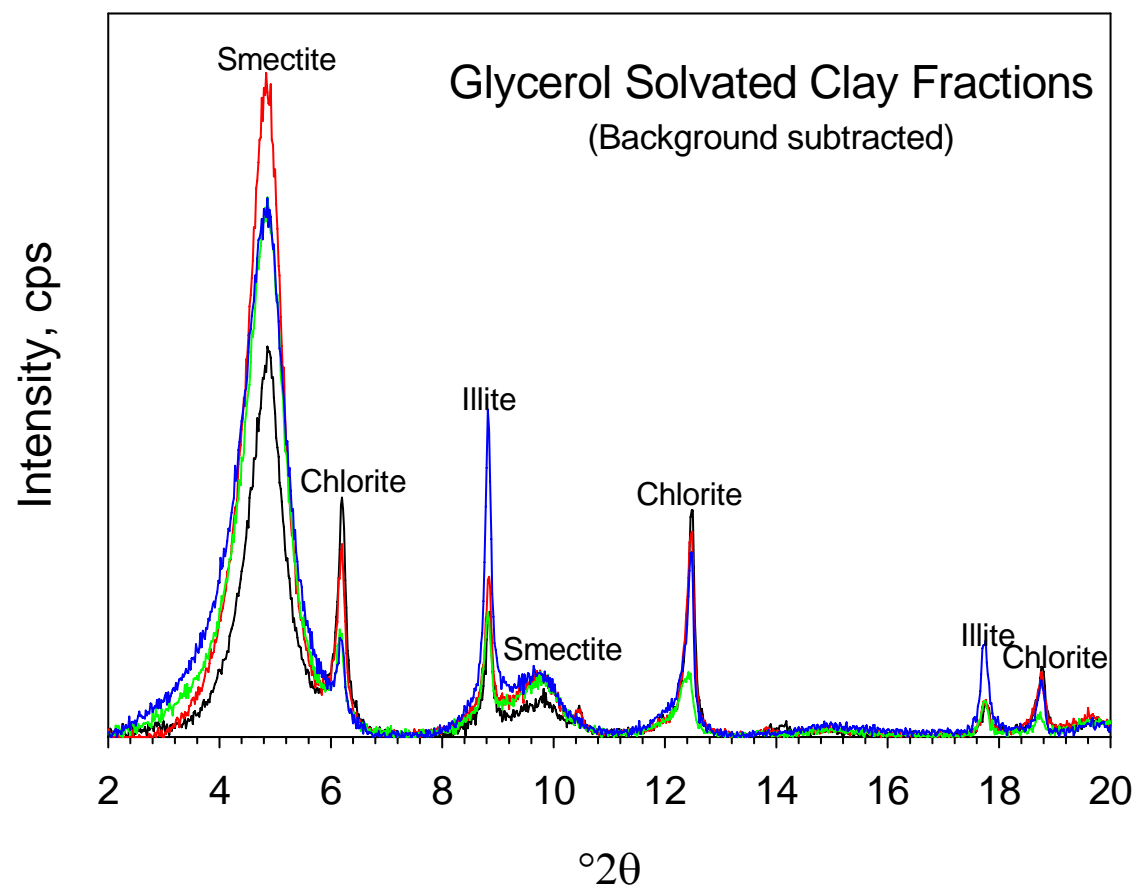

Figure 15. XRD Tracings of $\mathrm{Mg}^{+2}$ Saturated, Glycerol Solvated Clay Fractions from Boreholes C4298 (B192K1) (black), C4299 (B19136\&B19137) (red), C4299 (B19140) (green), and C4300 (B19377) (blue)

Illite produced reflections at 8.8 and $17.7^{\circ} 2 \theta$, which were easily distinguished from chlorite reflections at $6.15,12.4$, and $18.7^{\circ} 2 \theta$. Figure 15 shows that smectite, chlorite, and illite dominate the clay fractions. Minor amounts of non-clay minerals (quartz, feldspar) were also detected. No crystalline $\mathrm{Fe}^{2+}$ or $\mathrm{Fe}^{3+}$ compounds were identified in the XRD tracings of the clay fractions.

\subsubsection{Specific Surface Area}

The measurements of specific surface area for different size fractions for the four sediments are shown in Table 10. Highest surface area was found in B19140 sediment, which is dominated by silt and clay-sized particles. Relatively high specific surface area was also found in the sandsized fraction of B19140 sediments compared to the other samples (B192K1, B19136 and B19137, and B19377). This was attributed to a presence of the Fe oxide coatings around the surfaces of sand-size particles. These coatings are considered to be vesicular or porous, thus leading to high surface area. The highest specific surface area found in sample B19140 correlated well with the relatively high adsorption $\mathrm{K}_{\mathrm{d}}$ values found for this sediment compared with other samples (See Section 4.2.3). 
Table 10. Specific Surface Area of Different Size Fractions from 200-UP-1 Sediments

\begin{tabular}{|c|c|c|c|c|}
\hline Size Fraction & $\begin{array}{c}\text { B192K1 } \\
(\mathrm{C} 4298) \\
\left(\mathrm{m}^{2} / \mathrm{g}\right)\end{array}$ & $\begin{array}{c}\text { B19136 and } \\
\text { B19137 } \\
(\mathrm{C} 4299) \\
\left(\mathrm{m}^{2} / \mathrm{g}\right)\end{array}$ & $\begin{array}{c}\text { B19140 } \\
(\mathrm{C} 4299) \\
\left(\mathrm{m}^{2} / \mathrm{g}\right)\end{array}$ & $\begin{array}{c}\text { B19377 } \\
(\mathrm{C} 4300) \\
\left(\mathrm{m}^{2} / \mathrm{g}\right)\end{array}$ \\
\hline Bulk $(<2 \mathrm{~mm})$ & 1.94 & 3.33 & 23.4 & 8.40 \\
\hline $\begin{array}{l}\text { Sand Size (fine to medium) } \\
(0.125<\text { Size }<0.5 \mathrm{~mm})\end{array}$ & 1.27 & 0.97 & 13.2 & 2.40 \\
\hline $\begin{array}{l}\text { Silt and Clay Size } \\
(<0.05 \mathrm{~mm})\end{array}$ & 2.24 & 4.12 & 23.3 & 8.71 \\
\hline
\end{tabular}

\subsubsection{Labile U(VI)-Leaching}

Labile U(VI) leaching results for the <2-mm size fraction of the three sediments characterized showed average concentrations of $0.007,0.014$, and $0.032 \mu \mathrm{g}-\mathrm{U} / \mathrm{g}$ for samples B19136 and B19137, B19377, and B19140, respectively (Figure 16). The amount of U(VI) leached by the sodium bicarbonate-carbonate solution $(\mathrm{pH} \sim 9.3)$ reached a steady state after 7-days reaction. The leached $\mathrm{U}(\mathrm{VI})$ concentration was not significantly changed after the first 7 days as shown in Figure 16. For sediment B19140, which contained the iron oxide staining, there was a rapid release of $\mathrm{U}(\mathrm{VI})$ in the first 4 days, but again, steady-state release occurred after 7-days reaction. Because the extracted labile $\mathrm{U}(\mathrm{VI})$ was a very small portion of the total $\mathrm{U}$ in the 200-UP-1 sediments, most of total $\mathrm{U}$ in the sediments determined by fusion $(1.50,1.93$, and $2.96 \mu \mathrm{g} / \mathrm{g}$ for B19136 and B19137, B19377, and B19140, respectively in Table 9) must exist in more stable phases such as co-precipitates in calcium carbonate, iron oxides, or aluminolsilicate minerals. Even though the labile U(VI) concentration was small, it was used to correct the $\mathrm{U}(\mathrm{VI})$ concentration in batch $\mathrm{U}(\mathrm{VI})$ adsorption experiments (see Sections 3.3.2 and 4.3.2 , where the starting carbonate concentration was varied) to determine the exact amount of U(VI) adsorbed on the sediments during the 7-day contact time. However, because the amount of "labile" U(VI) left in the Task 2 batch adsorption tests after pre-equilibration with the simulated groundwater was miniscule, no labile $\mathrm{U}(\mathrm{VI})$ correction was needed for Task 2 results presented in Table 15 or the $\mathrm{U}(\mathrm{VI})$ adsorption $\mathrm{K}_{\mathrm{d}} \mathrm{S}$ as a function of varying $\mathrm{U}(\mathrm{VI})$ concentrations (results shown in Figure 21).

The dissolved Ca concentration (see Figure 17) in the sodium bicarbonate-carbonate leachates showed a slight drop and the $\mathrm{pH}$ decreased (see Figure 18) for up to 13 days reaction, indicating a minor amount of calcite precipitation might have occurred during this period. Geochemical modeling (MINEQL ${ }^{+}$; Schecher and McAvoy 1994) showed calcite should start to precipitate when the solution calcium concentration reaches $2 \mathrm{mg} / \mathrm{L}$ at $\mathrm{pH}$ values higher than 9.0 in the bicarbonate-carbonate leaching solutions. Leached U(VI) concentration also decreased during the initial stage between 2-10 days, and it was also attributed to U(VI)-co-precipitation with calcite. These data are further evaluated in Section 4.3.2, along with the dissolved U concentrations in the pore waters, to determine in-situ desorption $\mathrm{K}_{\mathrm{d}}$ values for $\mathrm{U}$. 


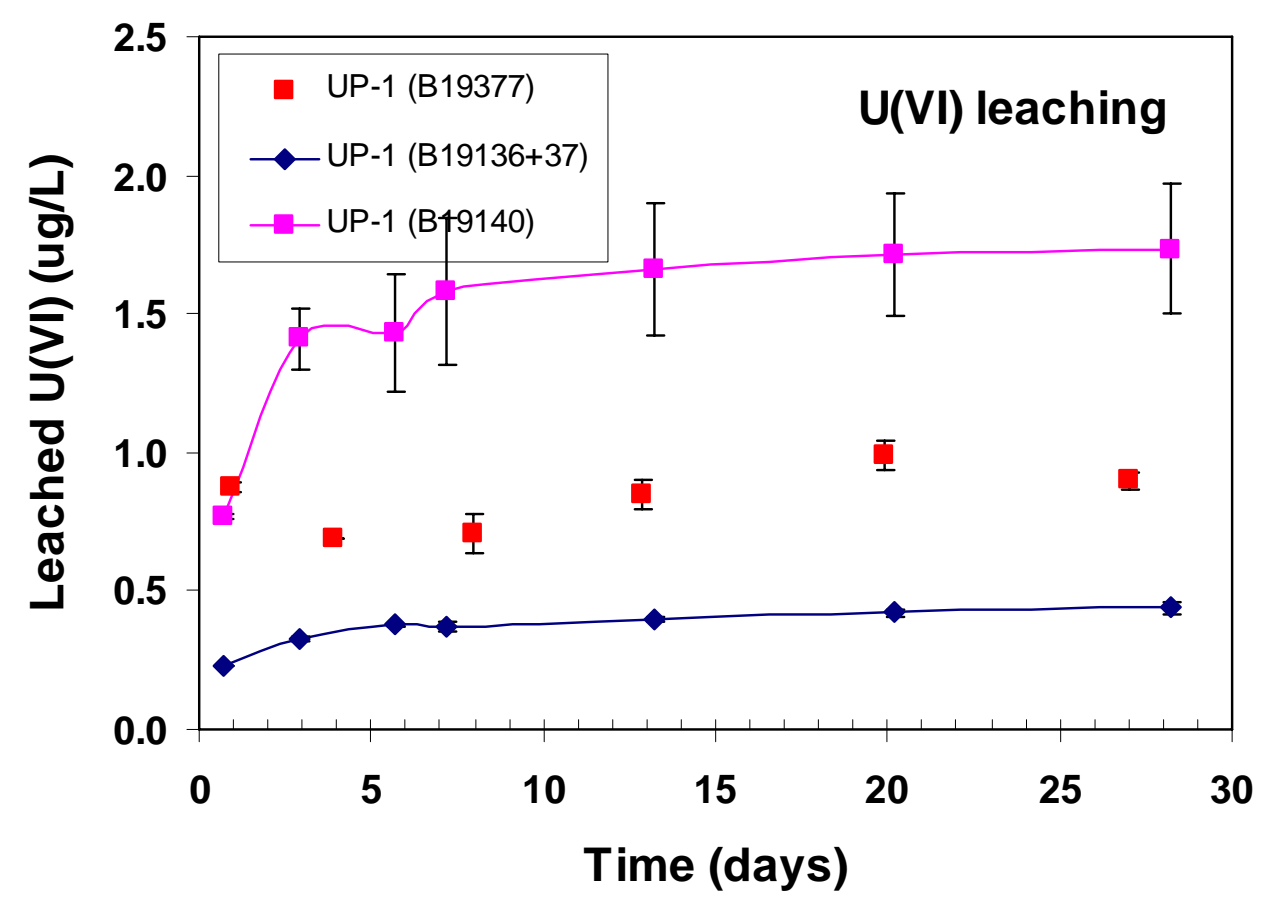

Figure 16. Labile U(VI) Concentration Leached by Carbonate Extractant

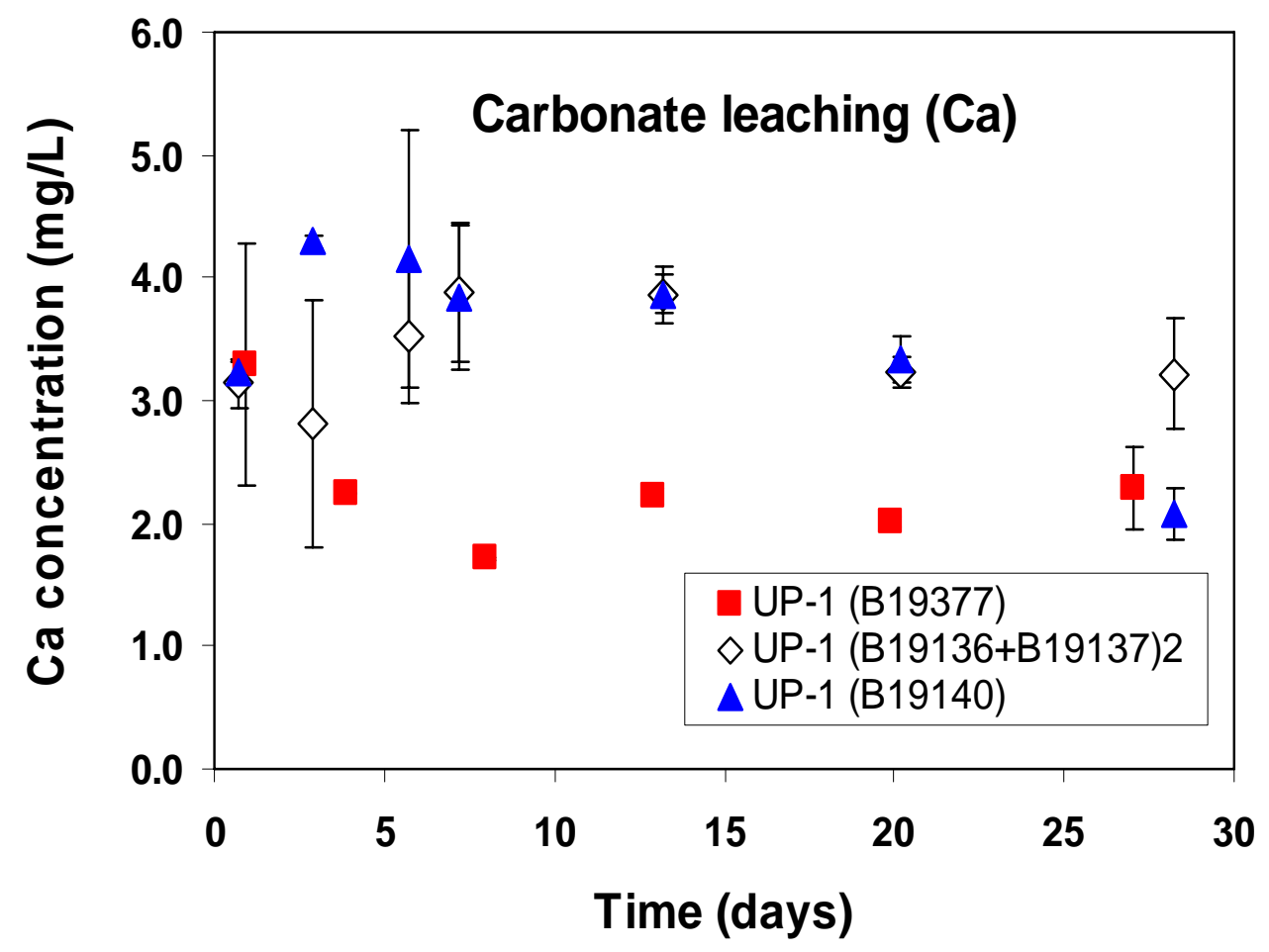

Figure 17. Calcium Released from Sediments by Carbonate Extractant 


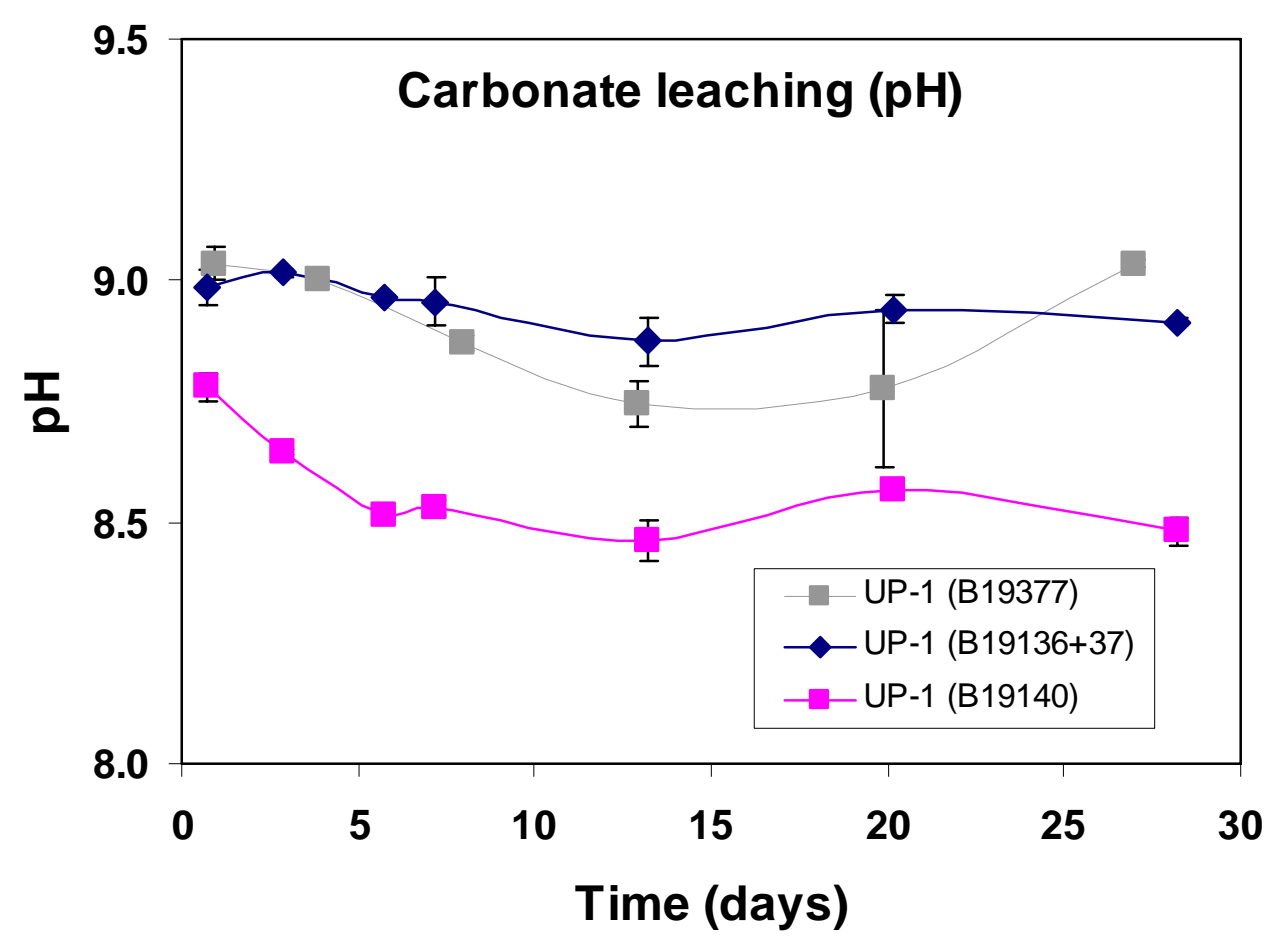

Figure 18. Measured pHs During Carbonate Leaching

\subsubsection{Cation Exchange Capacity}

The CEC results for five different 200-UP-1 samples are shown in Table 11. The highest CEC value was found for the B19140 sediment, consistent with previous specific surface area results. Clay minerals and hydrous iron oxides generally have a greater cation exchange capacity than other minerals. The minor difference, as opposed to the anticipated large difference, between bulk (with gravel) and without gravel samples for the B19136 and B19137 mixed sample was attributed to the presence of silt and clay mineral coatings on the gravel surfaces. The relatively higher CEC in both B19377 and B19140 resulted from the higher percentage of silt- and clay-sized particles in both sediments (see Table 7) and the high ferric oxide coating in the latter sediment. The clay minerals present in the clay-sized fraction (as reported in the mineralogy Section 4.1.3.3) include smectite, chlorite, and illite, which have high cation exchange capacities.

\subsubsection{Fe Oxide Extraction}

The extractable iron concentrations for 200-UP-1 sediments using three different methods are shown in Table 12. The 0.5-hr hydroxylamine hydrochloride (HH) and 2-hr ammonium oxalate (Tamm's reagent) methods were used to quantify the amount of amorphous iron oxide (generally dominated by ferrihydrite) in the sediments. Tamm's method results showed significantly higher 
Table 11. Cation Exchange Capacity of 200-UP-1 Sediments

\begin{tabular}{|c|c|c|c|c|c||}
\hline \hline Samples & $\begin{array}{c}\text { B192K1 } \\
(<2 \mathbf{m m})\end{array}$ & $\begin{array}{c}\text { B19136\&B19137 } \\
\text { (Bulk with } \\
\text { gravel) }\end{array}$ & $\begin{array}{c}\text { B19136\&B19137 } \\
(<\mathbf{2 m m})\end{array}$ & $\begin{array}{c}\text { B19377 } \\
\text { (Ringold } \\
\text { Low mud) }\end{array}$ & $\begin{array}{c}\text { B19140 } \\
(<2 \mathbf{m m})\end{array}$ \\
\hline $\begin{array}{c}\mathrm{CEC} \\
(\mathrm{meq} / 100 \mathrm{~g})\end{array}$ & $1.66 \pm 0.34$ & $3.28 \pm 3.29$ & $3.39 \pm 0.21$ & $17.12 \pm 2.45$ & $44.91 \pm 9.25$ \\
\hline
\end{tabular}

Table 12. Results of Fe Extraction of 200-UP-1 Sediments Using Three Different Methods

\begin{tabular}{|l|c|c|c|}
\hline \multirow{2}{*}{\multicolumn{1}{|c|}{ Samples }} & \multicolumn{3}{|c|}{ Fe ( $\mu$ moles/g of sediment) } \\
\cline { 2 - 4 } & Method 1 (HH) & Method 2 (Tamm's) & Method 3 (CBD) \\
\hline $\begin{array}{l}\text { B192K1 (C4298) } \\
\text { Bulk with gravel }\end{array}$ & $3.79 \pm 0.59$ & $48.13 \pm 12.24$ & $50.78 \pm 1.08$ \\
\hline $\begin{array}{l}\text { B19136 and B19137 (C4299) } \\
\text { Bulk with gravel }\end{array}$ & $1.71 \pm 0.39$ & $21.03 \pm 7.45$ & $38.35 \pm 5.85$ \\
\hline $\begin{array}{l}\text { B19136 and B19137 (C4299) } \\
\text { without gravel (<2mm) }\end{array}$ & $1.88 \pm 0.30$ & $21.82 \pm 3.91$ & $47.49 \pm 2.89$ \\
\hline $\begin{array}{l}\text { B19140 (C4299) } \\
\text { without gravel (<2 mm) }\end{array}$ & $3.27 \pm 0.38$ & $16.37 \pm 0.62$ & $111.21 \pm 2.60$ \\
\hline $\begin{array}{l}\text { B19377 (C4300) } \\
\text { Ringold lower mud }\end{array}$ & $1.38 \pm 0.35$ & $4.74 \pm 0.11$ & $37.41 \pm 0.33$ \\
\hline
\end{tabular}

amorphous iron extractions than the $\mathrm{HH}$ method. One explanation for the different results is that the $\mathrm{HH}$ method chosen uses low concentrations $(0.1 \mathrm{M}$ hydroxylamine hydrochloride in $0.01 \mathrm{M}$ nitric acid) rather than $0.25 \mathrm{M}$ hydroxylamine hydrochloride in $0.25 \mathrm{M}$ hydrochloric acid used by Chao and Zhou (1983). If the extracted iron quantities from Tamm's method are assumed to represent all the amorphous and poorly crystalline iron oxide, which is dominated by ferrihydrite, in the sediment, the first three samples in Table 12, (B192K1, B19136 and B19137 with gravel, and B19136 and B19137 without gravel, show that most of the iron oxides were present as amorphous iron oxides (ferrihydrite), especially in B192K1. Because method 3 (CBD) quantified the total free iron-oxide content in the sediment, approximately 46-95\% of the total extractable iron oxides in these 200-UP-1 sediments appears to be poorly crystallized iron oxide (ferrihydrite), as revealed by Method 2 (Tamm's reagent).

Although the B192K1 sample was identified as slough material in the previous core description (see Table 2 and Figure 1), the B192K1 sample showed relatively higher amounts of amorphous iron oxide (95\% of the total extractable iron oxides) compared with other samples from 200-UP-1. This high amorphous iron oxide content might result from newly precipitated amorphous iron oxide after oxidation of any fresh ferrous iron, released from broken gravel (generally basalt fragments containing ferrous iron) or from metal particles scraped off equipment during vigorous hard-tool drilling activities. Even though measurable soluble ferrous iron was not found in extracted pore water from this core, using the ferrozine method (see Table 4), significantly higher $K_{d}$ values were found for B192K1 sediments, especially for anions, Tc-99, and Cr(VI), which are usually considered to be non-reactive in most natural Hanford sediment conditions (Kaplan et al. 1996) (see the distribution coefficients of COC on 200-UP-1 
samples below in Section 4.2.3). Noticeably high $\mathrm{K}_{\mathrm{d}}$ values for Tc-99 and $\mathrm{Cr}(\mathrm{VI})$ on B192K1 (0.7 and $10.3 \mathrm{ml} / \mathrm{g}$, respectively) compared to other 200-UP-1 sediments are closely related, with the high percentage of amorphous/poorly crystalline iron oxide (ferrihydrite) present in the B192K1 sediment sample. This hypothesis that new precipitates of ferrihydrite formed in the sediments because of hard drilling is also suggested by examining two other samples (B19136 and B19137 with gravel, and B19136 and B19137 without gravel). These samples also showed that ferrihydrite was $46-55 \%$ of the extractable total iron oxides (Table 12), even though the absolute concentration of ferrihydrite is less than half the value found in the B192K1 slough material. Measurable ferrous iron concentrations were found in these two extracted pore water samples (see Table 4: 19 and $594 \mu \mathrm{g} / \mathrm{L}$ of Fe(II) in B19136 and B19137 pore water, respectively). Although the $\mathrm{K}_{\mathrm{d}}$ values for Tc-99 and $\mathrm{Cr}(\mathrm{VI})$ on the mixture sample (B19136 and B19137) (0.30-0.38 and 0.92-1.32 mL/g for Tc-99 and $\mathrm{Cr}(\mathrm{VI})$, respectively) were lower than values for B192K1, they still showed relatively higher $\mathrm{K}_{\mathrm{d}}$ values compared with other 200-UP-1 samples (range 0-0.07 mL/g, see Table 15) and Hanford formation vadose zone sediments (0 mL/g) (Kaplan 1998). Because the amount of ferrihydrite present was not different between samples (B19136 and B19137) with and without gravel, new precipitates of ferrihydrite might be present on all of the sediment particles as surface coatings or as mixtures with clay-sized particles that cling equally to all the bulk sediment. If the iron oxides were present as discrete particles, one would expect them to be small and thus would be concentrated in the sample that had gravel removed. However, on a weight basis the amounts of extractable amorphous iron oxides (ferrihydrite) were the same with or without gravel removed (B19136 and B19137).

However, based on previous particle size distributions for B19136 and B19137, bulk samples (Table 7), the clay-sized fraction was small (1.5\%) compared to sand-sized fraction (52.2\%), most of new ferrihydrite is considered to exist as surface coatings on both the sand- and gravelsized fractions.

In addition, the first two samples in Table 12, (B192K1, B19136 and B19137) were collected at relatively shallow depths (280-310 ft) compared to the bottom two samples, B19140 and B19377, collected at 420 and $428 \mathrm{ft}$, respectively. The top two samples collected at shallow depth had approximately 26-42\% gravel in the bulk sample (Table 7), which could be broken up by hard tool drilling activities thus releasing ferrous iron into their pore waters. Although sample B19140 also contained 55\% gravel, it showed only $15 \%$ of the total extractable iron oxide was dissolved in the Tamm's reagent, which typically indicates the poorly crystalline ferrihydrite content. Most of the iron oxides in B19140 (85\% of the total extractable iron oxide) was dissolved in the CBD step indicating the presence of more crystalline ferric oxides such as goethite or hematite. This finding suggests that the iron oxide minerals in B19140 were originally developed a long time ago after exposure to a near-surface weathering environment. After long periods of aging, the amorphous iron oxides in sediment B19140 likely transformed into more crystalline iron oxides. High concentrations of extractable iron in sediment B19140, using CBD method, was consistent with previous characterization results, which showed many red-orange colored iron oxides in the sediment (Figure 9). The presence of goethite in the B19140 sample was also identified by microscopic characterization of Fe oxide/clay coatings on gravel in B19140 (Figure 19 and Figure 20). Because no gravel was present in the B19377 sample (Ringold Lower Mud unit), and ferrihydrite was found to be only about $13 \%$ of the total 
extractable iron oxides in this sediment, most of the iron oxides in this sediment sample also exists as either goethite or hematite present as coatings or clay-sized particles.

The extractable aluminum (Al), silicon ( $\mathrm{Si}$ ), and manganese (Mn) was also measured, and the findings are reported in Table 13. The highest extractable Al concentration was found via method 2 (Tamm's) in all the sediments, suggesting ferrihydrite precipitates in association with Al-bearing minerals such as feldspar and clays. However, the highest Si concentration extracted was found via method 3 (CBD), indicating that most of the aged iron oxides, such as goethite and hematite, were likely present with clays as coatings on the quartz surfaces of the natural Ringold Formation sediments. Because higher amounts of extractable Si was found via method 3 (CBD) than method 2 (Tamm's) for both B19140 and B19377 sediments, most of the iron oxides found in B19140 and B19377 were assumed to be goethite and goethite coatings on quartz or gravel surfaces that co-dissolved in the CBD step. Bulk XRD analyses did not identify any crystalline iron oxides because the absolute mass of iron oxides is small, and it is also difficult to find distinct XRD patterns for very small-sized particles such as coatings. The SEM and TEM characterization for clay-sized particles and coatings scraped off of sediment B19140 (discussed below in Section 4.2.2) does show evidence of the presence of crystalline iron oxides.

Table 13. Extracted Iron, Aluminum, Silicon, and Manganese in 200-UP-1 Sediments

\begin{tabular}{|c|c|c|c|c|c|c|}
\hline \multirow[b]{2}{*}{ Elements } & \multirow[b]{2}{*}{ Methods } & \multicolumn{5}{|c|}{ Samples } \\
\hline & & $\begin{array}{c}\text { B192K1 } \\
\text { Bulk with } \\
\text { Gravel }\end{array}$ & $\begin{array}{c}\text { B19136 and } \\
\text { B19137 } \\
\text { Bulk with } \\
\text { Gravel } \\
\end{array}$ & $\begin{array}{c}\text { B19136 and } \\
\text { B19137 } \\
\text { Bulk w/o } \\
\text { Gravel }\end{array}$ & $\begin{array}{c}\text { B19140 } \\
\text { Bulk w/o } \\
\text { Gravel } \\
\end{array}$ & $\begin{array}{c}\text { B19377 } \\
\text { (C4300) } \\
\text { Ringold } \\
\text { Lower Mud } \\
\end{array}$ \\
\hline $\begin{array}{c}\mathrm{Fe} \\
(\mu \mathrm{moles} / \mathrm{g})\end{array}$ & $\begin{array}{l}\text { Method } 1 \\
\text { Method } 2 \\
\text { Method } 3 \\
\end{array}$ & $\begin{array}{l}3.79 \pm 0.59 \\
\mathbf{4 8 . 1 3} \pm 12.24 \\
\mathbf{5 0 . 7 8} \pm 1.08\end{array}$ & $\begin{array}{l}1.71 \pm 0.39 \\
21.03 \pm 7.45 \\
38.35 \pm 5.85 \\
\end{array}$ & $\begin{array}{l}1.88 \pm 0.30 \\
21.82 \pm 3.91 \\
47.49 \pm 2.89 \\
\end{array}$ & $\begin{array}{l}3.27 \pm 0.38 \\
16.37 \pm 0.62 \\
\mathbf{1 1 1 . 2 1} \pm 2.60\end{array}$ & $\begin{array}{l}1.38 \pm 0.35 \\
4.74 \pm 0.11 \\
37.41 \pm 0.33 \\
\end{array}$ \\
\hline $\begin{array}{c}\mathrm{Al} \\
(\mu \mathrm{moles} / \mathrm{g})\end{array}$ & $\begin{array}{l}\text { Method } 1 \\
\text { Method } 2 \\
\text { Method } 3\end{array}$ & $\begin{array}{l}2.40 \pm 0.43 \\
4.18 \pm 0.30 \\
2.28 \pm 0.20\end{array}$ & $\begin{array}{l}2.26 \pm 0.44 \\
4.63 \pm 1.05 \\
2.30 \pm 0.25\end{array}$ & $\begin{array}{l}2.36 \pm 0.37 \\
4.88 \pm 0.57 \\
2.51 \pm 0.07\end{array}$ & $\begin{array}{l}4.70 \pm 0.45 \\
\mathbf{1 6 . 3 0} \pm 0.17 \\
8.45 \pm 0.21\end{array}$ & $\begin{array}{l}4.48 \pm 0.79 \\
\mathbf{1 0 . 7 4} \pm 0.26 \\
6.26 \pm 0.12\end{array}$ \\
\hline $\begin{array}{c}\mathrm{Si} \\
(\mu \mathrm{moles} / \mathrm{g})\end{array}$ & $\begin{array}{l}\text { Method } 1 \\
\text { Method } 2 \\
\text { Method } 3 \\
\end{array}$ & $\begin{array}{l}1.59 \pm 0.34 \\
5.33 \pm 0.45 \\
7.52 \pm 0.52 \\
\end{array}$ & $\begin{array}{l}1.33 \pm 0.19 \\
3.55 \pm 0.89 \\
8.73 \pm 1.09 \\
\end{array}$ & $\begin{array}{l}1.40 \pm 0.21 \\
3.45 \pm 0.60 \\
9.66 \pm 0.15 \\
\end{array}$ & $\begin{array}{l}5.17 \pm 0.43 \\
7.98 \pm 0.42 \\
\mathbf{2 2 . 0 2} \pm 0.31 \\
\end{array}$ & $\begin{array}{l}3.11 \pm 0.42 \\
3.53 \pm 0.32 \\
\mathbf{2 2 . 9 7} \pm 0.74 \\
\end{array}$ \\
\hline $\begin{array}{c}\mathrm{Mn} \\
(\mu \mathrm{moles} / \mathrm{g})\end{array}$ & $\begin{array}{l}\text { Method } 1 \\
\text { Method } 2 \\
\text { Method } 3 \\
\end{array}$ & $\begin{array}{l}1.09 \pm 0.06 \\
1.24 \pm 0.15 \\
1.51 \pm 0.06 \\
\end{array}$ & $\begin{array}{l}0.97 \pm 0.11 \\
1.04 \pm 0.25 \\
1.22 \pm 0.14\end{array}$ & $\begin{array}{l}1.00 \pm 0.06 \\
1.01 \pm 0.06 \\
1.30 \pm 0.06 \\
\end{array}$ & $\begin{array}{l}11.78 \pm 0.89 \\
12.72 \pm 0.73 \\
11.68 \pm 0.69 \\
\end{array}$ & $\begin{array}{l}0.86 \pm 0.12 \\
0.88 \pm 0.03 \\
0.83 \pm 0.05\end{array}$ \\
\hline
\end{tabular}

Bold values represent samples with high extractable quantities compared to the other sediments.

High concentrations of Mn were extracted in sediment B19140 via all three methods, suggesting Mn oxide coatings are also present in this sample and they were associated with Fe oxides. However, because all three chemical extractants dissolved similar amounts of $\mathrm{Mn}$ in each of the 200-UP-1 sediments, the Mn oxides are likely highly amorphous and not associated with any specific type of iron oxide (either ferrihydrite or goethite/hematite). 


\subsection{Task 2 Batch Adsorption Experiments}

\subsubsection{Adsorbents Description}

A description of the sediments used for $\mathrm{K}_{\mathrm{d}}$ measurements with synthetic groundwater spiked with COC is shown in Table 14. Most of the intact sediments (i.e., cores that were not slough) were used as adsorbents along with additional Fe oxide/clay coatings and gravel-only samples from B19140 (C4299). Fe oxide/clay coatings present on the gravel surfaces (Figure 9) were removed using a spatula, and gravel-only adsorbents were separated from coated clays by vigorous water washing. Because Fe oxide/clay coatings were frequently found when the cores were opened, and the coatings were expected to be a potential sink for the COC, the coatings were used as adsorbents even though they were not included in the original task plan. B19140 gravel only was also used to ascertain whether there was any appreciable adsorption onto the large particles. All adsorption tests were allowed 7 days of contact. The gravel-only samples were also contacted with spiked groundwater for 1 month to investigate if there was diffusioncontrolled adsorption into minor cracks or defects present on the gravel surfaces.

Table 14. Description of Adsorbents used for Batch $K_{d}$ Measurements in Task 2

\begin{tabular}{||c|c|c|l||}
\hline Sample ID & Well & Formation & \multicolumn{1}{c||}{ Sample Description * } \\
\hline $\begin{array}{c}\text { B192K1 } \\
\text { B19136 and } \\
\text { B19137 }\end{array}$ & C4298 & Ringold Unit E & Bulk sample (slough) including gravel \\
\hline $\begin{array}{c}\text { B19136 and } \\
\text { B19137 }\end{array}$ & C4299 & Ringold Unit E & $\begin{array}{l}\text { Mixture of two good samples including gravel } \\
\text { (Mix A) }\end{array}$ \\
\hline B19140-A & C4299 & Ringold Unit E & $\begin{array}{l}\text { Mixture of two good samples without gravel } \\
\text { (Mix B) }\end{array}$ \\
\hline B19140-B & C4299 & Ringold Unit E & Bulk sample (good) without gravel \\
\hline B19140-C & C4299 & Ringold Unit E & Gravel only (good sample) \\
\hline B19140-D & C4299 & Ringold Unit E & Fe/clay coatings collected from gravel surfaces \\
\hline B19377 & C4300 & Ringold Lower Mud & $\begin{array}{l}\text { Bulk sample (good). Because of mud formation } \\
\text { there was no gravel in this liner. }\end{array}$ \\
\hline
\end{tabular}

* "Good" means material in split-spoon liner was intact and not slough.

\subsubsection{Characterization of Fe Oxide/Clay Coatings}

Although ferric iron-rich coatings were found on the gravel surfaces of sediment in core B19140, the bulk XRD pattern of scrapings of the fine-grained and orange-colored material did not show any distinguishable crystalline iron oxides peaks such as hematite or goethite. Thus, the mass of crystalline iron oxides in the sediment is likely less than 5\% wt., or alternatively, the crystals are very small and not amenable to bulk XRD because small crystals lead to more diffuse and overlapping peaks in the XRD spectra. We thus resorted to more sophisticated micro analyses of the Fe oxide/clay coatings. The surface morphology, obtained from FESEM), showed angular, platy shapes indicating crystalline minerals were present (Figure 19). EDS also showed Si, Al, K, Mn, and Fe in the scrapings. These elements suggest the presence of both 
aluminosilicate clays and iron oxides are present in the coatings. Based on Figure 19 findings, the needle-shaped crystals found attached to platy-shaped clay minerals are believed to be goethite.

The TEM images yielded weak electron diffraction patterns, which are presented in Figure 20. The TEM image of the same Fe oxide/clay coatings showed a needle-like structure, which is typical for goethite. Selected area electron diffraction indicates that this needle-like structure is indeed crystalline. However, due to the very limited orientation, identification of the phase based on one diffraction pattern is not possible. Based on previous bulk XRD analysis, smectite was one of the dominant clay minerals found in the Fe oxide/clay coatings. A weak electron diffraction pattern also suggested a small amount of goethite mixed with clay minerals.

The needle-shaped particle in the left image is tentatively identified as goethite. The right image, an electron diffraction image of the needle particle, indicates several crystalline materials are present. Amorphous materials would not yield the distinct "dots" and would look like an opaque cloud.
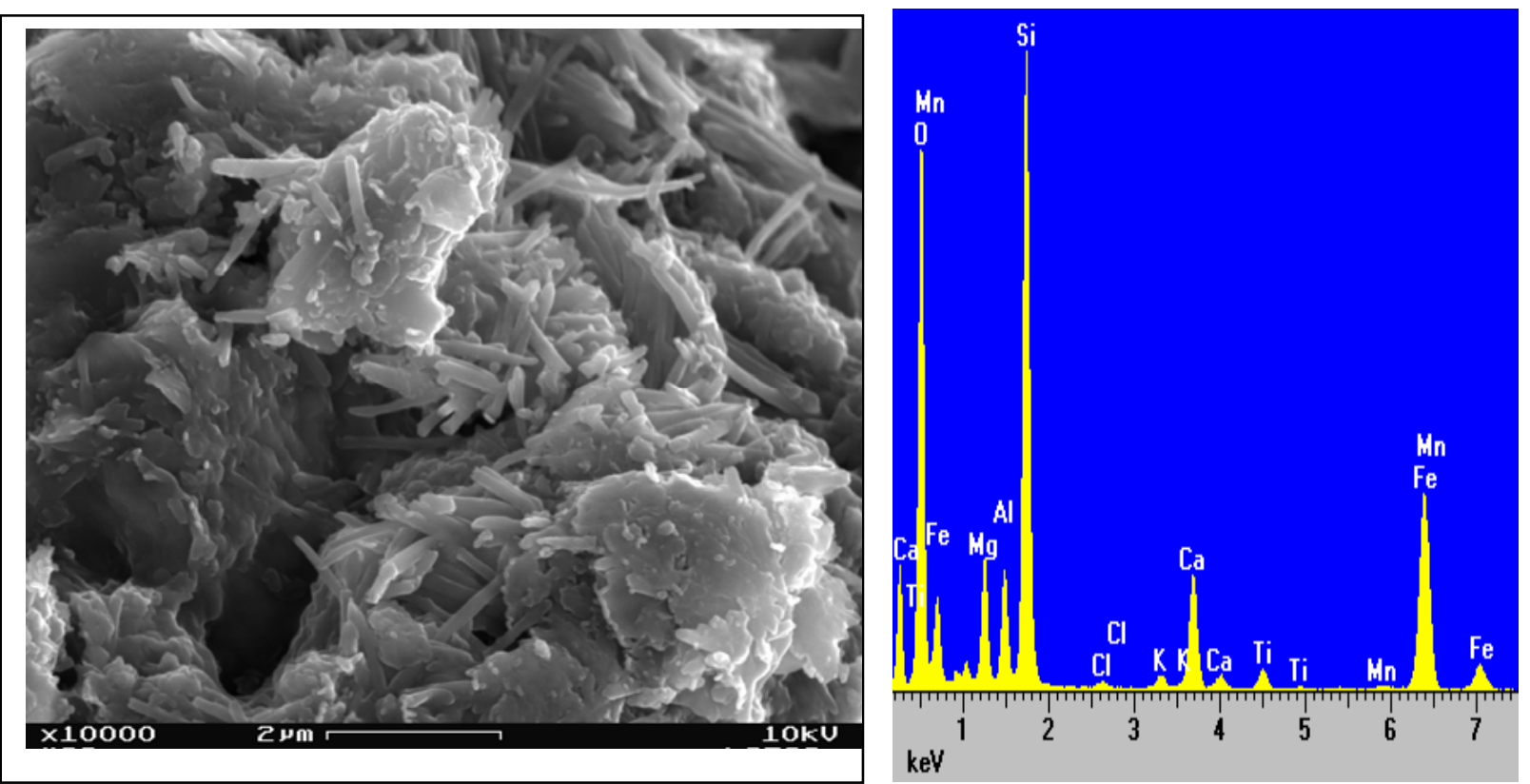

Figure 19. FESEM Images with EDS of Fe Oxide/Clay Coatings Found in B19140 (C4299) 

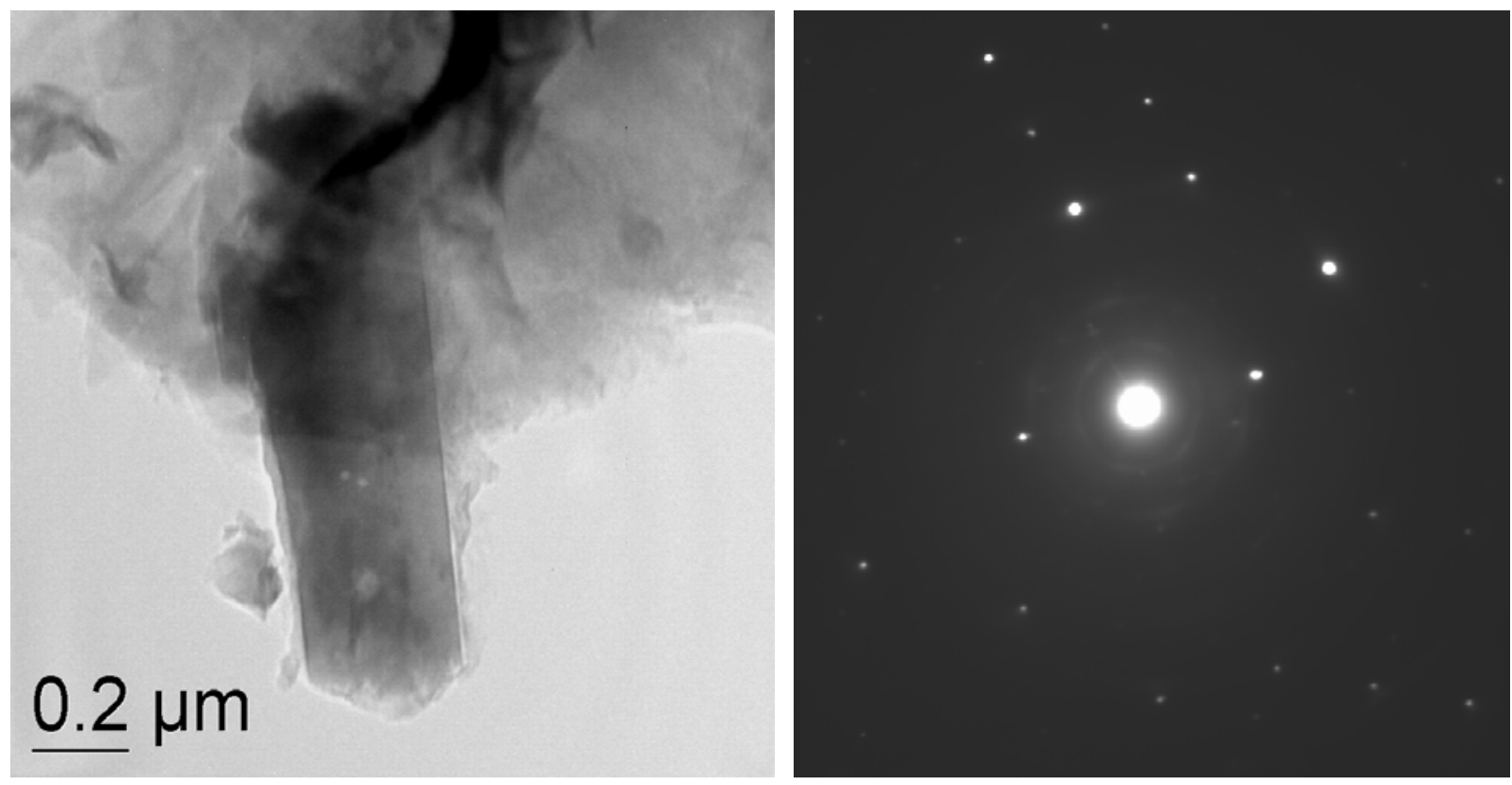

Figure 20. TEM Image and Electron Diffraction Pattern of Fe Oxide/Clay Coatings from B19140

\subsubsection{Distribution Coefficient $\left(K_{d}\right)$ Measurements}

The $\mathrm{K}_{\mathrm{d}}$ values for COC (Tc-99, U(VI), Cr(VI), I-129, Se-79, Np-237, Cs-137 and Sr-90) on various adsorbents contacted with synthetic groundwater (measured $\mathrm{pH}=7.6$ ) are shown in Table 15. All adsorption experiments were conducted for 7 days reaction time. In addition, the B19140 gravel-only sample was continuously reacted with groundwater spiked with COC for one month.

Tc-99 $\mathrm{K}_{\mathrm{d}}$ values were essentially $0 \mathrm{~mL} / \mathrm{g}$ on most of the adsorbents. The highest $\mathrm{K}_{\mathrm{d}}$ value for Tc-99 $(0.7 \pm 0.5 \mathrm{~mL} / \mathrm{g})$ was found for the slough sample B192K1. Based on the ferrous iron concentrations found in the groundwater from the same depth in borehole C4298 and the pore water extracted from liner B192K1, we can state that artificially low redox conditions, caused by the hard tooling drilling, might be the cause of this high Tc- $99 \mathrm{~K}_{\mathrm{d}}$. The mixture B19136\&B19137 sediment also showed a non-zero $K_{d}$ value for Tc-99, regardless of whether gravel was removed or not (triplicate average $\mathrm{K}_{\mathrm{d}}$ values range from 0.30 to $0.38 \mathrm{~mL} / \mathrm{g}$ ). The mixed B19136 and B19137 sediment sample showed the highest ferrous iron concentration in the extracted pore water (Table 4). Fresh ferrous iron-bearing breccia (broken gravels) or pieces of metal equipment resulting from the drilling procedure likely induced reducing conditions that led to some Tc-99 adsorption on or precipitation of insoluble $\mathrm{TcO}_{2}$ in this sample. For future risk modeling, we recommend that the $\mathrm{K}_{\mathrm{d}}$ for Tc-99 be set at $0 \mathrm{~mL} / \mathrm{g}$ for undisturbed Ringold Unit E sediments. The Tc-99 $\mathrm{K}_{\mathrm{d}}$ for the Ringold Lower Mud sample (B19377) was $0.08 \pm 0.03 \mathrm{~mL} / \mathrm{g}$. For future risk assessments, the Tc- $99 \mathrm{~K}_{\mathrm{d}}$ for the Ringold Lower Mud unit should be varied between 0 and $0.1 \mathrm{~mL} / \mathrm{g}$ to see if there is any significant change in risk. If not, using $0 \mathrm{~mL} / \mathrm{g}$ for the entire Ringold Formation is recommended. 
Uranium $\mathrm{K}_{\mathrm{d}} \mathrm{S}$ ranged from 0.1 to $7.7 \mathrm{~mL} / \mathrm{g}$ depending on the adsorbent. The highest $U \mathrm{~K}_{\mathrm{d}}$ value was found for the Fe oxide/clay coatings scraped off gravel in sample B19140, suggesting that the high ferric oxide and fine-grained clay content in this material enhanced $\mathrm{U}$ adsorption. For the bulk of the Ringold Unit E sediments, we recommend using a $U_{K_{d}}$ value of $0.5 \pm 0.2 \mathrm{~mL} / \mathrm{g}$. For the Ringold Lower Mud Unit the recommended $\mathrm{U} \mathrm{K}_{\mathrm{d}}$ value should be set at $1.8 \pm 0.1 \mathrm{~mL} / \mathrm{g}$. For the Ringold Unit $\mathrm{E}$ ferric-oxide rich coated gravels, a $\mathrm{U} \mathrm{K}_{\mathrm{d}}$ value of $5.0 \pm 1.3 \mathrm{~mL} / \mathrm{g}$ should be used.

$\mathrm{Np} \mathrm{K}_{\mathrm{d}} \mathrm{S}$ ranged from 0.4 to $23.4 \mathrm{~mL} / \mathrm{g}$ and also showed the highest $\mathrm{K}_{\mathrm{d}}$ value on Fe oxide/clay coatings from sediment B19140, consistent with the coatings being the best adsorbent for the actinides ( $\mathrm{Np}$ and $\mathrm{U}$ ). For the typical Ringold Unit $\mathrm{E}$ sediments, the $\mathrm{Np} \mathrm{K}_{\mathrm{d}}$ value of $2.5 \pm 0.5 \mathrm{~mL} / \mathrm{g}$ is recommended. For the Ringold Lower Mud Unit, the recommended $\mathrm{Np} \mathrm{K}_{\mathrm{d}}$ value should be set at $3.6 \pm 0.2 \mathrm{~mL} / \mathrm{g}$. For the Ringold Unit E ferric-oxide-rich coated gravels, a $\mathrm{Np} \mathrm{K}$ value of $9.0 \pm 2.0 \mathrm{~mL} / \mathrm{g}$ should be used.

The $\mathrm{K}_{\mathrm{d}}$ values for $\mathrm{Cr}(\mathrm{VI})$ ranged from 0.0 to $1.3 \mathrm{~mL} / \mathrm{g}$ for the intact sediments dependent on the sediment. Again, the slough sample B192K1 showed an anomalously high $\mathrm{Cr}(\mathrm{VI})$ value of 10 to $19 \mathrm{~mL} / \mathrm{g}$. In general, oxyanions such as chromate show low to no adsorption onto sediments at neutral to alkaline $\mathrm{pH}$ values (Krupka et al. 2004). The low but non-zero $\mathrm{K}_{\mathrm{d}}$ values observed for the mixture B19136 and B19137 sediment is likely indicative of some artificial reducing conditions caused by the crushing and grinding of the gravels during the drilling process. We recommend using a $\mathrm{Cr}(\mathrm{VI}) \mathrm{K}_{\mathrm{d}}$ value of $0 \pm 0.5 \mathrm{~mL} / \mathrm{g}$ to model adsorption to the Ringold Unit $\mathrm{E}$ sediments and the Ringold Unit $\mathrm{E}$ ferric-oxide rich coated gravels. For the Ringold Lower Mud Unit, the recommended $\mathrm{Cr}(\mathrm{VI}) \mathrm{K}_{\mathrm{d}}$ value should be set at $0.1 \pm 0.1 \mathrm{~mL} / \mathrm{g}$. It appears that the ferric oxides that coat the gravel in sediment sample B19140 does not adsorb much $\mathrm{Cr}(\mathrm{VI})$ at the slightly alkaline $\mathrm{pH}$ values found at Hanford. Although $\mathrm{Cr}(\mathrm{VI})$ showed the highest $\mathrm{K}_{\mathrm{d}}$ value $(10.3 \mathrm{ml} / \mathrm{g})$ on the B192K1 sample, because this sediment was considered to be slough, the $K_{d}$ value was not considered in our data interpretation. $\operatorname{Cr}(\mathrm{VI}) \mathrm{K}_{\mathrm{d}}$ values were determined using both stable $\mathrm{Cr}$ and radioactive $\mathrm{Cr}$-51. In general, the agreement between the calculated $\mathrm{K}_{\mathrm{d}}$ values for the radionuclide and stable $\mathrm{Cr}$ was adequate and strengthens the validity of the batch test protocol.

$\mathrm{Se}(\mathrm{VI})$ adsorption $\mathrm{K}_{\mathrm{d}} \mathrm{S}$ were low similar to Tc-99, except for adsorption to Fe oxide/clay coatings. The higher ferric oxide content in the coatings increased $\mathrm{Se}(\mathrm{VI})$ adsorption affinity. The highest $\mathrm{K}_{\mathrm{d}}$ value for $\mathrm{Se}(0.62 \mathrm{~mL} / \mathrm{g})$ was on the Fe oxide/clay coatings in B19140 sediment. The $\mathrm{Se}(\mathrm{VI})$ adsorption data suggested that $\mathrm{Se}(\mathrm{VI})$ was not as redox-sensitive as the $\mathrm{Tc}(\mathrm{VII})$ and $\mathrm{Cr}(\mathrm{VI})$ based on adsorption to the mixed B19136 and B19137 sediment, which showed atypical ferrous iron concentrations in its pore waters that were likely indicative of some artificial reducing conditions caused by the hard tool drilling. For the Ringold Unit E sediments, we recommend a Se(VI) $\mathrm{K}_{\mathrm{d}}$ value of $0 \pm 0.05 \mathrm{~mL} / \mathrm{g}$. For the Ringold Lower Mud Unit and the Ringold Unit $\mathrm{E}$ ferric-oxide rich coated gravels, we recommend setting the $\mathrm{Se}(\mathrm{VI}) \mathrm{K}_{\mathrm{d}}$ value at $0.05 \pm 0.02 \mathrm{~mL} / \mathrm{g}$.

Iodide ( $\left.\mathrm{I}^{-}\right)$, the most likely form of I-129 in Hanford groundwaters, showed adsorption $\mathrm{K}_{\mathrm{d}} \mathrm{S}$ close to zero on most of the sediments. The highest iodide $\mathrm{K}_{\mathrm{d}}$ value $(0.1 \mathrm{~mL} / \mathrm{g})$ was found for the Ringold Lower Mud (B19377) and B19140 (<2-mm particles) sediments. The mixed 
B19136 and B19137 sediment, which showed the artificial low redox conditions because of hard tooling, had a zero $\mathrm{K}_{\mathrm{d}}$ value of iodide, suggesting that iodide adsorption was not redox-sensitive. In addition, because iodide adsorption was close to zero on sediments that contained a high percentage of Fe oxide, iodide adsorption was not significantly influenced by Fe oxide content in the sediments. Instead, iodide adsorption might be more related to clay mineral content, especially illite as found by Kaplan et al. (2000).

Although not mobile, COC in groundwater at 200-UP-1 and $\mathrm{K}_{\mathrm{d}}$ values for Sr-90 (based on using Sr-85) and Cs-137 were also determined. For the Ringold Unit E sediments, the recommended Sr-90 $\mathrm{K}_{\mathrm{d}}$ value should be set at $8 \pm 3 \mathrm{~mL} / \mathrm{g}$. For the Ringold Unit E ferric-oxiderich coated gravels, a Sr-90 K $\mathrm{d}_{\mathrm{d}}$ value of $15 \pm 10 \mathrm{~mL} / \mathrm{g}$ should be used. For the Ringold Lower Mud Unit, we recommend setting the $\mathrm{Sr}-90 \mathrm{~K}_{\mathrm{d}}$ value at $25 \pm 5 \mathrm{~mL} / \mathrm{g}$.

Cs-137 is very strongly adsorbed to most sediment present below the Hanford Site as long as the water composition is dilute such as found for typical Hanford groundwaters. For the Ringold Unit $E$ and the Ringold Unit $E$ ferric-oxide-rich coated gravels, we recommend setting the Cs- $137 \mathrm{~K}_{\mathrm{d}}$ value at $500 \pm 100 \mathrm{~mL} / \mathrm{g}$. For the Ringold Unit E gravels, a Cs-137 $\mathrm{K}_{\mathrm{d}}$ value of $300 \pm 100 \mathrm{~mL} / \mathrm{g}$ would be a conservative value to use to account for the lower surface area of gravel. For the Ringold Lower Mud Unit, we recommend setting the Cs-137 $\mathrm{K}_{\mathrm{d}}$ value at $1000 \pm 200 \mathrm{~mL} / \mathrm{g}$.

Longer contact times for adsorbates with adsorbents (gravel only) might increase adsorption affinity, especially for $\mathrm{U}(\mathrm{VI})$ and $\mathrm{Np}(\mathrm{V})$, because of diffusion-controlled adsorption into the micro-pores within the gravel interiors. However, for anionic radionuclides such as Tc(VII), $\mathrm{Cr}(\mathrm{VI}), \mathrm{I}(-\mathrm{I})$, and $\mathrm{Se}(\mathrm{VI})$, increased contact time did not affect significantly the adsorption affinities, especially on the gravel-only adsorbents, because of the very limited adsorption sites for anions. The 1-month contact time data for the gravel-only sample of B19140 provides some insight. 
Table 15. Batch Adsorption Distribution Coefficients $\left(\mathrm{K}_{\mathrm{d}} \mathrm{s}\right)$ for COC on 200-UP-1 Samples

\begin{tabular}{|c|c|c|c|c|c|c|c|c|}
\hline \multirow[b]{2}{*}{ Adsorbents } & \multicolumn{8}{|c|}{$K_{d} \mathbf{s}(m L / g)$} \\
\hline & Tc(VII)-99 & $\mathbf{U}(\mathrm{VI})$ & Sr(II)-85 & Cs(I)-137 & $\mathrm{Np}(\mathrm{V})-237$ & $\operatorname{Cr}(\mathrm{VI})^{*}$ & $\mathrm{Se}(\mathrm{VI})$ & I(-I)-129 \\
\hline \multirow{2}{*}{ B192K1 bulk (slough) } & \multirow{2}{*}{$0.70 \pm 0.46$} & \multirow{2}{*}{$0.52 \pm 0.27$} & \multirow{2}{*}{$5.34 \pm 0.98$} & \multirow{2}{*}{$688 \pm 207$} & \multirow{2}{*}{$2.71 \pm 0.48$} & $10.3 \pm 3.01$ & \multirow{2}{*}{$0.00 \pm 0.00$} & \multirow{2}{*}{$0.05 \pm 0.05$} \\
\hline & & & & & & $(19.3 \pm 14.7)$ & & \\
\hline \multirow{2}{*}{$\begin{array}{l}\text { B19136 and B19137 } \\
\text { bulk with gravel }\end{array}$} & \multirow{2}{*}{$0.38 \pm 0.00$} & \multirow{2}{*}{$0.37 \pm 0.00$} & \multirow{2}{*}{$9.46 \pm 2.86$} & \multirow{2}{*}{$1038 \pm 339$} & \multirow{2}{*}{$2.09 \pm 0.53$} & $1.32 \pm 1.50$ & \multirow{2}{*}{$0.06 \pm 0.04$} & \multirow{2}{*}{$0.08 \pm 0.03$} \\
\hline & & & & & & $(0.74 \pm 1.16)$ & & \\
\hline \multirow{2}{*}{$\begin{array}{l}\text { B19136 and B19137 } \\
\text { bulk without gravel }\end{array}$} & \multirow{2}{*}{$0.30 \pm 0.15$} & \multirow{2}{*}{$0.46 \pm 0.05$} & \multirow{2}{*}{$10.6 \pm 1.25$} & \multirow{2}{*}{$472 \pm 31$} & \multirow{2}{*}{$2.75 \pm 0.30$} & $0.92 \pm 0.50$ & \multirow{2}{*}{$0.07 \pm 0.04$} & \multirow{2}{*}{$0.00 \pm 0.00$} \\
\hline & & & & & & $(0.60 \pm 0.53)$ & & \\
\hline \multirow{2}{*}{$\begin{array}{l}\text { B19140 bulk with gravel } \\
\text { (A) }\end{array}$} & \multirow{2}{*}{$0.00 \pm 0.00$} & \multirow{2}{*}{$4.72 \pm 0.90$} & \multirow{2}{*}{$47.9 \pm 7.65$} & \multirow{2}{*}{$1963 \pm 1110$} & \multirow{2}{*}{$9.33 \pm 1.96$} & $0.00 \pm 0.00$ & \multirow{2}{*}{$0.00 \pm 0.00$} & \multirow{2}{*}{$0.02 \pm 0.00$} \\
\hline & & & & & & $(0.03 \pm 0.06)$ & & \\
\hline B19140 bulk without & $0.02 \pm 0.00$ & $5.23 \pm 1.33$ & $53.7 \pm 13.2$ & $984 \pm 267$ & $11.7 \pm 2.96$ & $0.00 \pm 0.00$ & $0.04 \pm 0.03$ & $0.10 \pm 0.01$ \\
\hline gravel (B) & & & & & $11.7 \pm 2.90$ & $(0.14 \pm 0.17)$ & $0.04 \pm 0.05$ & $0.10 \pm 0.01$ \\
\hline & $0.07+0.00$ & $010+0.08$ & $392+308$ & $269+186$ & $036+021$ & $0.00 \pm 0.00$ & $0.06+0.00$ & $002+0.00$ \\
\hline B19140 gravel only (C) & $0.07-0.00$ & $0.10-0.00$ & (5. & & $0.50-0.21$ & $(0.00 \pm 0.00)$ & $0.00-0.00$ & \\
\hline B19140 gravel only after & $000+000$ & $024+003$ & $000+000$ & $932+667$ & $125+076$ & $0.00 \pm 0.00$ & $002+0.02$ & $008+005$ \\
\hline 1 month & & & & & & $(0.00 \pm 0.00)$ & $0.02 \pm 0.02$ & \\
\hline B19140 Fe/clay coatings & 0 & 772 & 79 & 8378 & 234 & 0 & 062 & $000+000$ \\
\hline (D) & & & & & & $(0)$ & & \\
\hline & $0.08 \pm 0.03$ & $1.84 \pm 0.07$ & $24.0 \pm 4.56$ & $1359+235$ & $3.56 \pm 0.17$ & $0.29 \pm 0.23$ & $0.05 \pm 0.02$ & $0.11+0.08$ \\
\hline B19377 bulk & & & & & & $(0.04 \pm 0.07)$ & & \\
\hline $\begin{array}{l}\text { Triplicate samples for } \mathrm{K}_{\mathrm{d}} \mathrm{S} \\
\mathrm{Cr}(\mathrm{Cr}-51) \text { samples were ana } \\
\text { Values highlighted in yellow } \\
\text { around the average of the thr } \\
\text { (A), (B),(C), and (D) are sam }\end{array}$ & $\begin{array}{l}\text { e prepared and } \\
\text { zed using GE } \\
\text { re suspect (sus } \\
\text { replicates. } \\
\text { le designation }\end{array}$ & $\begin{array}{l}\text { veraged, exc } \\
\text { The } \mathrm{K}_{\mathrm{d}} \text { valu } \\
\text { iciously large } \\
\text { hown in Tab }\end{array}$ & $\begin{array}{l}\text { for } \mathrm{Fe} \text { oxide/c } \\
\text { or } \mathrm{Cr}(\mathrm{VI}) \text { wer } \\
\text { and the sedime } \\
14 .\end{array}$ & $\begin{array}{l}\text { coatings. Mos } \\
\text { easured by botl } \\
\text { vas slough. Th }\end{array}$ & $\begin{array}{l}\text { Imples were an } \\
\text { chniques. * GE } \\
\text { ncertainty valu }\end{array}$ & $\begin{array}{l}\text { using ICP-M } \\
\text { for Cr is shov } \\
\text { values) represe }\end{array}$ & $\begin{array}{l}\mathrm{Sr}(\mathrm{Sr}-85), \mathrm{Cs} \\
\text { n parenthese } \\
\text { one standard }\end{array}$ & $\begin{array}{l}\text { s-137), and } \\
\text { viation }\end{array}$ \\
\hline
\end{tabular}




\subsection{Task 3 Results: Additional U(VI) $K_{d}$ Measurements}

\subsubsection{In-situ Desorption U(VI) $\mathbf{K}_{\mathbf{d}}$}

In-situ desorption $\mathrm{U}(\mathrm{VI}) \mathrm{K}_{\mathrm{d}} \mathrm{s}$ for the <2-mm size fraction of three 200-UP-1 sediments were determined by calculating the ratio of the amount of labile $\mathrm{U}(\mathrm{VI})$ that could be leached by the sodium bicarbonate-carbonate leachant to the dissolved $\mathrm{U}(\mathrm{VI})$ concentration present in the pore water removed from the cores. The calculated in-situ desorption $\mathrm{U}(\mathrm{VI}) \mathrm{K}_{\mathrm{d}} \mathrm{s}$ are given in Table 16. The measured in-situ desorption $\mathrm{U}(\mathrm{VI}) \mathrm{K}_{\mathrm{d}} \mathrm{S}$ are one to two orders of magnitude higher than those determined in the laboratory batch adsorption tests (Task 2) as shown in Table 15. The high in-situ desorption $\mathrm{K}_{\mathrm{d}}$ values could be attributed to 1) non-linearity of uranium adsorption (or desorption) as a function of dissolved $\mathrm{U}(\mathrm{VI})$ concentration (measured pore water extracts were $<3 \mu \mathrm{g} / \mathrm{L}$ in comparison to the final concentrations in the laboratory tests, where the uranium concentrations ranged from 10 to $30 \mu \mathrm{g} / \mathrm{L}$ ), 2) other geochemical reactions such as (co)precipitation rather than adsorption over the 20 to 30 years that contaminated groundwater has interacted with the sediments leading to low dissolved $\mathrm{U}(\mathrm{VI})$ concentrations (recall that laboratory batch adsorption tests had only a 7-day contact time), 3) different geochemical conditions in pore water (alkalinity, ionic strength, and $\mathrm{pHs}$ ) compared to simulated groundwater, 4) uncertainty in the true value for adsorbed U(VI) concentration based on the sodium bicarbonate-carbonate solution leaching, and 5) known hysteresis in desorption reactions versus adsorption reactions (see discussion in Barney 1978 and EPA 1999). Because in-situ desorption $\mathrm{K}_{\mathrm{d}} \mathrm{s}$ results have high uncertainties, the values in Table 16 should be considered as supplementary information to define the ease of removal of U(VI) from these 200-UP-1 sediments. Because the sediment samples available are not significantly contaminated with Hanford-derived uranium, the $\mathrm{K}_{\mathrm{d}}$ values in Table 16 represent more the desorption of natural uranium out of the 200-UP-1 sediments rather than adsorption/desorption of uranium added to the environment by Hanford activities. Based on previous selective extraction studies on 300-Area sediments (see Serne et al. 2002), natural uranium is bound much more strongly in sediment than uranium added by Hanford activities. Therefore, the desorption $\mathrm{U} \mathrm{K}_{\mathrm{d}}$ values in Table 16 are likely not good proxies for Hanford-derived U contamination.

Table 16. In-situ U(VI) Desorption $\mathrm{K}_{\mathrm{d}} \mathrm{s}$

\begin{tabular}{|c|c|c|c|}
\hline Sediments & $\begin{array}{c}\text { Adsorbed U(VI) } \\
\text { Concentration }(\mu \mathrm{g} / \mathrm{g})\end{array}$ & $\begin{array}{c}\text { Dissolved U(VI) } \\
\text { Concentration }(\mu \mathrm{g} / \mathrm{L})\end{array}$ & In-Situ $K_{d} s(m L / g)$ \\
\hline $\mathrm{B} 19136(<2 \mathrm{~mm})$ & $0.0074 *$ & 0.973 & 7.61 \\
\hline $\mathrm{B} 19137(<2 \mathrm{~mm})$ & $0.0074 *$ & 2.230 & 3.32 \\
\hline $\mathrm{B} 19377(<2 \mathrm{~mm})$ & 0.0142 & 1.310 & 10.8 \\
\hline $\mathrm{B} 19140(<2 \mathrm{~mm})$ & 0.0316 & 0.052 & 608 \\
\hline
\end{tabular}

* Because we did not measure the U(VI) labile concentration for each B19136 and B19137 sediment separately, labile $\mathrm{U}(\mathrm{VI})$ concentration from the mixed composite of these two sediments was used to calculate in-situ $U(V I) \mathrm{K}_{\mathrm{d}} \mathrm{s}$ for the two sediments. 


\subsubsection{U(VI) Adsorption $\mathrm{K}_{\mathrm{d}} \mathrm{S}$ with Varying Dissolved Uranium Concentrations}

Uranium batch adsorption $\mathrm{K}_{\mathrm{d}} \mathrm{S}$ were determined for simulated groundwaters with varying total U(VI) concentration for the <2-mm size fractions of the three 200-UP-1 sediments (B19136 and B19137, B19377, and B19140). Initial U(VI) concentration was varied from $5 \times 10^{-8} \mathrm{M}$ $(12.0 \mu \mathrm{g} / \mathrm{L})$ to $5 \times 10^{-6} \mathrm{M}(1190 \mu \mathrm{g} / \mathrm{L})$. Decreasing adsorption $\mathrm{U} \mathrm{K}_{\mathrm{d}}$ values with increasing total initial concentration of $U$ are often observed, because of saturation of the most favorable adsorption sites with increasing total concentration of adsorbate. However, $\mathrm{U}(\mathrm{VI}) \mathrm{K}_{\mathrm{d}} \mathrm{s}$ for the three 200-UP-1 sediments with varying $\mathrm{U}(\mathrm{VI})$ concentration up to $5 \times 10^{-6} \mathrm{M}$ showed constant values, suggesting a linear isotherm within this $\mathrm{U}(\mathrm{VI})$ concentration range (Figure 21).

Apparently, there are plenty of U(VI) favorable adsorption sites in the 200-UP-1 sediments given the high solid-to-solution ratio chosen $(300 \mathrm{~g} / \mathrm{L})$, such that a linear isotherm was observed up to $\mathrm{U}(\mathrm{VI})$ concentration of $5 \times 10^{-6} \mathrm{M}$, which was the highest $\mathrm{U}(\mathrm{VI})$ concentration used. A similar linear adsorption isotherm was found for $\mathrm{U}(\mathrm{VI})$ adsorption onto coarse-grained Hanford formation sediments using two simulated 300 Area groundwaters ( $\mathrm{pH}$ ranged from 7.5 to 8 ) and a solid-to-solution ratio of $100 \mathrm{~g} / \mathrm{L}$ up to a $\mathrm{U}(\mathrm{VI})$ solution concentration of $3,000 \mu \mathrm{g} / \mathrm{L}$ (Serne et al. 2002). In addition, because a linear isotherm was found to be valid up to $5 \times 10^{-6} \mathrm{M}$ $(\sim 1 \mathrm{mg} / \mathrm{L})$ of $\mathrm{U}(\mathrm{VI})$ initial concentration, and the existing groundwater plume contains dissolved $\mathrm{U}(\mathrm{VI})$ concentrations below $1 \mathrm{mg} / \mathrm{L}$ (Hartman et al. 2005), a linear $\mathrm{K}_{\mathrm{d}}$ model can be applied to predict U(VI) transport in the 200-UP-1 groundwater condition. This statement should not be interpreted as meaning that the $\mathrm{U}(\mathrm{VI}) \mathrm{K}_{\mathrm{d}}$ value is constant if the groundwater chemical composition changes with space and time. It merely means that the concentration of total dissolved $\mathrm{U}(\mathrm{VI})$ in the groundwater will not influence the $\mathrm{K}_{\mathrm{d}}$ value.

The measured $\mathrm{U}(\mathrm{VI})$ adsorption $\mathrm{K}_{\mathrm{d}} \mathrm{s}$ for these experiments are $1.3,4.9$, and $7.3 \mathrm{~mL} / \mathrm{g}$ for B19136 and B19137, B19377, and B19140, respectively. These values are reasonably similar to those reported in Task 2, where comparable sediment samples yielded values of $0.46,1.8$, and $5.2 \mathrm{~mL} / \mathrm{g}$, respectively. As found in the Task 2 batch adsorption experiments (see Table 15), U(VI) showed the highest adsorption affinity on B19140 sediment because of the high concentration of Fe oxides in the B19140 sediment. Based on Table 15 results, where the U(VI) $\mathrm{K}_{\mathrm{d}}$ value for the B19140 Fe oxide/clay coating materials was $7.72 \mathrm{~mL} / \mathrm{g}$, most U(VI) adsorption is expected to occur on Fe oxide/clay coatings in the Ringold Unit $\mathrm{E}$ sediments in the upper unconfined aquifer. The $\mathrm{U}(\mathrm{VI}) \mathrm{K}_{\mathrm{d}}$ values measured for B19136 and B19137 $(4.9 \mathrm{~mL} / \mathrm{g})$ and B19377 (1.3 mL/g) sediments are a little higher than those shown in Table 15. The differences may be caused by differing final $\mathrm{pH}$ values between the two tests. The $\mathrm{K}_{\mathrm{d}}$ values presented in Figure 21 (the slopes of the linear regression lines) could be used as the upper limit of $U(V I) K_{d}$ range for the these sediments.

\subsection{3 $\quad \mathrm{U}(\mathrm{VI})$ Adsorption $\mathrm{K}_{\mathrm{d}}$ as a Function of Dissolved Total Carbonate}

Because the analysis of groundwater samples collected from 200-UP-1 boreholes C4298, C4299, and C4300 after well completion showed varying alkalinity values from 76 to $156 \mathrm{mg} / \mathrm{L}$ as $\mathrm{CaCO}_{3}$ (Table A5 in the Appendix), synthetic groundwater solutions with varying alkalinities were independently prepared to investigate the effects of alkalinity on U(VI) adsorption. Varying the groundwater alkalinity should result in a variable adsorption affinity for dissolved U(VI) in the 200-UP-1 groundwater plume and also cause other more complicated interactions 
with the sediments such as calcite precipitation and dissolution as the groundwater chemical composition changes in time and location. Uranium(VI) adsorption $\mathrm{K}_{\mathrm{d}} \mathrm{S}$ determined under varying dissolved carbonate concentrations showed decreasing $\mathrm{U}(\mathrm{VI}) \mathrm{K}_{\mathrm{d}} \mathrm{s}$ with increasing carbonate concentrations (Figure 22). Because aqueous U(VI) forms strong U(VI)-carbonate complexes that have neutral or negative charges, especially at high $\mathrm{pH}, \mathrm{U}(\mathrm{VI})$-carbonate complexes showed low U(VI) adsorption on these 200-UP-1 sediments when alkalinity was increased.

The calculated U(VI) adsorption $\mathrm{K}_{\mathrm{d}} \mathrm{S}$ for the three 200-UP-1 sediments with varying alkalinities are shown in Table 17. The measured $\mathrm{U}(\mathrm{VI}) \mathrm{K}_{\mathrm{d}} \mathrm{S}$ with similar carbonate concentration to synthetic 200-UP-1 groundwater $(\sim 170 \mathrm{mg} / \mathrm{L}$ in Table 1 and used in Task 2 batch tests) were consistent with previous Task 2 results $(0.46,1.84$, and $5.23 \mathrm{~mL} / \mathrm{g}$ for less than $2 \mathrm{~mm}$ size separates from B19136 and B19137, B19377, and B19140, respectively; see Table 15). The slight increase in $U(V I) K_{d} S$ at the highest alkalinity conditions shown in Table 17 may result from U(VI) co-precipitation with calcite, consistent with decreased calcium concentration in the solution samples. Even though geochemical modeling showed calcite could precipitate for this condition. especially at high $\mathrm{pH}$, more geochemical studies including spectroscopic investigations for $\mathrm{U}(\mathrm{VI})$ incorporation within fresh calcite or calcite surfaces should be conducted to corroborate this process as the cause of the enhanced $\mathrm{U}(\mathrm{VI}) \mathrm{K}_{\mathrm{d}}$.

\subsubsection{Column Experiment for U(VI)}

Adsorption/desorption and transport behavior of U(VI) spiked into 200-UP-1 synthetic groundwater was investigated using a flow-through column experiment. The column was packed with B19140 sediment ( $<2-\mathrm{mm}$ fraction). The column conditions and transport

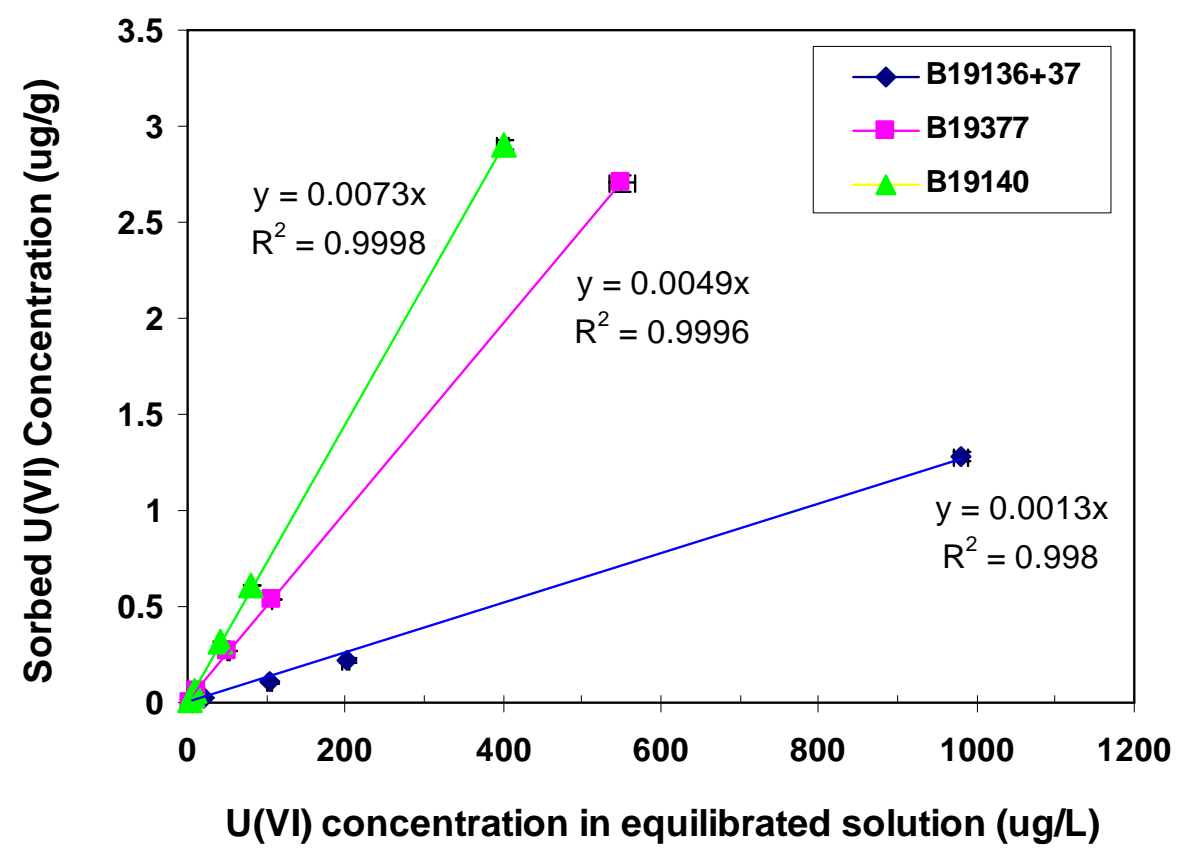

Figure 21. U(VI) Adsorption Isotherms for 200-UP-1 Sediments 
parameters obtained from the column experiment are shown in Table 18. The hydrodynamic dispersion coefficient (D) was determined using the computer code CXTFIT to fit the measured non-reactive tracer (Br-) breakthrough. The classical equilibrium advection-dispersion modeling showed a reasonable fit to the measured $\mathrm{U}(\mathrm{VI})$ breakthrough data, especially for the adsorption part (the leading edge of Figure 23). The fitted retardation factor $(\mathrm{R})$ was $19.57\left(\mathrm{~K}_{\mathrm{d}}=4.44 \mathrm{~mL} / \mathrm{g}\right)$, similar to that measured in previous batch $\mathrm{K}_{\mathrm{d}}$ measurements (5.23 \pm 1.33 for B19140 without gravel as shown in Table 15). However, the equilibrium model did not fit the latter part (desorption portion) of the $\mathrm{U}(\mathrm{VI}) \mathrm{BTC}$. The predicted $\mathrm{U}(\mathrm{VI})$ desorption data using the CXTFIT code indicated that $\mathrm{U}(\mathrm{VI})$ desorption data at the latter part of the BTC (pore volume > 45) were better fitted using a higher $\mathrm{K}_{\mathrm{d}}$ value $\left(\mathrm{K}_{\mathrm{d}}=5 \mathrm{~mL} / \mathrm{g}\right)$ than the value for the leading edge of the $\mathrm{BTC}$, fitted value $\left(\mathrm{K}_{\mathrm{d}}=4.44 \mathrm{~mL} / \mathrm{g}\right)$.

Even though the prediction using a higher $\mathrm{K}_{\mathrm{d}}$ value $\left(\mathrm{K}_{\mathrm{d}}=5 \mathrm{~mL} / \mathrm{g}\right)$ did not fit the leading edge of the U(VI) BTC, the better fit to the desorption data at the higher pore volume (pore volume $>45$ ) qualitatively suggested that $\mathrm{U}(\mathrm{VI})$ desorption is slower than the adsorption reaction, as required by the better fit using the higher desorption $\mathrm{K}_{\mathrm{d}}$ value than adsorption $\mathrm{K}_{\mathrm{d}}(4.44 \mathrm{~mL} / \mathrm{g})$.

The input flow using a synthetic 200-UP-1 groundwater without U(VI) was temporarily stopped for 66 hours during the desorption phase to evaluate the importance of the nonequilibrium processes. The first effluent after stop flow (filled circle in Figure 23) showed an increased $\mathrm{U}$ concentration relative to the $\mathrm{U}$ concentration in the previous effluent collected before the flow was stopped, suggesting that desorption is occurring at a slower rate than the

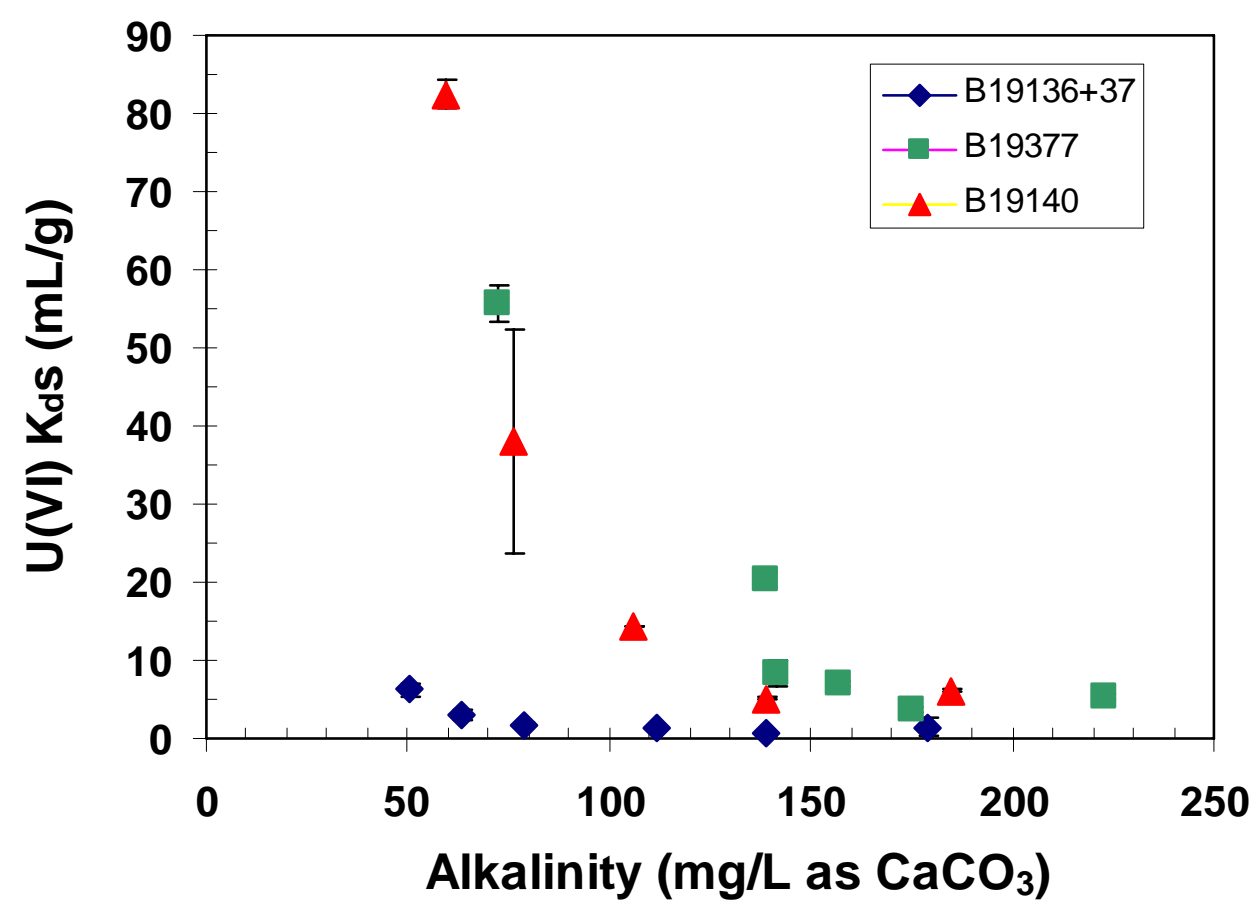

Figure 22. U(VI) Adsorption $\mathrm{K}_{\mathrm{d}} \mathrm{S}$ as a Function of Alkalinity 
Table 17. U(VI) Adsorption $\mathrm{K}_{\mathrm{d}} \mathrm{s}$ as a Function of Alkalinity

\begin{tabular}{|c|c|c|c|c|c|c|c|c|c|c|c|}
\hline \multicolumn{4}{|c|}{ B19136\&B10137 (<2 mm) } & \multicolumn{4}{|c|}{ B19377 (<2 mm) } & \multicolumn{4}{|c|}{ B19140 (<2 mm) } \\
\hline $\begin{array}{l}\text { Alk } \\
(\mathrm{mg} / \mathrm{L})\end{array}$ & $\begin{array}{r}\mathrm{K}_{\mathrm{d}} \\
(\mathrm{mL} / \mathrm{g})\end{array}$ & $\mathrm{pH}$ & $\begin{array}{l}\mathrm{Ca}^{2+} \\
(\mathrm{mg} / \mathrm{L})\end{array}$ & $\begin{array}{l}\text { Alk } \\
(\mathrm{mg} / \mathrm{L})\end{array}$ & $\begin{array}{r}\mathrm{K}_{\mathrm{d}} \\
(\mathrm{mL} / \mathrm{g})\end{array}$ & $\mathrm{pH}$ & $\begin{array}{l}\mathrm{Ca}^{2+} \\
(\mathrm{mg} / \mathrm{L})\end{array}$ & $\begin{array}{l}\text { Alk } \\
(\mathrm{mg} / \mathrm{L})\end{array}$ & $\begin{array}{r}\mathrm{K}_{\mathrm{d}} \\
(\mathrm{mL} / \mathrm{g})\end{array}$ & $\mathrm{pH}$ & $\begin{array}{l}\mathrm{Ca}^{2+} \\
(\mathrm{mg} / \mathrm{L})\end{array}$ \\
\hline 50.1 & $6.19 \pm 0.78$ & 7.12 & 39.8 & 72.6 & $55.8 \pm 2.38$ & 7.83 & 39.1 & 37.8 & $640.8 \pm 230.0$ & 7.34 & 39.4 \\
\hline 63.3 & $2.97 \pm 0.79$ & 7.30 & 37.8 & 138.9 & $20.4 \pm 1.02$ & 8.01 & 36.6 & 59.4 & $82.4 \pm 1.82$ & 7.40 & 39.9 \\
\hline 78.7 & $1.81 \pm 0.08$ & 7.65 & 38.5 & 141.3 & $8.34 \pm 1.77$ & 8.23 & 34.4 & 76.4 & $37.9 \pm 14.3$ & 7.45 & 37.7 \\
\hline 111.9 & $1.35 \pm 0.06$ & 7.80 & 37.5 & 156.7 & $6.98 \pm 0.21$ & 8.35 & 34.2 & 105.8 & $14.2 \pm 0.01$ & 7.60 & 37.3 \\
\hline 138.9 & $0.52 \pm 0.08$ & 7.84 & 31.9 & $175.2^{*}$ & $3.69 \pm 0.19$ & 8.49 & 32.2 & 139.0 & $5.05 \pm 0.13$ & 7.96 & 34.7 \\
\hline 179.1 & $0.76 \pm 0.06$ & 8.12 & 29.7 & 223.1 & $5.31 \pm 0.30$ & 8.46 & 30.5 & 184.5 & $6.16 \pm 0.29$ & 8.15 & 34.3 \\
\hline
\end{tabular}

Values highlighted in yellow are for a groundwater that has about the same alkalinity as the spiked simulated groundwater used in Task 2 batch adsorption experiments.

Table 18. Column Conditions and Transport Parameters

\begin{tabular}{|c|c|c|c|c|c|c|c|c|c|}
\hline \multirow{2}{*}{ Method } & $\theta$ & $\beta \rho$ & $\mathbf{V}$ & D & $\mathbf{R}$ & $\mathbf{K}_{\mathbf{d}}$ & $\beta$ & $\omega$ & $\overline{\mathbf{r}^{2}}$ \\
\hline & (unitless) & $\left(\mathrm{g} / \mathrm{cm}^{3}\right)$ & (cm/day) & (cm²/day) & (unitless) & $(\mathrm{mL} / \mathrm{g})$ & (unitless) & $\left(\right.$ day $\left.^{-1}\right)$ & (unitless) \\
\hline $\begin{array}{l}\text { Equilibrium (best fit of } \\
\text { whole curve) }\end{array}$ & 0.39 & 1.63 & 38.4 & 40.1 & $19.6 *$ & 4.44 & NA & NA & 0.96 \\
\hline $\begin{array}{l}\text { Equilibrium (fit of } \\
\text { leading edge of curve) }\end{array}$ & 0.39 & 1.63 & 38.4 & 40.1 & 17.7 & 4.00 & NA & NA & NA \\
\hline $\begin{array}{l}\text { Equilibrium (fit of } \\
\text { trailing edge of curve) }\end{array}$ & 0.39 & 1.63 & 38.4 & 40.1 & 21.9 & 5.00 & NA & NA & NA \\
\hline $\begin{array}{l}\text { Nonequilibrium (best fit } \\
\text { of whole curve) }\end{array}$ & 0.39 & 1.63 & 38.4 & $43.9^{*}$ & 19.6 & 4.44 & $0.61 *$ & $0.34 *$ & 0.98 \\
\hline
\end{tabular}

* Parameters were floated during fit to U(VI) data. Other parameters were fixed during fit. Porosity $(\theta)$, bulk density $\left(\rho_{\mathrm{b}}\right)$, and pore water velocity $(\mathrm{V})$ were directly measured from the column experiment. Hydrodynamic dispersion coefficient (D) was obtained from fitting the result to non-reactive tracer $(\mathrm{Br})$ data. The fraction of mobile region $(\beta)$ and the rate constant of mass transfer between mobile and immobile regions $(\omega)$ were also floated in non-equilibrium, two-region model fit. The value of $r^{2}$ indicated the goodness-of fit. 


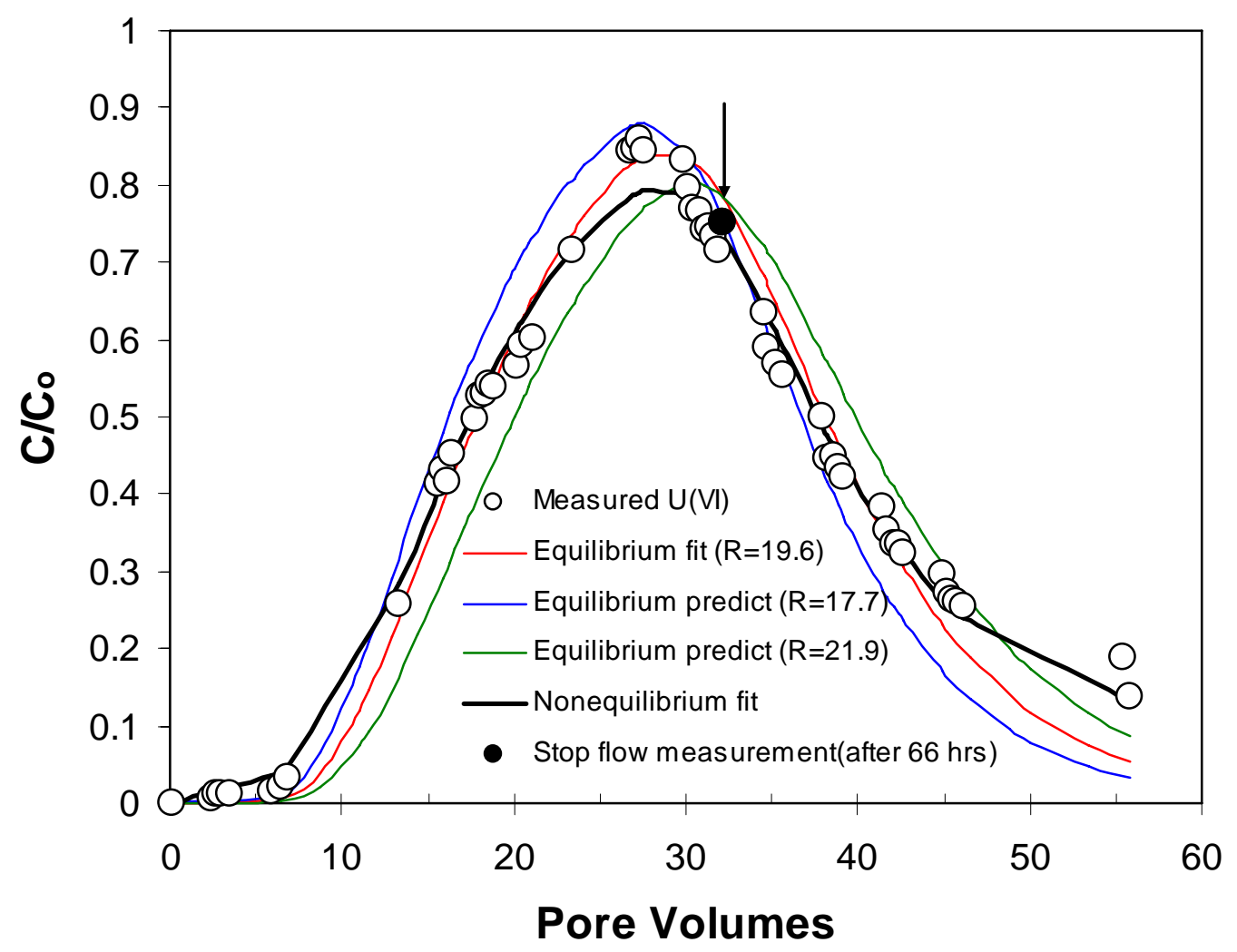

Figure 23. Breakthrough Curve for U(VI) with Measured Data and CXTFIT Model Fits. The arrow shows the first measured data after 66 hours stop flow.

time allowed for solution to move through the entire column $(6.8 \mathrm{hr})$. Therefore, the U BTC was also fit using the non-equilibrium two-region (mobile and immobile) conceptual model within CXTFIT. The non-equilibrium fit to the U BTC yielded a better fit than the equilibrium model. The non-equilibrium fit suggests that the flow paths within the packed column consist of two hydrodynamic regions, a mobile region (61\%) and an "immobile" region (39\%), and the mass transfer between the two hydrodynamic regions requires more than 8.16 hours ( 0.34 days) to reach equilibrium. The residence time for the solution was only 6.8 hours, thus not enough time was allotted for complete mass transfer between the two hydrodynamic regions. The nonequilibrium analysis showed better fitting results especially for data at the higher pore volume (desorption) portion of the BTC. The non-equilibrium fit is also another indication that a higher desorption $\mathrm{U} \mathrm{K}_{\mathrm{d}}$ value should be used to predict $\mathrm{U}(\mathrm{VI})$ release from the $\mathrm{U}(\mathrm{VI})$ contaminated 200-UP-1 sediments.

At the end of the column experiment, $86.2 \%$ of the total $\mathrm{U}$ introduced during the spike injection phase (total injected $=133.4 \mu \mathrm{g}$ ) had been recovered. Thus, the tailing edge of the BTC would likely slowly reach a $\mathrm{C} / \mathrm{C}_{0}$ of 0 after many more pore volumes of leaching. Alternatively, perhaps there is a small \% of the $\mathrm{U}(\mathrm{VI})$ introduced that becomes irreversibly adsorbed to the sediments packed into the column, which would be another indication of adsorption-desorption hysteresis. 
The results of these more detailed studies (Task 3) of U(VI) adsorption and desorption suggest that the fate of uranium in the existing 200-UP-1 groundwater plume is quite complicated. These studies and numerous other studies (both laboratory and field) show that the $\mathrm{K}_{\mathrm{d}}$ for $\mathrm{U}(\mathrm{VI})$ is quite sensitive to groundwater alkalinity (total bicarbonate/carbonate), $\mathrm{pH}$, dissolved U(VI) concentration, and time of reaction (kinetics) (see discussions both germane to Hanford and other sites in Serne et al. (2002), Zachara et al. (2005), Davis et al. (2004)).

If remediation of the existing groundwater U(VI) plume at 200-UP-1/200-ZP-1 operable units is required and some form of pump and treat operation is chosen, it is recommended that the aquifer be treated with chemicals to increase $\mathrm{pH}$, alkalinity, and to decrease dissolved calcium and magnesium (to prevent the precipitation of additional calcite). Manipulating the groundwater chemical composition in this fashion would decrease the adsorption affinity of $\mathrm{U}(\mathrm{VI})$ to the aquifer sediments. However, if the dissolved calcium and magnesium are not reduced, it is quite possible that increasing the alkalinity and $\mathrm{pH}$ will cause the co-precipitation of U(VI) with calcite or other alkaline-earth carbonates, thus making it more difficult to remove uranium from the aquifer. Such a uranium sequestration process has been suggested as being a likely cause for strong binding of U(VI) in the sediments below the TX tank farm (see Appendix D in Myers 2005) and in the 300 Area (see Zachara et al. 2005).

One should also consider that desorbing U(VI) that has been sequestered for tens of years in the 200-UP-1 aquifer sediments may be more difficult than predictions based on the adsorption $\mathrm{K}_{\mathrm{d}}$ values, shown in Table 15 and Table 17. "Aged" contamination is often much harder to desorb. Although the desorption $\mathrm{K}_{\mathrm{d}}$ data in Table 16, which are as much as one to two orders of magnitude larger than the short-term adsorption $\mathrm{K}_{\mathrm{d}}$ values shown in Table 15 and Table 17, may not represent the desorption $\mathrm{K}_{\mathrm{d}}$ for $\mathrm{U}(\mathrm{VI})$ that is Hanford-derived, some aging effects are likely still operative. Even though the flow-through column test used a relatively fast flow rate (short contact time for solution in the sediment), the U(VI) BTC showed evidence that a higher desorption $K_{d}$ value than the adsorption $K_{d}$ was required to get the best fit. One could speculate that after tens of years of aging the U(VI) in the 200-UP-1 aquifer sediments would show even less tendency to desorb. Because the desorption $\mathrm{K}_{\mathrm{d}}$ is expected to be higher than the values in Tables 15, 17, and 18, the methods to immobilize the U(VI) in place, to create permanently fixed U(VI) within the 200-UP-1 sediments, might be more effective than trying to remove the U(VI) by pump and treat. Unfortunately, no aquifer sediments were obtained that contained enough Hanford-generated uranium within them to perform quantitative desorption tests germane to the 200-UP-1 uranium plume remediation issue. 


\subsection{Summary and Conclusion}

Based on Task 1 and 2, no highly contaminated sediments were found in the cores from the three new boreholes in 200-UP-1 operable unit, especially for uranium. Instead of conducting the planned Task 3 desorption experiments on U-contaminated sediments, additional U(VI) adsorption $\mathrm{K}_{\mathrm{d}}$ studies were performed on Ringold Formation sediments subjected to varying geochemical solution conditions such as varying the dissolved U(VI) and total. The proposed characterization work in Task 1 was successfully completed but showed only 4 out of 13 core liner samples were intact samples and that the others were slough material that dropped to the bottom of the borehole prior to the split-spoon sampling. The intact samples showed typical Ringold Unit E characteristics such as being dominated by gravel and sand. Moderately reducing conditions are inferred in some core liners, especially B19136 and B19137, from borehole C4299. This reducing condition was likely caused by the hard tool process used to drill the wells. Hard tooling breaks apart large gravel particles and exposes fresh surfaces of sediment grains that contain ferrous iron, which causes reducing conditions upon interacting with groundwater. The hard tool equipment also loses small pieces of metallic iron that is also readily oxidized and in the process reduces some materials present in the slurry. One core liner from C4299 (B19140) showed a significant presence of ferric iron oxide/clay coatings on its gravel surfaces. The noticeable red-orange colored sediments suggested the presence of ferric iron and a highly oxidative condition, although the pore water from this core did show some presence of dissolved ferrous iron, a general indication of reducing conditions. Thus, non-equilibrium conditions in field-moist sediments at different depths are sometimes found in the cores obtained by hard tool cable drilling. Because the B19140 sample, with the high amount of ferric iron staining, was collected from a deeper location (about $110 \mathrm{ft}$ deeper than B19136 and B19137), the induced reducing conditions at relatively shallower locations (B19136 and B19137) likely resulted from the presence of fresh faces of broken gravel or pebbles exposing ferrous ironbearing minerals and/or the presence of small pieces of metal (zero-valent iron) that sloughed off the drilling equipment during the drilling processes. In general, there was a larger percentage of gravel in the shallower sediments than the deeper sediments, thus promoting more chances for hard tooling artifacts to be found in the shallow sediments. High ferrous iron concentrations in the extracted pore water from several of the shallow sediments supported this hypothesis.

The 200-UP-1 sediments do contain some clay minerals that exhibit significant cation exchange capacity and thus should be good adsorbers for cationic contaminants. This is especially true of the Ringold Lower Unit mud sample, B19377 from borehole C4300. The presence of slough and "flour" caused by hard tooling is a serious challenge to obtaining field-relevant sediments for use in geochemical experiments to determine the adsorptiondesorption tendencies of redox sensitive elements such as uranium.

The adsorption of COC on intact Ringold Formation sediments and Fe oxide/clay coatings showed that the anionic contaminants [Tc(VII), Se(VI), U(VI), Cr(VI), and I(-I)] did not adsorb very well compared to cationic $[\mathrm{Np}(\mathrm{V}), \mathrm{Sr}(\mathrm{II})$, and $\mathrm{Cs}(\mathrm{I})]$ radionuclides. The high hydrous iron oxide content in the coatings caused the highest $\mathrm{K}_{\mathrm{d}}$ values for $\mathrm{U}$ and $\mathrm{Np}$, suggesting these hydrous iron oxides are the key solid adsorbent in the sediments that control the fate of $U$ and Np. Enhanced adsorption behavior for Tc, $\mathrm{Cr}$ and perhaps Se on the composite of B19136 and 
B19137 sediment was considered an "artifact" result caused by the induced reducing conditions from the hard tool drilling. We suggest that these reducing conditions and accompanying enhanced adsorption (i.e., moderately high $\mathrm{K}_{\mathrm{d}}$ values) are temporary and not relevant to actual field conditions in the Hanford upper unconfined aquifer. However, Se was not as redoxbicarbonate/carbonate concentration in the groundwater to develop a more robust $\mathrm{K}_{\mathrm{d}}$ data base for U(VI). The <2-mm-size separates of three 200-UP-1 sediments (B19136 and B19137, B19377, and B19140) showed a linear U(VI) adsorption isotherm up to $5 \times 10^{-6} \mathrm{M}(\sim 1 \mathrm{ppm})$ of total U(VI) concentration in solution. This fact validates the use of a linear adsorption isotherm to predict U(VI) adsorption; however, this is not the same as stating that the U(VI) $\mathrm{K}_{\mathrm{d}}$ values will be constant for varying groundwater conditions at 200-UP-1. The additional U(VI) $\mathrm{K}_{\mathrm{d}} \mathrm{s}$ obtained from varying carbonate concentration indicated that $\mathrm{U}(\mathrm{VI})$ adsorption was strongly influenced by the concentration of carbonate in solution. Because U(VI) aqueous species form strong U(VI)carbonate complexes with carbonate present in solution, U(VI) adsorption decreased with increasing concentrations of carbonate up to a point. Then, as carbonate and calcium concentrations in the groundwater reach values that exceed the solubility limit for the mineral calcite, there is a slight increase in $\mathrm{U}(\mathrm{VI}) \mathrm{K}_{\mathrm{d}}$ likely caused by uranium co-precipitation with the fresh calcite. The association of U(VI) with calcite precipitation has also been observed below single-shell tanks and in the capillary fringe of the sediment-aquifer water table at the 300 Area at Hanford. Thus, uranium sorption-desorption processes at Hanford are quite complicated and highly variable with changes in groundwater conditions ( $\mathrm{pH}$, dissolved carbonate and alkalineearth cation concentrations and to some extent dissolved uranium concentrations). The dissolution of co-precipitated U(VI) with calcite may be kinetically slower than the desorption of U(VI) off clay and hydrous iron oxides surface sites. This hypothesis needs to be considered if pump and treat is proposed to remediate uranium in the 200-UP-1 aquifer plume.

In-situ desorption $\mathrm{U}(\mathrm{VI}) \mathrm{K}_{\mathrm{d}} \mathrm{s}$ were calculated by assuming that 1) alkaline sodium bicarbonate-carbonate solution is a good measure of the labile U(VI) concentration in the sediments (equal to concentration of U(VI) adsorbed/calcite co-precipitated) and 2) dissolved U(VI) concentration measured in pore water extracts was a reasonable estimate of the dissolved $\mathrm{U}(\mathrm{VI})$ concentration at equilibrium with the sediments. However, the measured in-situ U(VI) $\mathrm{K}_{\mathrm{d}} \mathrm{S}$ for the $<2-\mathrm{mm}$ particle size fraction from the three 200-UP-1 sediments tested were a factor of 10 to 100 larger than the laboratory short-term $\mathrm{U}(\mathrm{VI})$ adsorption $\mathrm{K}_{\mathrm{d}}$ values. This discrepancy might result from high uncertainty in measuring either dissolved U(VI) concentration or adsorbed U(VI) concentration in the cores; however, because the sediments obtained did not contain total uranium concentrations above natural background values, they might not be relevant for determining in-situ desorption $\mathrm{K}_{\mathrm{d}}$ values for Hanford-contaminated sediments. Selective chemical extraction studies of natural and contaminated sediments from the 300 Area showed that contaminated sediments released much more uranium into "mild" chemical extractants, such as the alkaline sodium bicarbonate-carbonate solution used in this effort, than natural background sediments (Serne et al. 2002).

The results of the more detailed studies (Task 3) of U(VI) adsorption and desorption suggest that the fate of uranium in the existing 200-UP-1 groundwater plume is complicated. These studies and numerous other studies (both laboratory and field) show that the $\mathrm{K}_{\mathrm{d}}$ values for U(VI) are quite sensitive to groundwater alkalinity (total bicarbonate/carbonate) and $\mathrm{pH}$, and in some cases although not manifested for the 200-UP-1 existing plume, to dissolved U(VI) 
concentration. See discussions both germane to Hanford and other sites in Serne et al. (2002), Zachara et al. (2005), Davis et al. (2004), and Bargar et al. (2000). If remediation of the existing groundwater U(VI) plume at 200-UP-1/200-ZP-1 operable units is required and some form of pump and treat is chosen, it is recommended that the aquifer be treated with chemicals to increase $\mathrm{pH}$ and alkalinity and to decrease dissolved calcium and magnesium (to prevent the precipitation of additional calcite). Manipulating the groundwater chemical composition in this fashion would decrease the adsorption affinity of U(VI) to the aquifer sediments. However, if the dissolved calcium and magnesium are not reduced it is quite possible that increasing the alkalinity and $\mathrm{pH}$ will cause the co-precipitation of U(VI) with calcite or other alkaline-earth carbonates, thus making it more difficult to remove uranium from the aquifer. Such a uranium sequestration process has been suggested as being a likely cause for strong binding of U(VI) in the sediments below the TX tank farm (see Appendix D in Myers 2005) and in the 300 Area (see Zachara et al. 2005).

One should also consider that desorbing U(VI) that has been sequestered for tens of years in the 200-UP-1 aquifer sediments may be more difficult than equilibrium predictions based on the adsorption $\mathrm{K}_{\mathrm{d}}$ values shown in Table 15 and Table 17. Even though the flow through column test used a relatively fast flow rate (short contact time for solution in the sediment), the U(VI) BTC showed evidence that a higher desorption $\mathrm{K}_{\mathrm{d}}$ value than the adsorption $\mathrm{K}_{\mathrm{d}}$ was required to get the best fit to the trailing edge of the BTC. One could speculate that after tens of years of aging that the U in the 200-UP-1 aquifer sediments would show even less tendency to desorb. Because the desorption $\mathrm{K}_{\mathrm{d}}$ could be higher than the values in Table 15 and Table 17, which were used to create Table 19, the methods to immobilize the uranium in place and to create permanently fixed U within the 200-UP-1 sediments might be more effective than trying to remove the uranium by pump and treat. Unfortunately, no aquifer sediments were obtained that contained enough Hanford generated uranium within them to perform quantitative desorption tests germane to the 200-UP-1 uranium plume remediation issue.

Table 19 lists the recommended $\mathrm{K}_{\mathrm{d}}$ values that should be used for risk predictions for the 200-UP-1 groundwater plume traveling through the lithologies within the aquifer present at the 200-UP-1 (and by proxy 200-ZP-1) operable units. The recommended values do not consider the impacts of the temporary generation of reducing conditions caused by hard tool drilling within the coarse Ringold Unit E sediments, which contain appreciable percentages of gravels that release ferrous ions upon being broken up. The recommended $\mathrm{K}_{\mathrm{d}}$ values are chosen to include some conservatism (lower values are emphasized from the available range) as is standard risk assessment practice. The $\mathrm{K}_{\mathrm{d}}$ values in Tables 15 and 17, which were used to populate Table 19, were determined in short-term laboratory adsorption tests and may not represent the desorption $\mathrm{K}_{\mathrm{d}}$ values for contaminated sediments that have been aging for tens of years. For contaminant risk analysis, use of short-term laboratory-derived $\mathrm{K}_{\mathrm{d}}$ values may over-predict the 
migration and groundwater risk impacts at the various points of compliance down-gradient from existing plumes. That is, the use of short-term laboratory-derived $\mathrm{K}_{\mathrm{d}}$ values will lead to conservative risk predictions.

In general, desorption $\mathrm{K}_{\mathrm{d}}$ values for aged contaminated sediments can be larger than $\mathrm{K}_{\mathrm{d}}$ values determined in the adsorption direction in short-term laboratory experiments. This possibility is most important when predictive modeling is used to estimate release of contaminants back to water such as soil flushing and pump and treat remediation alternatives. That is, using the laboratory-derived adsorption $\mathrm{K}_{\mathrm{d}}$ values may over-predict the release of contaminants by various remediation alternatives and will predict that remediation will be more readily achieved than what will actually be observed in the field. To accommodate the potential for desorption hysteresis and other complications, the uranium desorption $\mathrm{K}_{\mathrm{d}}$ values in Table 20 should be used to estimate removal of uranium by pump and treat techniques using natural groundwater. If chemical lixiviants were used, more laboratory testing would be required to estimate desorption $\mathrm{K}_{\mathrm{d}}$ values.

No detailed studies were performed to get better estimates of other contaminants' desorption tendencies for removal from the 200-UP-1 aquifer sediments. As a default, we recommend the use of values that are twice as large as the values presented in Table 19 for the following COC: Tc, Sr, Np, Cr, Se, and I. One can assume that Cs removal from contaminated 200-UP-1 aquifer sediments using groundwater pump and treat will be ineffective given the very large $\mathrm{K}_{\mathrm{d}}$ values.

Table 19. Recommended $K_{d}$ Values to Use in 200-UP-1 Risk Transport Predictions

\begin{tabular}{||c|c|c|c||}
\hline & Ringold Unit E & $\begin{array}{c}\text { Ferric Oxide/Clay Rich } \\
\text { Coated Gravel (Ringold) }\end{array}$ & $\begin{array}{c}\text { Ringold Lower Mud } \\
\text { Unit }\end{array}$ \\
\hline $\mathrm{K}_{\mathrm{d}}$ Values & $\mathrm{mL} / \mathrm{g}$ & $\mathrm{mL} / \mathrm{g}$ & $\mathrm{mL} / \mathrm{g}$ \\
\hline $\mathrm{Tc}(\mathrm{VII})$ & $0 \pm 0.1$ & $0 \pm 0.1$ & $0.08 \pm 0.03$ \\
\hline $\mathrm{U}(\mathrm{VI})$ & $0.5 \pm 0.2$ & $5.0 \pm 1.3$ & $1.8 \pm 0.1$ \\
\hline $\mathrm{Sr}-90$ & $8 \pm 3$ & $15 \pm 10$ & $25 \pm 5$ \\
\hline $\mathrm{Cs}-137$ & $500 \pm 100$ & $500 \pm 100$ & $1000 \pm 200$ \\
\hline $\mathrm{Np}(\mathrm{V})$ & $2.5 \pm 0.5$ & $9.0 \pm 2.0$ & $3.6 \pm 0.2$ \\
\hline $\mathrm{Cr}(\mathrm{VI})$ & $0 \pm 0.05$ & $0 \pm 0.05$ & $0.1 \pm 0.1$ \\
\hline $\mathrm{Se}(\mathrm{VI})$ & $0 \pm 0.5$ & $0.05 \pm 0.02$ & $0.05 \pm 0.02$ \\
\hline $\mathrm{I}-129$ & $0 \pm 0.05$ & $0 \pm 0.02$ & $0 \pm 0.05$ \\
\hline
\end{tabular}

Table 20. Recommended Desorption $K_{d}$ Values for Uranium to Use in Remediation Effectiveness Predictions

\begin{tabular}{||c|c|c|c||}
\hline & Ringold Unit E & $\begin{array}{c}\text { Ferric Oxide/Clay Rich } \\
\text { Coated Gravel (Ringold) }\end{array}$ & $\begin{array}{c}\text { Ringold Lower Mud } \\
\text { Unit }\end{array}$ \\
\hline $\mathrm{K}_{\mathrm{d}}$ Values & $\mathrm{mL} / \mathrm{g}$ & $\mathrm{mL} / \mathrm{g}$ & $\mathrm{mL} / \mathrm{g}$ \\
\hline $\mathrm{U}(\mathrm{VI})$ & $2.5 \pm 1$ & $8.0 \pm 3$ & $5 \pm 2$ \\
\hline
\end{tabular}




\subsection{References}

Anderson BJ and EA Jenne. 1970. "Free-Iron and Manganese Oxide Content of Reference Clays.” Soil Science, 109: 163-169.

ASTM D422-63. 1986. "Standard Test Method for Particle-Size Analysis of Soils." In: Annual Book of ASTM Standards. American Society of Testing Material, Philadelphia, Pennsylvania.

ASTM D2216-98. 1986. "Laboratory Determination of Water (Moisture) Content of Soil, Rock, and Soil-Aggregate Mixtures.” In: Annual Book of ASTM Standards. American Society of Testing Material, Philadelphia, Pennsylvania.

ASTM E1915-01. 2001. "Standard Test Methods for Analysis of Metal Bearing Ores and Related Materials by Combustion Infrared Absorption Spectrometry." In: Annual Book of ASTM Standards. American Society of Testing Material, Philadelphia, Pennsylvania.

Bargar JR, R Reitmeyer, JJ Lenhart, and JA Davis. 2000. “Characterization of U(VI)-Carbonate Ternary Complexes on Hematite: EXAFS and Electrophoretic Mobility Measurements." Geochim. Cosmochim. Acta 64: 2737-2749.

Barney GS. 1978. Variables Affecting Sorption and Transport of Radionuclides in Hanford Subsoils. RHO-SA-87, Rockwell Hanford Operations, Richland, Washington.

Bjornstad BN. 1984. Suprabasalt Stratigraphy Within and Adjacent to the Reference Repository Location. SD-BWI-DP-039, Rockwell Hanford Operations, Richland, Washington.

Bjornstad BN. 1990. Geohydrology of the 218-W-5 Burial Ground. PNL-7336, Pacific Northwest Laboratory, Richland, Washington.

Bjornstad BN, KR Fecht, and CJ Pluhar. 2001. "Long History of Pre-Wisconsin, Ice-Age, Cataclysmic Floods: Evidence from Southeastern Washington State.” J. of Geology. 109: 695-713.

Bjornstad BN, GV Last, SP Reidel, DG Horton, KR Fecht, GA Smith, and KA Lindsey. 2002. "Characterization and Proposed Formalization (Hanford formation) for Ice Age Flood Deposits Within the Pacific Northwest." In: Geological Society of America, Abstracts with Programs, p. A-24, Geological Society of America, Boulder, Colorado.

Bjornstad BN, JP McKinley, TO Stevens, SA Rawson, JK Fredrickson, and PE Long. 1994. "Generation of Hydrogen Gas as a Result of Drilling Within the Saturated Zone." Groundwater Monitoring and Remediation, 14(4): 140-147.

Brown DJ. 1959. Subsurface Geology of the Hanford Separation Areas. HW-61780, General Electric Company, Richland, Washington. 
Brunauer S, PH Emmett, and E Teller. 1938. "Adsorption of Gases in Multimolecular Layers." J. Am. Chem. Soc., 60: 309-319.

Chao TT and L Zhou. 1983. "Extraction Techniques for Selective Dissolution of Amorphous Iron Oxides from Soils and Sediments." Soil Sci. Soc. Am. J. 47: 225-232.

Connelly MP, BH Ford, and JV Borghese. 1992. Hydrogeologic Model for the 200 West Groundwater Aggregate Area. WHC-SD-EN-TI-014, Westinghouse Hanford Company, Richland, Washington.

Davis JA, DE Meece, M Kohler, and GP Curtis. 2004. "Approaches to Surface Complexation Modeling of Uranium(VI) Adsorption on Aquifer Sediments." Geochim. Cosmochim. Acta 68: 3621-3641.

Delaney, CD, KA Lindsey, and SP Reidel. 1991. Geology and Hydrology of the Hanford Site: A Standardized Text for Use in Westinghouse Hanford Company Documents and Reports. WHC-SC-ER-TI-003, Westinghouse Hanford Company, Richland, Washington.

DOE. 2002. Sampling and Analysis Plan for the 200-UP-1 Groundwater Monitoring Well Network. DOE/RL-2002-10 Rev. 0, U.S. Department of Energy, Richland, Washington.

DOE. 1992. Hanford Site Background: Part 2, Soil Background for Radionuclides. DOE/RL-96-12, U.S. Department of Energy, Richland, Washington.

Dong D, YM Nelson, LW Lion, ML Shuler, and WC Ghiorse. 2000. “Adsorption of $\mathrm{Pb}$ and $\mathrm{Cd}$ onto Metal Oxides and Organic Material in Natural Surface Coatings as Determined by Selective Extractions: New Evidence for the Importance of Mn and Fe Oxides.” Water Resources 34(2): 427-436.

EPA (U.S. Environmental Protection Agency). 2000a. "Method 6010B. Inductively Coupled Plasma-Atomic Emission Spectrometry.” In: Test Methods for Evaluating Solid Waste, Physical/Chemical Methods. EPA Publication SW-846. Available at http://www.epa.gov/epaoswer/hazwaste/test/sw846.htm

EPA (U.S. Environmental Protection Agency). 2000b. "Method 6020. Inductively Coupled Plasma-Mass Spectrometry." In: Test Methods for Evaluating Solid Waste, Physical/Chemical Methods. EPA Publication SW-846. Available at http://www.epa.gov/epaoswer/hazwaste/test/sw846.htm

EPA (U.S. Environmental Protection Agency). 2000c. "Method 9060. Total Organic Carbon." In: Test Methods for Evaluating Solid Waste, Physical/Chemical Methods. EPA Publication SW-846. Available at http://www.epa.gov/epaoswer/hazwaste/test/sw846.htm 
EPA (U.S. Environmental Protection Agency. 1999. Understanding Variation in Partition Coefficient,Kd, Values: Volume I. The Kd Model, Methods of Measurement, and Application of Chemical Reaction Codes. EPA 402-R-99-004A, prepared by KM Krupka, DI Kaplan, G Whelan, RJ Serne and SV Mattigod at Pacific Northwest National Laboratory for the U.S. Environmental Protection Agency, Washington, D.C.

EPA (U.S. Environmental Protection Agency). 1984. Test Method for the Determination of Inorganic Anions in Water by Ion Chromatography. EPA Method 300.0A. EPA-600/4-84-017, U.S. Environmental Protection Agency, Washington, D.C.

Fecht KR and DC Weekes. 1996. Geologic Field Inspection of the Sedimentary Sequence at the Environmental Restoration Disposal Facility. BHI-00230, Bechtel Hanford, Inc., Richland, Washington.

Gibbs CR. 1976. "Characterization and Application of Ferrozine Iron Reagent as a Ferrous Indicator." Analytical Chemistry 48(8): 1197-1201.

Gregg SJ and KSW Sing. 1982. Adsorption, Surface Area, and Porosity. Second edition, Academic Press, Orlando, Florida, 303 pp.

Hartman MJ, LF Morasch, and WD Webber (eds.). 2005. Hanford Site Groundwater Monitoring for Fiscal Year 2004. PNNL-15070, Pacific Northwest National Laboratory, Richland, Washington.

Kaplan DI, RJ Serne, AT Owen, JA Conca, TW Wietsma, and TL Gervais. 1996. Radionuclide Adsorption Distribution Coefficients Measured in Hanford Sediments for the Low Level Waste Performance Assessment Project. PNNL-11385, Pacific Northwest National Laboratory, Richland, Washington.

Kaplan DI, KE Parker, and IV Kutnyakov. 1998. Radionuclide Distribution Coefficients for Sediments Collected from Borehole 299-E17-21: Final report for Subtask 1a. PNNL-11966, Pacific Northwest National Laboratory, Richland, Washington.

Kaplan DI, RJ Serne, KE Parker, and IV Kutnyanov. 2000. "Iodide Sorption to Subsurface Sediments and Illitic Minerals." Environ. Sci. Technol. 34: 399-405.

Kohler M, GP Curtis, DE Meece, and JA Davis. 2004. "Methods for Estimating Adsorbed Uranium(VI) and Distribution Coefficients of Contaminated Sediments." Environ. Sci. Technol. 38:240-247.

Krupka KM, RJ Serne, and DI Kaplan. 2004. Geochemical Data Package for the 2005 Hanford Integrated Disposal Facility Performance Assessment. PNNL-13037 Rev. 2, Pacific Northwest National Laboratory, Richland, Washington. 
Last GV, ed. 1994. 216-U-10 Pond and 216-Z19 Ditch Characterization Studies. WHC-EP-0707 (formerly RHO-ST-45), Westinghouse Hanford Company, Richland, Washington.

Lindsey KA. 1995. Miocene-to Pliocene-Aged Suprabasalt Sediments of the Hanford Site, South-Central Washington. BHI-00184, Bechtel Hanford Inc., Richland, Washington.

Lindsey KA. 1996. Miocene-Pliocene Ringold Formation and Associated Deposits of the Ancestral Columbia River System, South-Central Washington and North-Central Oregon, Washington. Department of Natural Resources, Division of Geology and Earth Resources OpenFile Report 96-8, Olympia, Washington, 45 pp.

Lindsey KA, BN Bjornstad, JW Lindberg, and KM Hoffman. 1992a. Geologic Setting of the 200 East Area: An Update. WHC-SD-EN-TI-012, Westinghouse Hanford Company, Richland, Washington.

Lindsey KA, MP Connelly, and BN Bjornstad. 1992b. Geologic Setting of the 200 West AreaAn Update. WHC-SD-EN-TI-008, Westinghouse Hanford Company, Richland, Washington.

Lindsey KA, SP Reidel, KR Fecht, JL Slate, AG Law, and AM Tallman. 1994. "Geohydrologic Setting of the Hanford Site, South-Central Washington." In: Geologic Field Trips in the Pacific Northwest, DA Swanson and RA Hagerud, eds., Geological Society of America Meeting, Geological Society of America, Boulder, Colorado. pp. 1C-1 to 1C-16.

Loeppert RH and WP Inskeep. 1996. "Iron.” In: Methods of Soil Analysis, Part 3-Chemical Methods, DL Sparks, Soil Science Society of America, Inc., Madison, Wisconsin, pp. 639-664.

McAlister JJ and BJ Smith. 1999. "Selectivity of Ammonium Acetate, Hydroxylamine Hydrochloride, and Oxalic Ascorbic Acid Solutions for the Speciation of Fe, Mn, Zn, Cu, Ni, and Al in Early Tertiary Paleosols." Microchem. Journal, 63: 415-426.

Myers D. 2005. Field Investigation Report for Waste Management Areas T and TX-TY. RPP23752, Rev. 0, CH2M HILL Hanford Group, Richland, Washington.

Myers CW and SM Price (eds.). 1979. Geologic Studies of the Columbia Plateau - A Status Report. RHO-BWI-ST-4, Rockwell Hanford Operations, Richland, Washington.

Parker JC and MT Van Genuchten. 1984. Determining Transport Parameters from Laboratory and Field Tracer Experiments. Report Bull. 84-3, Virginia Agricultural Experiment Station, Blacksburg, Virginia.

PNNL. 1990. Procedures for Groundwater Investigations. PNL-MA-567-DO-1, Pacific Northwest Laboratory, Richland, Washington. 
PNNL. 1997. Gamma Energy Analysis Operation and Instrument Verification Using the Genie2000 ${ }^{T M}$ Support Software. PNNL-RRL-01, Pacific Northwest National Laboratory, Richland, Washington.

Reidel SP, KA Lindsey, and KR Fecht. 1992. Field Trip Guide to the Hanford Site. WHC-MR_0391, Westinghouse Hanford Company, Richland, Washington.

Routson RC, RE Wildung, and RJ Serne. 1973. "A Column Cation-Exchange-Capacity Procedure for Low Exchange Capacity Sands.” Soil Sci. 115(2):107-112.

Schecher WD and DC McAvoy. 1994. Mineql+ User's Manual. Environmental Research Software, Hallowell, Maine. http://www.mineql.com.

Serne RJ, CF Brown, HT Schaef, EM Pierce, MJ Lindberg, Z Wang, PL Gassman, and JG Catalano. 2002. 300 Area Uranium Leach and Adsorption Project. PNNL-14022, Pacific Northwest National Laboratory, Richland, Washington.

Slate JL. 2000. Nature and Variability of the Plio-Pleistocene Unit in the 200 West Area of the Hanford Site. BHI-01203, Rev. 0, Bechtel Hanford, Inc., Richland, Washington.

Tallman AM, JT Lillie, and KR Fecht. 1981. "Suprabasalt Sediment of the Cold Creek Syncline Area." In Subsurface Geology of the Cold Creek Syncline, CW Myers and SM Price, eds., RHO-BWI-ST-14, Rockwell Hanford Operations, Richland, Washington.

Tallman, AM, KR Fecht, MC Marratt, and GV Last. 1979. Geology of the Separations Areas, Hanford Site, South-Central Washington. RHO-ST-23, Rockwell Hanford Operations, Richland, Washington.

USGS (United States Geological Survey). 2004. "Alkalinity and Acid Neutralizing Capacity." National Field Manual for the Collection of Water-Quality Data, Second edition., SA Rounds and FD Wilde, eds. March 23, 2004. Available URL: http://water.usgs.gov/owq/FieldManual/Chapter6/section6.6/html/section6.6.htm

Webb PA and C Orr. 1997. Analytical Methods in Fine Particle Technology. Micromeritics Instrument Corporation, Norcross, Georgia, 301 pp.

Williams BA, BN Bjornstad, R Schalla, and WD Webber. 2002. Revised Hydrogeology for the Suprabasalt Aquifer System, 200-West Area and Vicinity, Hanford Site, Washington. PNNL-13858, Pacific Northwest National Laboratory, Richland, Washington.

Wood MI, R Schalla, BN Bjornstad, and FN Hodges. 2001. Subsurface Conditions Description of the T and TX-TY Waste Management Areas. RPP-7123, Rev. 0, CH2MHill Hanford Group, Inc., Richland, Washington. 
Zachara JM, JA Davis, JP McKinley, DM Wellman, C Liu, N Qafoku, and SB Yabusaki. 2005. Uranium Geochemistry in Vadose Zone and Aquifer Sediments from the 300 Area Uranium Plume. PNNL-15121, Pacific Northwest National Laboratory, Richland, Washington. 


\section{Appendix}

Additional Data for 200-UP-1 Samples 


\section{Appendix}

\section{Additional Data for 200-UP-1 Samples}

Table A1. ICP-OES for Cations Analyses of 200-UP-1 Groundwater Samples

\begin{tabular}{|c|c|c|c|c|c|c|c|c|c|c|c|}
\hline Input & Input & Input & Input & Input & Input & Input & Input & Input & Input & Input & Input \\
\hline Analyte: & $\mathrm{Al}$ & As & B & $\mathrm{Ba}$ & $\mathrm{Be}$ & $\mathrm{Bi}$ & $\mathrm{Ca}$ & $\mathrm{Cd}$ & Co & $\mathrm{Cr}$ & $\mathrm{Cu}$ \\
\hline Instrument EQL: & 50 & 50 & 1,000 & 2.5 & 2.5 & 50 & 25,000 & 2.5 & 2.5 & 12.5 & 10 \\
\hline Sample ID & $\mu \mathrm{g} / \mathrm{L}$ & $\mu \mathrm{g} / \mathrm{L}$ & $\mu \mathrm{g} / \mathrm{L}$ & $\mu \mathrm{g} / \mathrm{L}$ & $\mu \mathrm{g} / \mathrm{L}$ & $\mu \mathrm{g} / \mathrm{L}$ & $\mu \mathrm{g} / \mathrm{L}$ & $\mu \mathrm{g} / \mathrm{L}$ & $\mu \mathrm{g} / \mathrm{L}$ & $\mu \mathrm{g} / \mathrm{L}$ & $\mu \mathrm{g} / \mathrm{L}$ \\
\hline B19J01 (C4298) & (25) & (6) & (268) & 72 & ND & ND & 36,787 & ND & 7 & ND & (1) \\
\hline B19J05 (C4299) & 1,930 & ND & (222) & 184 & ND & ND & 67,580 & ND & ND & 29 & 26 \\
\hline B19J06 (C4299) & ND & (12) & (198) & 82 & ND & (2) & 25,971 & ND & ND & ND & (2) \\
\hline B19J07 (C4299) & ND & (5) & (206) & 71 & ND & ND & $(22,146)$ & ND & ND & ND & (2) \\
\hline B19J08 (C4299) & 226 & (5) & (179) & 106 & ND & ND & 49,292 & ND & ND & ND & (1) \\
\hline B19J09 (C4299) & ND & (10) & (177) & 73 & ND & ND & 40,187 & ND & ND & ND & (1) \\
\hline B19J10 (C4300) & ND & (10) & (166) & 127 & ND & ND & 136,811 & ND & ND & ND & (2) \\
\hline
\end{tabular}


Table A1. ICP-OES for Cations Analyses of 200-UP-1 Groundwater Samples (cont.)

\begin{tabular}{|c|c|c|c|c|c|c|c|c|c|c|c|}
\hline Input & Input & Input & Input & Input & Input & Input & Input & Input & Input & Input & Input \\
\hline Analyte: & $\mathrm{Fe}$ & $\begin{array}{c}\mathrm{K} \\
766.490\end{array}$ & $\mathrm{Li}$ & $\begin{array}{c}\mathrm{Mg} \\
285.213\end{array}$ & $\mathrm{Mn}$ & Mo & $\mathrm{Ni}$ & $\mathrm{P}$ & $\mathrm{Pb}$ & $\mathrm{Se}$ & $\begin{array}{c}\mathrm{Sr} \\
407.771\end{array}$ \\
\hline Wavelength: & 273.955 & $\mathrm{R}$ & 610.362 & $\mathrm{R}$ & 257.610 & 202.031 & 231.604 & 213.617 & 220.353 & 196.026 & $\mathrm{R}$ \\
\hline Sample EQL: & 10 & 62,500 & 5,000 & 1,000 & 25 & 25 & 25 & 125 & 25 & 50 & 1 \\
\hline Sample ID & $\mu \mathrm{g} / \mathrm{L}$ & $\mu \mathrm{g} / \mathrm{L}$ & $\mu \mathrm{g} / \mathrm{L}$ & $\mu \mathrm{g} / \mathrm{L}$ & $\mu \mathrm{g} / \mathrm{L}$ & $\mu \mathrm{g} / \mathrm{L}$ & $\mu \mathrm{g} / \mathrm{L}$ & $\mu \mathrm{g} / \mathrm{L}$ & $\mu \mathrm{g} / \mathrm{L}$ & $\mu \mathrm{g} / \mathrm{L}$ & $\mu \mathrm{g} / \mathrm{L}$ \\
\hline B19J01(C4298) & 83 & $(7,165)$ & (22) & 12,313 & 551 & 73 & (5) & (48) & ND & 67 & 170 \\
\hline B19J05(C4299) & 6,674 & $(9,979)$ & (30) & 21,078 & 623 & (14) & (21) & 338 & ND & (40) & 330 \\
\hline B19J06(C4299) & (1) & $(6,512)$ & (22) & 6,218 & 245 & 172 & (3) & (57) & ND & 59 & 126 \\
\hline B19J07(C4299) & (1) & $(7,112)$ & (27) & 6,552 & 96 & 95 & (3) & (53) & ND & 51 & 101 \\
\hline B19J08(C4299) & 364 & $(6,308)$ & (21) & 15,590 & 250 & (15) & (4) & (54) & ND & 71 & 194 \\
\hline B19J09(C4299) & 32 & $(6,905)$ & (23) & 13,455 & 649 & 41 & (3) & (52) & ND & 59 & 166 \\
\hline $\mathrm{B} 19 \mathrm{~J} 10(\mathrm{C} 4300)$ & 32 & $(8,168)$ & (43) & 39,334 & 26 & (1) & (4) & (61) & ND & 117 & 566 \\
\hline
\end{tabular}


Table A1. ICP-OES for Cations Analyses of 200-UP-1 Groundwater Samples (cont.)

\begin{tabular}{||ccccccccc||}
\hline Input & Input & Input & Input & Input & Input & Input & Input & Input \\
\hline \hline Analyte: & $\mathrm{Tl}$ & $\mathrm{V}$ & $\mathrm{Zn}$ & $\mathrm{Na}$ & $\mathrm{Si}$ & $\mathrm{S}$ & $\mathrm{Ti}$ & $\mathrm{Zr}$ \\
& & & & 589.592 & & & & \\
Wavelength: & 190.801 & 290.880 & 213.857 & $\mathrm{R}$ & 288.158 & 180.669 & 334.940 & 343.823 \\
Instrument EQL: & 100 & 50 & 50 & 100 & 5,000 & 100 & 5 & 2.5 \\
Sample EQL: & 100 & 50 & 50 & 100 & 5,000 & 100 & 5 & 2.5 \\
Sample ID & $\mu \mathrm{g} / \mathrm{L}$ & $\mu \mathrm{g} / \mathrm{L}$ & $\mu \mathrm{g} / \mathrm{L}$ & $\mu \mathrm{g} / \mathrm{L}$ & $\mu \mathrm{g} / \mathrm{L}$ & $\mu \mathrm{g} / \mathrm{L}$ & $\mu \mathrm{g} / \mathrm{L}$ & $\mu \mathrm{g} / \mathrm{L}$ \\
\hline \hline & & & & & & & & \\
B19J01(C4298) & $(5)$ & $\mathrm{ND}$ & $(29)$ & 18,567 & 14,341 & 8,903 & $(2)$ & $\mathrm{ND}$ \\
B19J02(C4298) & $(4)$ & $\mathrm{ND}$ & $(25)$ & 19,265 & 17,403 & 9,056 & $\mathrm{ND}$ & $\mathrm{ND}$ \\
B19J03(C4298) & $(1)$ & $\mathrm{ND}$ & $(23)$ & 19,408 & 19,333 & 8,732 & $\mathrm{ND}$ & $\mathrm{ND}$ \\
B19J05(C4299) & $(5)$ & $\mathrm{ND}$ & 435 & 24,530 & 19,038 & 14,978 & 13 & $\mathrm{ND}$ \\
B19J06(C4299) & $(21)$ & $\mathrm{ND}$ & $(8)$ & 22,559 & $(3,400)$ & 8,584 & $\mathrm{ND}$ & $\mathrm{ND}$ \\
B19J07(C4299) & $(20)$ & $\mathrm{ND}$ & $(13)$ & 22,039 & 5,878 & 11,293 & $\mathrm{ND}$ & $\mathrm{ND}$ \\
B19J08(C4299) & $(9)$ & ND & $(33)$ & 17,207 & 22,987 & 9,940 & 10 & ND \\
B19J09(C4299) & $(8)$ & ND & 420 & 19,746 & 13,088 & 8,361 & ND & ND \\
B19J10(C4300) & ND & ND & 163 & 29,259 & 24,091 & 18,738 & ND & ND \\
B19J12(C4300) & ND & ND & $(31)$ & 15,482 & 21,590 & 8,370 & ND & ND \\
B19J14(C4300) & $(6)$ & $(3)$ & 135 & 16,535 & 23,463 & 8,257 & ND & ND \\
& & & & & & & & \\
\hline
\end{tabular}


Table A2. ICP-OES Cation Analysis Results for 200-UP-1 Samples (1:1 Water Extracts)

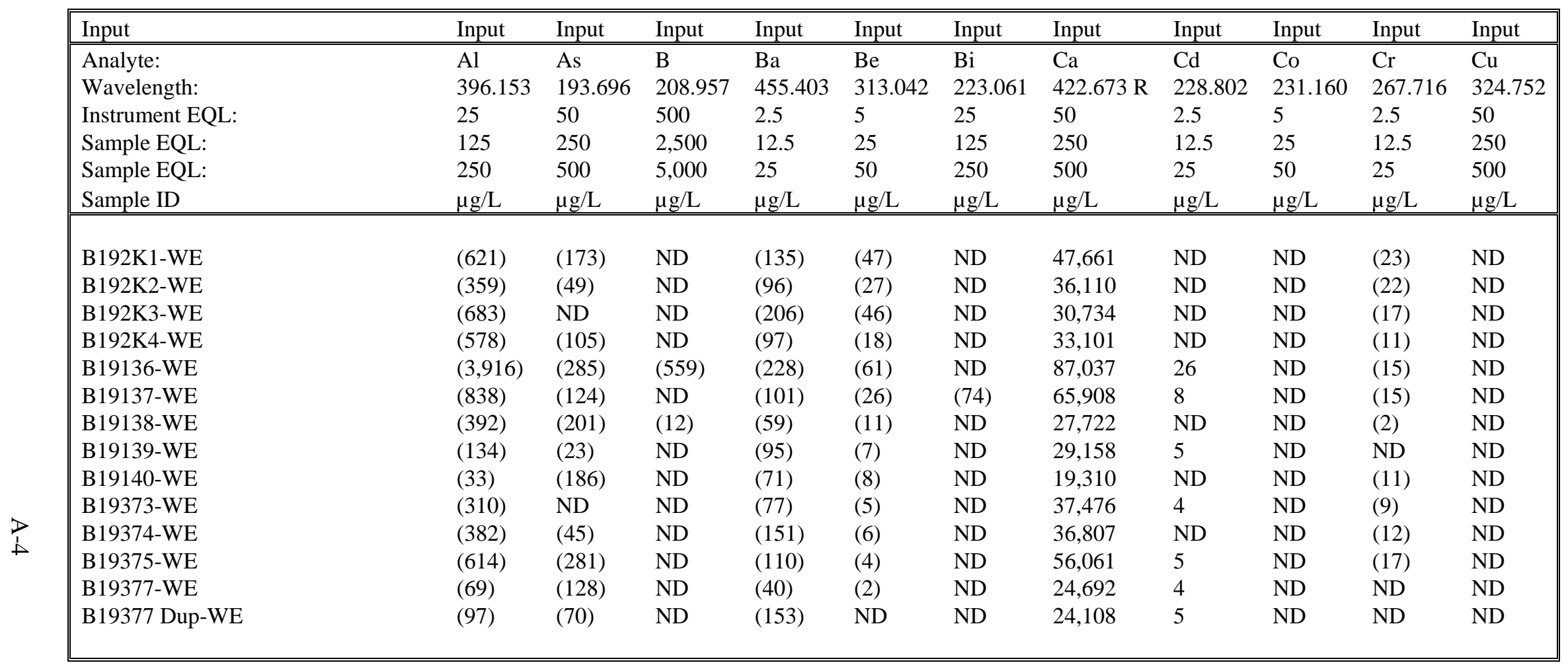

* Concentration values of 1:1 water extracts were already dilution corrected. 
Table A2. ICP-OES Cation Analysis Results for 200-UP-1 Samples (1:1 Water Extracts) (cont.)

\begin{tabular}{|c|c|c|c|c|c|c|c|c|c|c|c|}
\hline Input & Input & Input & Input & Input & Input & Input & Input & Input & Input & Input & Input \\
\hline Analyte: & $\overline{\mathrm{Fe}}$ & 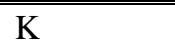 & $\overline{\mathrm{Li}}$ & $\mathrm{Mg}$ & $\mathrm{Mn}$ & Mo & $\mathrm{Ni}$ & $\bar{P}$ & $\mathrm{~Pb}$ & $\overline{\mathrm{Se}}$ & $\mathrm{Sr}$ \\
\hline Wavelength: & 259.939 & $766.490 \mathrm{R}$ & 610.362 & 285.213 & 257.610 & 202.031 & 231.604 & 213.617 & 220.353 & 203.985 & 407.771 \\
\hline Instrument EQL: & 25 & 250 & 10 & 5 & 2.5 & 25 & 5 & 25 & 25 & 50 & 1 \\
\hline Sample EQL: & 125 & 1,250 & 50 & 25 & 12.5 & 125 & 25 & 125 & 125 & 250 & 5 \\
\hline Sample EQL: & 250 & 2,500 & 100 & 50 & 25 & 250 & 50 & 250 & 250 & 500 & 10 \\
\hline Sample ID & $\mu \mathrm{g} / \mathrm{L}$ & $\mu \mathrm{g} / \mathrm{L}$ & $\mu \mathrm{g} / \mathrm{L}$ & $\mu \mathrm{g} / \mathrm{L}$ & $\mu \mathrm{g} / \mathrm{L}$ & $\mu \mathrm{g} / \mathrm{L}$ & $\mu \mathrm{g} / \mathrm{L}$ & $\mu \mathrm{g} / \mathrm{L}$ & $\mu \mathrm{g} / \mathrm{L}$ & $\mu \mathrm{g} / \mathrm{L}$ & $\mu \mathrm{g} / \mathrm{L}$ \\
\hline B192K1-WE & (466) & 44,871 & ND & 17,202 & 469 & (295) & (227) & $(2,110)$ & (212) & (299) & 247 \\
\hline B192K2-WE & (435) & 24,204 & ND & 13,202 & 359 & (89) & (146) & $(1,221)$ & (96) & ND & 176 \\
\hline B192K3-WE & (794) & 34,266 & 38 & 12,322 & 84 & (394) & (196) & $(2,926)$ & (141) & (402) & 175 \\
\hline B192K4-WE & $(441)$ & 23,272 & 8 & 12,612 & 358 & $(1,108)$ & (67) & $(850)$ & (60) & (137) & 168 \\
\hline B19136-WE & $(3,683)$ & 77,020 & 56 & 32,410 & 208 & $(622)$ & (439) & $(3,571)$ & (62) & $\mathrm{ND}$ & 454 \\
\hline B19137-WE & (744) & 37,310 & 11 & 21,901 & 254 & (419) & (205) & $(1,216)$ & (151) & ND & 301 \\
\hline B19138-WE & (392) & 16,230 & ND & 10,422 & 316 & (58) & (83) & (743) & $\mathrm{ND}$ & ND & 127 \\
\hline B19139-WE & (182) & 15,447 & ND & 10,494 & 79 & (36) & (60) & $(762)$ & (16) & ND & 125 \\
\hline B19140-WE & (197) & 25,869 & ND & 7,374 & 20 & (7) & (81) & $(2,122)$ & ND & ND & 103 \\
\hline B19373-WE & (401) & 23,038 & 23 & 12,495 & 99 & $(561)$ & (52) & (874) & (34) & ND & 184 \\
\hline B19374-WE & (295) & 29,281 & ND & 12,966 & 144 & $(1,062)$ & (69) & $(1,054)$ & ND & ND & 176 \\
\hline B19375-WE & (599) & 28,824 & 61 & 19,531 & 197 & (277) & (145) & $(1,621)$ & (124) & ND & 245 \\
\hline B19377-WE & (106) & 16,547 & ND & 9,511 & 15 & ND & (39) & (602) & $\mathrm{ND}$ & ND & 112 \\
\hline B19377 Dup-WE & (150) & 19,081 & ND & 9,325 & 17 & ND & (31) & (595) & ND & ND & 116 \\
\hline
\end{tabular}

* Concentration values of 1:1 water extracts were already dilution corrected. 
Table A2. ICP-OES Cation Analysis Results for 200-UP-1 Samples (1:1 Water Extracts) (cont.)

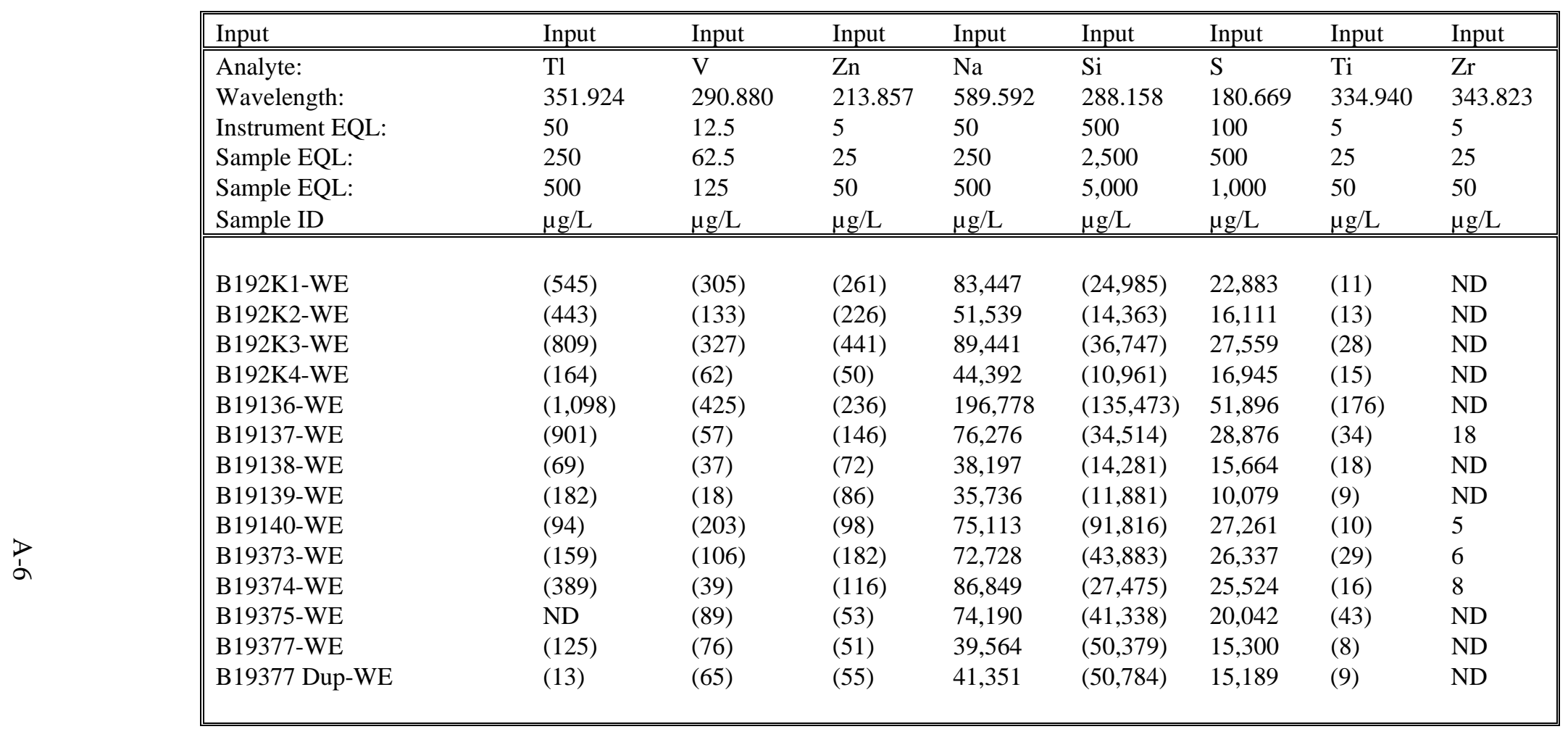

* Concentration values of 1:1 water extracts were already dilution corrected. 
Table A3. ICP-OES Cation Analysis Results for 200-UP-1 Pore Water

\begin{tabular}{|c|c|c|c|c|c|c|c|c|c|c|c|c|c|}
\hline Input & Input & Input & Input & Input & Input & Input & Input & Input & Input & Input & Input & Input & Input \\
\hline Analyte: & $\mathrm{Al}$ & As & $\mathrm{B}$ & $\mathrm{Ba}$ & $\mathrm{Be}$ & $\mathrm{Bi}$ & $\mathrm{Ca}$ & $\mathrm{Cd}$ & Co & $\mathrm{Cr}$ & $\mathrm{Cu}$ & $\mathrm{Fe}$ & $\mathrm{K}$ \\
\hline $\begin{array}{l}\text { Wavelength: } \\
\text { Instrument }\end{array}$ & 396.153 & 193.696 & 208.957 & 455.403 & 313.042 & 223.061 & 422.673 & 228.802 & 228.616 & 267.716 & 324.752 & 259.939 & 766.490 \\
\hline $\begin{array}{l}\text { EQL: } \\
\text { Sample }\end{array}$ & 50 & 100 & 25 & 2.5 & 2.5 & 50 & 50 & 2.5 & 5 & 2.5 & 25 & 25 & 1,250 \\
\hline $\begin{array}{l}\text { EQL: } \\
\text { Sample ID } \\
\end{array}$ & $\begin{array}{r}500 \\
\mu \mathrm{g} / \mathrm{L} \\
\end{array}$ & $\begin{array}{l}1,000 \\
\mu \mathrm{g} / \mathrm{L}\end{array}$ & $\begin{array}{r}250 \\
\mu \mathrm{g} / \mathrm{L} \\
\end{array}$ & $\begin{array}{r}25 \\
\mu \mathrm{g} / \mathrm{L} \\
\end{array}$ & $\begin{array}{r}25 \\
\mu \mathrm{g} / \mathrm{L} \\
\end{array}$ & $\begin{array}{r}500 \\
\mu \mathrm{g} / \mathrm{L} \\
\end{array}$ & $\begin{array}{r}500 \\
\mu \mathrm{g} / \mathrm{L} \\
\end{array}$ & $\begin{array}{r}25 \\
\mu \mathrm{g} / \mathrm{L} \\
\end{array}$ & $\begin{array}{r}50 \\
\mu \mathrm{g} / \mathrm{L} \\
\end{array}$ & $\begin{array}{r}25 \\
\mu \mathrm{g} / \mathrm{L} \\
\end{array}$ & $\begin{array}{r}250 \\
\mu \mathrm{g} / \mathrm{L} \\
\end{array}$ & $\begin{array}{r}250 \\
\mu \mathrm{g} / \mathrm{L} \\
\end{array}$ & $\begin{array}{c}12,500 \\
\mu \mathrm{g} / \mathrm{L} \\
\end{array}$ \\
\hline B192K1 & ND & (17) & (83) & 54 & (1) & ND & 28,066 & ND & ND & (2) & (27) & (25) & $(4,946)$ \\
\hline B192K2 & (4) & (1) & (85) & 46 & (1) & ND & 21,943 & ND & (2) & (2) & (47) & (13) & $(5,453)$ \\
\hline B192K3 & ND & (4) & (72) & 42 & (1) & (8) & 19,542 & ND & ND & (3) & (16) & (3) & $(3,451)$ \\
\hline B192K4 & (35) & ND & (105) & 58 & (1) & (27) & 22,319 & ND & ND & (1) & (22) & (7) & $(6,600)$ \\
\hline B19136 & ND & ND & (63) & 27 & (1) & (8) & 12,898 & ND & ND & (4) & (22) & (98) & $(4,257)$ \\
\hline B19137 & (380) & ND & (52) & 46 & (1) & ND & 22,224 & ND & ND & (3) & (22) & 1,104 & $(4,826)$ \\
\hline B19138 & ND & ND & (39) & 69 & (1) & ND & 35,679 & ND & (2) & (3) & (6) & (4) & $(4,615)$ \\
\hline B19139 & ND & ND & (174) & 49 & (2) & (1) & 25,777 & (1) & (3) & (4) & (48) & (8) & $(5,578)$ \\
\hline B19140 & ND & ND & $(87)$ & (2) & (1) & (8) & 1,056 & ND & (1) & (3) & (15) & (5) & ND \\
\hline B19373 & ND & ND & (83) & 57 & (1) & ND & 47,745 & ND & ND & (3) & (5) & (6) & $(6,017)$ \\
\hline B19374 & (10) & ND & (91) & 50 & (1) & ND & 25,651 & ND & (2) & (1) & ND & (4) & $(5,218)$ \\
\hline B19375 & ND & ND & (73) & 59 & (1) & ND & 34,866 & ND & (1) & (3) & ND & (4) & $(4,534)$ \\
\hline B19377 & ND & (37) & (34) & 38 & (1) & ND & 26,663 & (1) & ND & ND & (6) & (2) & $(4,344)$ \\
\hline
\end{tabular}


Table A3. ICP-OES Cation Analysis Results for 200-UP-1 Pore Water (cont.)

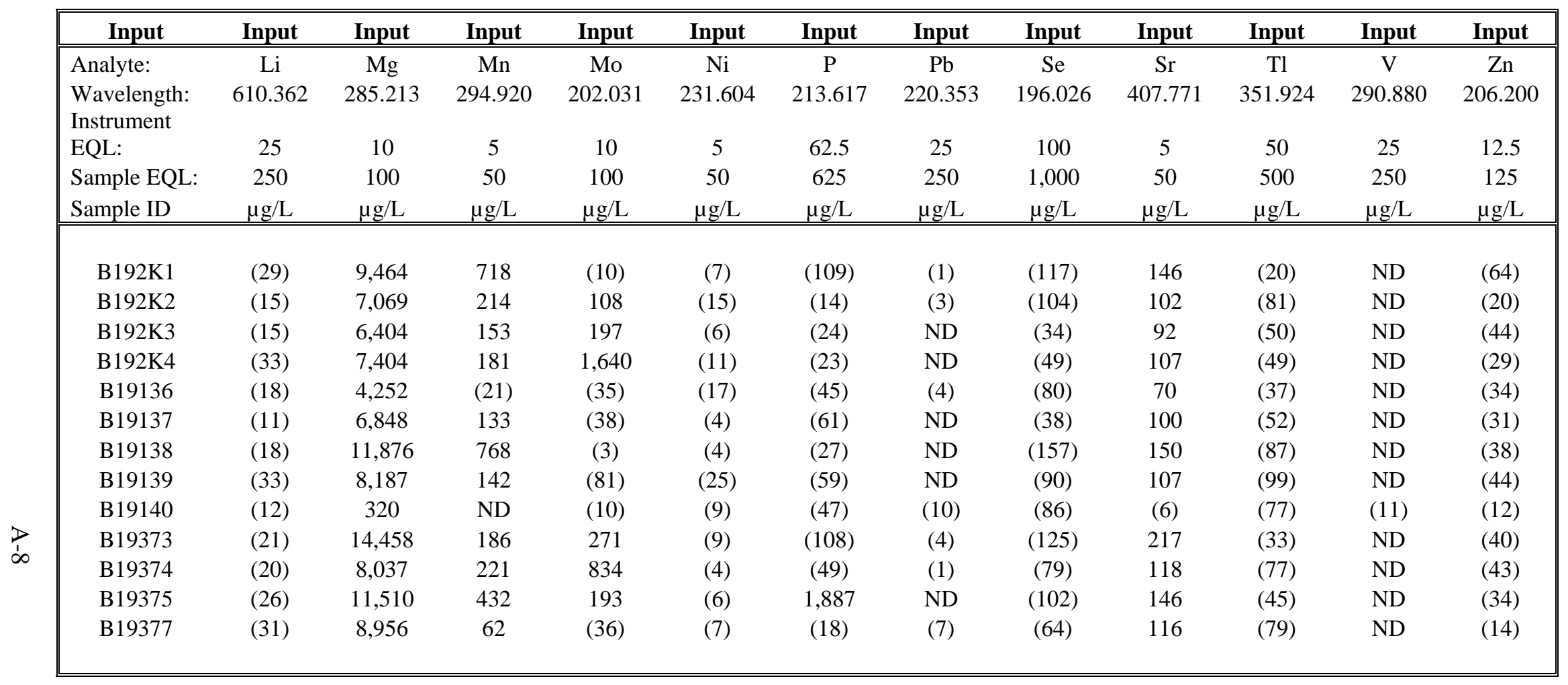


Table A3. ICP-OES Cation Analysis Results for 200-UP-1 Pore Water (cont.)

\begin{tabular}{||cccccc||}
\hline Input & Input & Input & Input & Input & Input \\
\hline \hline Analyte: & $\mathrm{Na}$ & $\mathrm{Si}$ & $\mathrm{S}$ & $\mathrm{Ti}$ & $\mathrm{Zr}$ \\
Wavelength: & 589.592 & 251.611 & 180.669 & 334.940 & 343.823 \\
Instrument & & & & & \\
EQL: & 50 & 500 & 200 & 12.5 & 5 \\
Sample EQL: & 500 & 5,000 & 2,000 & 125 & 50 \\
Sample ID & $\mu \mathrm{g} / \mathrm{L}$ & $\mu \mathrm{g} / \mathrm{L}$ & $\mu \mathrm{g} / \mathrm{L}$ & $\mu \mathrm{g} / \mathrm{L}$ & $\mu \mathrm{g} / \mathrm{L}$ \\
\hline \hline \multicolumn{7}{r}{} & & & & \\
B192K1 & 22,681 & $(3,368)$ & 10,594 & $\mathrm{ND}$ & $\mathrm{ND}$ \\
B192K2 & 18,365 & $(3,937)$ & 9,165 & $\mathrm{ND}$ & $\mathrm{ND}$ \\
B192K3 & 18,006 & $(3,704)$ & 11,439 & $\mathrm{ND}$ & $\mathrm{ND}$ \\
B192K4 & 18,703 & $(3,069)$ & 10,367 & $\mathrm{ND}$ & $\mathrm{ND}$ \\
B19136 & 21,875 & 5,448 & 9,364 & $\mathrm{ND}$ & $\mathrm{ND}$ \\
B19137 & 16,888 & $(4,498)$ & 11,292 & $(39)$ & $(1)$ \\
B19138 & 16,579 & $(3,934)$ & 9,490 & $\mathrm{ND}$ & $\mathrm{ND}$ \\
B19139 & 14,921 & $(4,394)$ & 4,269 & $\mathrm{ND}$ & $\mathrm{ND}$ \\
B19140 & 1,001 & $(631)$ & $(665)$ & $(1)$ & $\mathrm{ND}$ \\
B19373 & 31,315 & 7,872 & 18,408 & ND & $\mathrm{ND}$ \\
B19374 & 29,303 & $(4,161)$ & 15,597 & ND & ND \\
B19375 & 24,983 & 5,257 & 12,197 & ND & ND \\
B19377 & 16,578 & 18,326 & 9,298 & ND & ND \\
& & & & & \\
\hline
\end{tabular}


Table A4. IC Anion Analysis Results for 200-UP-1 Samples

\begin{tabular}{|c|c|c|c|c|c|c|c|c|c|c|}
\hline \multicolumn{11}{|c|}{ Dionex DX600 Chromatographic System RPL Rm 312 Analysis Results: (all results in ppm unless otherwise stated) } \\
\hline Sample Name & $\begin{array}{c}\text { Amount } \\
\mu \mathrm{g} / \mathrm{mL} \\
\text { Fluoride }\end{array}$ & $\begin{array}{l}\text { Amount } \\
\mu \mathrm{g} / \mathrm{mL} \\
\text { Acetate } \\
\end{array}$ & $\begin{array}{l}\text { Amount } \\
\mu \mathrm{g} / \mathrm{mL} \\
\text { Formate } \\
\end{array}$ & $\begin{array}{l}\text { Amount } \\
\mu \mathrm{g} / \mathrm{mL} \\
\text { Chloride } \\
\end{array}$ & $\begin{array}{l}\text { Amount } \\
\mu \mathrm{g} / \mathrm{mL} \\
\text { Nitrite } \\
\end{array}$ & $\begin{array}{l}\text { Amount } \\
\mu \mathrm{g} / \mathrm{mL} \\
\text { Bromide } \\
\end{array}$ & $\begin{array}{l}\text { Amount } \\
\mu g / m L \\
\text { Nitrate }\end{array}$ & $\begin{array}{l}\text { Amount } \\
\mu \mathrm{g} / \mathrm{mL} \\
\text { Sulfate } \\
\end{array}$ & $\begin{array}{l}\text { Amount } \\
\mu \mathrm{g} / \mathrm{mL} \\
\text { Oxalate } \\
\end{array}$ & $\begin{array}{l}\text { Amount } \\
\mu \mathrm{g} / \mathrm{mL} \\
\text { Phosphate }\end{array}$ \\
\hline \multicolumn{11}{|c|}{$\begin{array}{l}\text { 200-UP-1 GROUNDWATER } \\
\text { SAMPLES }\end{array}$} \\
\hline B19J00 (C4298) & 0.68 & & $<0.404$ & Out of Range & 0.72 & $<0.481$ & 13.98 & 26.12 & & $<0.505$ \\
\hline B19J01 (C4298) & 0.47 & & $<0.404$ & 39.75 & $<0.451$ & $<0.481$ & $>200$ & 26.40 & & $<0.505$ \\
\hline B19J02-F (C4298) & 0.52 & & $<0.404$ & 33.26 & $<0.451$ & $<0.481$ & $>200$ & 27.55 & & $<0.505$ \\
\hline B19J03-F (C4298) & 0.50 & & $<0.404$ & 26.52 & $<0.451$ & $<0.481$ & $>200$ & 26.41 & & $<0.505$ \\
\hline B19J05 (C4299) & 0.47 & & $<0.404$ & 47.42 & $<0.451$ & $<0.481$ & $>200$ & 43.11 & & 1.17 \\
\hline B19J06 (C4299) & 0.43 & & $<0.404$ & 29.98 & $<0.451$ & $<0.481$ & 0.52 & 23.17 & & $<0.505$ \\
\hline B19J07 (C4299) & 0.67 & & $<0.404$ & 23.13 & $<0.451$ & $<0.481$ & $<0.433$ & 30.52 & & $<0.505$ \\
\hline B19J08 (C4299) & 0.46 & & $<0.404$ & 40.28 & $<0.451$ & $<0.481$ & $>200$ & 30.00 & & $<0.505$ \\
\hline B19J09 (C4299) & 0.56 & & $<0.404$ & 34.99 & $<0.451$ & $<0.481$ & $>200$ & 25.54 & & $<0.505$ \\
\hline B19J10 (C4300) & 0.37 & & 0.89 & 40.97 & $<0.451$ & $<0.481$ & $>200$ & 52.32 & & $<0.505$ \\
\hline B19J11 (C4300) & 0.52 & & $<0.404$ & 29.77 & $<0.451$ & $<0.481$ & $>200$ & 30.33 & & $<0.505$ \\
\hline B19J12 (C4300) & 0.53 & & $<0.404$ & 20.80 & $<0.451$ & $<0.481$ & $>200$ & 25.16 & & 0.54 \\
\hline B19J14 (C4300) & 0.49 & & $<0.404$ & 43.10 & $<0.451$ & $<0.481$ & $>200$ & 25.93 & & $<0.505$ \\
\hline
\end{tabular}


Table A4. IC Anion Analysis Results for 200-UP-1 Samples (cont.)

\begin{tabular}{|c|c|c|c|c|c|c|c|c|c|c|}
\hline Sample Name & $\begin{array}{c}\text { Amount } \\
\mu \mathrm{g} / \mathrm{mL} \\
\text { Fluoride }\end{array}$ & $\begin{array}{l}\text { Amount } \\
\mu \mathrm{g} / \mathrm{mL} \\
\text { Acetate }\end{array}$ & $\begin{array}{l}\text { Amount } \\
\mu \mathrm{g} / \mathrm{mL} \\
\text { Formate }\end{array}$ & $\begin{array}{l}\text { Amount } \\
\mu \mathrm{g} / \mathrm{mL} \\
\text { Chloride }\end{array}$ & $\begin{array}{l}\text { Amount } \\
\mu \mathrm{g} / \mathrm{mL} \\
\text { Nitrite }\end{array}$ & $\begin{array}{l}\text { Amount } \\
\mu \mathrm{g} / \mathrm{mL} \\
\text { Bromide }\end{array}$ & $\begin{array}{l}\text { Amount } \\
\mu \mathrm{g} / \mathrm{mL} \\
\text { Nitrate }\end{array}$ & $\begin{array}{l}\text { Amount } \\
\mu \mathrm{g} / \mathrm{mL} \\
\text { Sulfate }\end{array}$ & $\begin{array}{l}\text { Amount } \\
\mu \mathrm{g} / \mathrm{mL} \\
\text { Oxalate }\end{array}$ & $\begin{array}{l}\text { Amount } \\
\mu \mathrm{g} / \mathrm{mL} \\
\text { Phosphate }\end{array}$ \\
\hline \multicolumn{11}{|c|}{$\begin{array}{l}\text { 200-UP-1 SOILS (POREWATER } \\
\text { SAMPLES) }\end{array}$} \\
\hline B192K1 (C4298) & 1.15 & $<1.37$ & $<0.404$ & 10.59 & $<0.451$ & $<0.481$ & 0.98 & 32.17 & $<0.345$ & $<0.505$ \\
\hline B192K2 (C4298) & 0.88 & $<1.37$ & $<0.404$ & 10.51 & $<0.451$ & $<0.481$ & 0.89 & 26.17 & $<0.345$ & $<0.505$ \\
\hline B19136 (C4299) & 0.99 & $<1.37$ & $<0.404$ & 39.05 & $<0.451$ & $<0.481$ & $<0.433$ & 54.91 & $<0.345$ & $<0.505$ \\
\hline B19137 (C4299) & 0.65 & $<1.37$ & $<0.404$ & 28.65 & $<0.451$ & $<0.481$ & $<0.433$ & 33.24 & $<0.345$ & $<0.505$ \\
\hline B19138 (C4299) & 0.42 & $<1.37$ & $<0.404$ & 31.67 & $<0.451$ & $<0.481$ & 0.98 & 28.49 & $<0.345$ & $<0.505$ \\
\hline B19139 (C4299) & 1.53 & $<1.37$ & $<0.404$ & 23.61 & $<0.451$ & $<0.481$ & $<0.433$ & 11.92 & $<0.345$ & $<0.505$ \\
\hline B19140 (C4299) & $<0.117$ & $<1.37$ & $<0.404$ & 29.05 & $<0.451$ & $<0.481$ & 3.24 & 49.87 & $<0.345$ & 1.16 \\
\hline B19373 (C4300) & 0.74 & $<1.37$ & $<0.404$ & 28.39 & 9.71 & $<0.481$ & 11.40 & 53.50 & $<0.345$ & $<0.505$ \\
\hline
\end{tabular}


Table A4. IC Anion Analysis Results for 200-UP-1 Samples (Cont.)

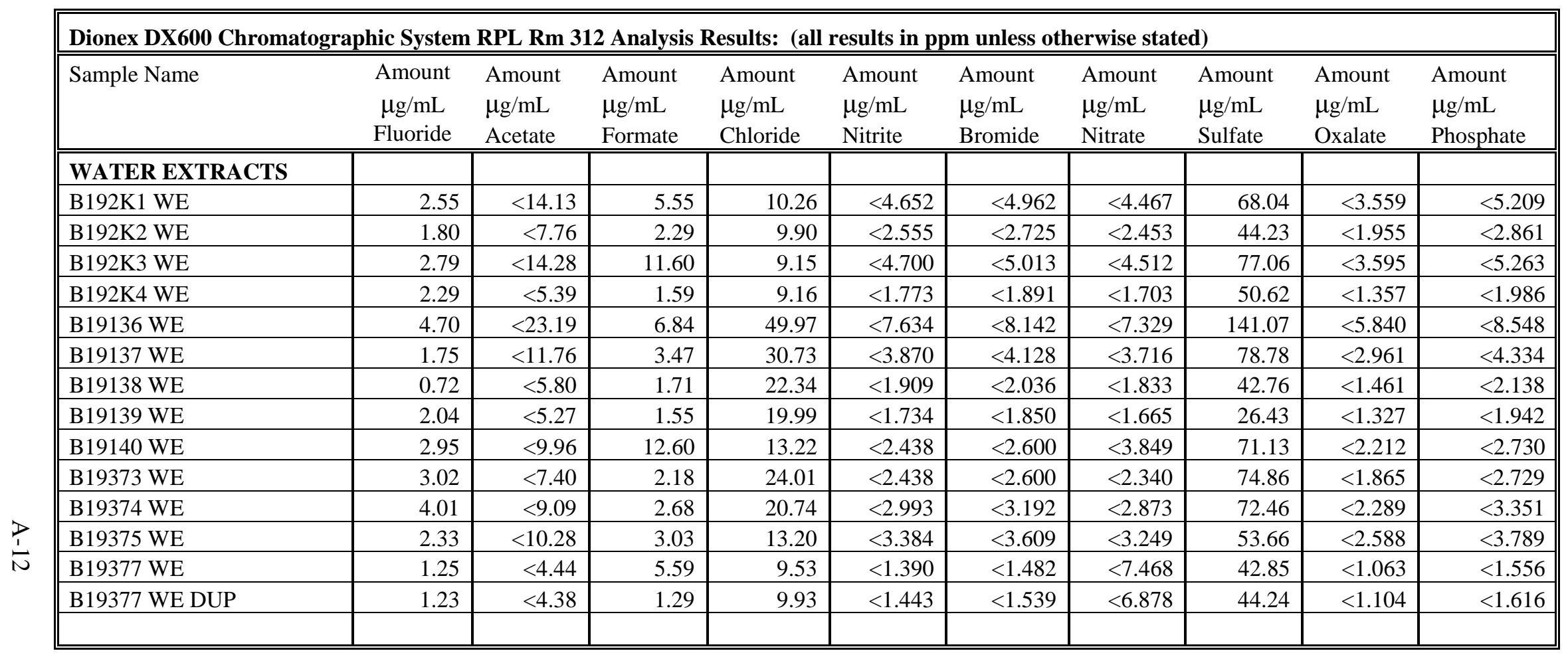

* Concentration values of 1:1 water extracts were already dilution corrected. 
Table A5. Major Composition of 200-UP-1 Groundwater Samples

\begin{tabular}{|c|c|c|c|c|c|c|c|c|c|c|c|c|c|}
\hline WELL_NAME & Locations & $\begin{array}{l}\text { Major cc } \\
\mathrm{Ca}\end{array}$ & $\begin{array}{l}\text { nstituent } \\
\mathrm{Mg}\end{array}$ & $\begin{array}{l}(\mu \mathrm{g} / \mathrm{L}) \\
\mathrm{Mn}\end{array}$ & $\mathrm{K}$ & $\mathrm{Na}$ & $\mathrm{Cl}-$ & NO3- & $\mathrm{Si}$ & SO42- & $\begin{array}{l}\text { alkalinity }(\mu \mathrm{g} / \mathrm{L} \\
\text { as CaCO3) }\end{array}$ & $\mathrm{pH}$ & Collection date \\
\hline $\begin{array}{l}\text { C4300 } \\
\text { (299-W19-48; } \\
\text { Well K) }\end{array}$ & $\begin{array}{l}\text { center } \\
\text { plume }\end{array}$ & $\begin{array}{l}39500 \\
42650 \\
\end{array}$ & $\begin{array}{l}13600 \\
14300 \\
\end{array}$ & $\begin{array}{l}309 \\
187 \\
\end{array}$ & $\begin{array}{l}5060 \\
5090 \\
\end{array}$ & $\begin{array}{l}13700 \\
14450 \\
\end{array}$ & $\begin{array}{r}9140 \\
16550 \\
\end{array}$ & $\begin{array}{l}14100 \\
20000 \\
\end{array}$ & $\begin{array}{l}21200 \\
20850 \\
\end{array}$ & $\begin{array}{l}21200 \\
23350 \\
\end{array}$ & $\begin{array}{l}\text { ND } \\
\text { ND }\end{array}$ & $\begin{array}{l}8.1 \\
8.1 \\
\end{array}$ & $\begin{array}{r}12 / 14 / 2004 \\
12 / 9 / 2004 \\
\end{array}$ \\
\hline $\begin{array}{l}\text { Well near } \\
\text { C4300 } \\
299-W 19-46 \\
\end{array}$ & & 34000 & 10900 & 0.99 & 2960 & 20200 & 6800 & 31300 & & 20800 & & 7.8 & $9 / 3 / 2004$ \\
\hline $\begin{array}{l}\text { C4299 } \\
\text { (699-36-70B; } \\
\text { Well P) }\end{array}$ & $\begin{array}{l}\text { periphery } \\
\text { (middle } \\
\text { south) }\end{array}$ & $\begin{array}{l}52900 \\
34100 \\
18600 \\
\end{array}$ & $\begin{array}{r}17100 \\
12950 \\
5940 \\
\end{array}$ & $\begin{array}{r}176 \\
699.5 \\
207 \\
\end{array}$ & $\begin{array}{l}6640 \\
6860 \\
6720 \\
\end{array}$ & $\begin{array}{l}21800 \\
18150 \\
18700 \\
\end{array}$ & $\begin{array}{r}23800 \\
11800 \\
9530 \\
\end{array}$ & $\begin{array}{r}62400 \\
\\
8850 \\
57.5 \\
\end{array}$ & $\begin{array}{r} \\
10310 \\
4670 \\
\end{array}$ & $\begin{array}{l}38500 \\
20350 \\
26300 \\
\end{array}$ & $\begin{array}{r}86800 \\
75800 \\
\end{array}$ & $\begin{array}{r}7.6 \\
\\
8.3 \\
7.85 \\
\end{array}$ & $\begin{array}{r}11 / 30 / 2004 \\
9 / 24 / 2004 \\
9 / 9 / 2004 \\
\end{array}$ \\
\hline $\begin{array}{l}\text { C4298 } \\
\text { (699-30-66; } \\
\text { Well R) }\end{array}$ & $\begin{array}{l}\text { periphery } \\
\text { (far } \\
\text { south) }\end{array}$ & $\begin{array}{l}41000 \\
42900 \\
42700 \\
42100 \\
23100 \\
\end{array}$ & $\begin{array}{r}15500 \\
15600 \\
15400 \\
14700 \\
8340 \\
\end{array}$ & $\begin{array}{l}580 \\
\\
303 \\
725 \\
670 \\
149 \\
\end{array}$ & $\begin{array}{l}6760 \\
5300 \\
5850 \\
7700 \\
9610 \\
\end{array}$ & $\begin{array}{l}16800 \\
17200 \\
18800 \\
19200 \\
31200 \\
\end{array}$ & $\begin{array}{l}8100 \\
\\
9720 \\
9090 \\
9450 \\
9460 \\
\end{array}$ & $\begin{array}{l}17300 \\
22400 \\
22100 \\
23500 \\
15550\end{array}$ & $\begin{array}{r}16600 \\
20400 \\
17800 \\
15500 \\
8680 \\
\end{array}$ & $\begin{array}{l}19800 \\
21400 \\
20100 \\
20800 \\
22800 \\
\end{array}$ & $\begin{array}{l}148000 \\
153000 \\
132000 \\
134000 \\
102000 \\
\end{array}$ & $\begin{array}{l}8.0 \\
\\
8.1 \\
7.7 \\
7.8 \\
8.3 \\
\end{array}$ & $\begin{array}{r}10 / 12 / 2004 \\
10 / 5 / 2004 \\
9 / 21 / 2004 \\
9 / 21 / 2004-2 \text { nd } \\
9 / 9 / 2004 \\
\end{array}$ \\
\hline
\end{tabular}




\section{Distribution}

No. of

Copies

\section{OFFSITE}

Steve Airhart

Freestone Environmental Services

1933 Jadwin Ave.

Suite 135

Richland, WA 99352

Dr. Harry Babad

2540 Cordoba Court

Richland, WA 9935

Geochemistry Department, 6118

Sandia National Laboratories

P.O. Box 5800

Albuquerque, NM 87185-0750

Dr. James A. Davis

U. S. Geological Survey

MS-465

345 Middlefield Rd.

Menlo Park, CA 94025

Dirk A. Dunning

Oregon Office of Energy

625 Mariona St. N. E.

Salem, OR 97301-3742

Dr. Daniel I. Kaplan

Westinghouse Savannah River Company Bldg. 774-43A, Rm 215

Aiken, SC 29808

Kevin A. Lindsey

Kennedy/Jenks Consultants, Inc. 1020 N. Center Parkway, Suite F

Kennewick, WA 99336
No. of

Copies
Mitzi Miller

EQM Inc

1777 Terminal Dr.

Richland, WA 99352

Phil Reed

U.S. Nuclear Regulatory Commission Office of Nuclear Regulatory Research Division of Systems Analysis and

Regulatory Effectiveness

Radiation Protection, Env. Risk and

Waste Management Branch

Mail Stop: T9-F31

Washington, DC 20555-0001

Al Robinson

68705, E 715 PRNE

Richland WA 99352

Doug Sherwood

Rivers Edge Environmental

1616 Riverside Drive

West Richland, WA 99353

Stan Sobczyk

242 N. Laurel St.

Genesee, ID 83832-9760

\section{ONSITE}

\section{DOE Office of River Protection}
P. E. LaMont
H6-60
R. W. Lober
H6-60
S. A. Wiegman
H6-60 
No. of

Copies

8 DOE Richland Operations Office

B. L. Foley

A6-38

J. P. Hanson

R. D. Hildebrand

K. A. Kapsi

J. G. Morse

K. M. Thompson

DOE Public Reading Room (2)

A5-13

A6-38

A5-13

A6-38

A6-38

$\mathrm{H} 2-53$

2 Washington Closure Hanford, Inc.

C. S. Cearlock

$\mathrm{H} 0-23$

K. R. Fecht

H0-02

4 CH2M HILL Hanford Group, Inc.

F. J. Anderson

E6-35

T. E. Jones

E6-35

F. M. Mann

E6-35

D. A. Myers

E6-35

2 Duratek Federal Services, Inc., Northwest Operations

M. G. Gardner

H1-11

K. D. Reynolds

H1-11

2 Environmental Protection Agency

Nick Ceto

B5-01

D. A. Faulk

B5-01

23 Fluor Hanford, Inc.

M. W. Benecke

E6-35

J. V. Borghese

E6-35

M. E. Byrnes(10)
No. of

Copies

T. W. Fogwell

E6-35

E6-35

E6-35

E6-35

E6-35

E6-35

E6-35

E6-35

A0-21

H8-44

E6-35

\section{Pacific Northwest National Laboratory}

S. R. Baum P7-22

M. P. Bergeron K9-36

B. N. Bjornstad K6-81

T. M. Brouns K9-69

C. F. Brown P7-22

R. W. Bryce E6-35

K. J. Cantrell K6-81

R. E. Clayton P7-22

W.J. Deutsch K6-81

P. E. Dresel K6-96

K. M. Geisler P7-22

M. J. Fayer K9-33

A. R. Felmy K8-96

V. L. Freedman K9-36

M. D. Freshley K9-33

J. S. Fruchter K6-96

G. W. Gee K9-33

D. G. Horton K6-81

C. T. Kincaid E6-35

K. M. Krupka K6-81

I. V. Kutnyakov P7-22

G. V. Last K6-81

M. J. Lindberg P7-22

R. Mackley K6-81

W. J. Martin K6-81

Nik Qafoku K3-61

S. P. Reidel K6-81 
No. of

Copies

R. J. Serne (5)

H. T. Schaef

W. Um (5)

M. Valenta

T. S. Vickerman

A. L. Ward

B. A. Williams

S. B. Yabusaki

J. M. Zachara

F. Zhang

Hanford Technical Library (2)

Information Release Office (7)
No. of

Copies

P7-22

K6-81

P7-22

P7-22

P7-22

K9-33

K6-81

K9-36

K8-96

K9-33

P8-55

\section{Washington State Department of Ecology}

$\begin{array}{ll}\text { J. A. Caggiano } & \text { HO-57 } \\ \text { F. Hodges } & \text { HO-57 } \\ \text { Beth Rochette } & \text { HO-57 }\end{array}$

